Florida International University FIU Digital Commons

4-29-2016

\title{
The Ecology of Extrafloral Nectar in Senna mexicana var. chapmanii
}

Ian M. Jones

ijone002@fiu.edu

DOI: $10.25148 /$ etd.FIDC000730

Follow this and additional works at: https://digitalcommons.fiu.edu/etd

Part of the Botany Commons, Entomology Commons, Other Ecology and Evolutionary Biology Commons, and the Plant Biology Commons

\section{Recommended Citation}

Jones, Ian M., "The Ecology of Extrafloral Nectar in Senna mexicana var. chapmanii" (2016). FIU Electronic Theses and Dissertations. 2594.

https://digitalcommons.fiu.edu/etd/2594

This work is brought to you for free and open access by the University Graduate School at FIU Digital Commons. It has been accepted for inclusion in FIU Electronic Theses and Dissertations by an authorized administrator of FIU Digital Commons. For more information, please contact dcc@fiu.edu. 


\title{
FLORIDA INTERNATIONAL UNIVERSITY
}

\author{
Miami, Florida
}

THE ECOLOGY OF EXTRAFLORAL NECTAR IN SENNA MEXICANA VAR.

\section{CHAPMANII}

\author{
A dissertation submitted in partial fulfillment of the \\ requirements for the degree of \\ DOCTOR OF PHILOSOPHY \\ in \\ BIOLOGY \\ by
}

Ian Matthew Jones

2016 
To: Dean Michael R. Heithaus

College of Arts, Sciences and Education

This dissertation, written by Ian Matthew Jones, and entitled The Ecology of Extrafloral Nectar in Senna mexicana var. chapmanii, having been approved in respect to style and intellectual content, is referred to you for judgment.

We have read this dissertation and recommend that it be approved.

Eric von Wettberg

Jamie Theobald

Jennifer Richards

$\begin{array}{r}\hline \text { Jorge Peña } \\ \hline \text { Suzanne Koptur, Major Professor }\end{array}$

Date of Defense: April 29, 2016

The dissertation of Ian Matthew Jones is approved.

Dean Michael R. Heithaus College of Arts, Sciences and Education

Andrés G. Gil

Vice President for Research and Economic Development and Dean of the University Graduate School

Florida International University, 2016 
"When one tugs at a single thing in nature, he finds it attached to the rest of the world"

- John Muir 


\section{ACKNOWLEDGMENTS}

This research was supported in part by the Kelly Foundation for Tropical Botany. Along with financial support I am indebted to several people for allowing me to use facilities and study sites, without which the work would have not been possible. For use of the Florida International University (FIU) nature preserve I thank Ryan Vogel. For use of greenhouse facilities at FIU, and for his generous support and guidance, I thank Dr. Scott Zona. For use of land at the Tropical Research and Education Center in Homestead I thank the University of Florida and Dr. Jorge Pena.

I am grateful to numerous undergraduate field assistants for their committed and tireless work. Renata Gallegos, Joseph Tardanico, Patricia Trainer, and Andel Sinanan all gave up huge amounts of their time for no financial reward. I thank them not only for their help, but also for their companionship in the field, and I know that each of them will go on to do great things in science.

For aid and advice on statistical analysis I thank Dr. Paulette Johnson, and Dr. Alejandra Matemala. I am also grateful to Daniel Gann for assistance with the statistical program R, and the production of one of the figures in chapter 3.

For their guidance, advice, and encouragement, I thank the members of my doctoral committee. Dr. Jorge Pena helped enormously with experimental design, and provided valuable insights about insect-plant interactions. Dr. Jamie Theobald has been a constant source of great advice throughout the $\mathrm{PhD}$ process, and also shares many of my scientific interests outside the scope of this dissertation. I am grateful that he has welcomed my frequent visits to his lab, where I have learned a huge amount and also 
shared many laughs. Dr. Eric von Wettberg has encouraged me to be ambitious, and has inspired me with his seemingly boundless knowledge of all things scientific. Finally Dr. Jennifer Richards has instilled me with a greater degree of professionalism, and taught me how to use comas.

I owe huge thanks to my major professor Suzanne Koptur. Suzanne's own research has been the primary inspiration for much of my work. I have loved every minute of my time in her lab, during which she has been consistently available and encouraging, while giving me ample freedom to make my own choices and, crucially, my own mistakes. I have enjoyed getting to know Suzanne and her family personally. I hope I will continue to collaborate with Suzanne for years to come, and I hope I can come close to emulating her skills as a mentor in my future career.

I am grateful to all of my fellow students in Suzanne's lab: Roxanneh Khorsand, Beyte Barrios, Jaeson Clayborn, Julia Gehring, Andrea Salas, Brittany Harris, Cleo Pimienta, and Imena Valdes. I thank them all for their help and advice, but mostly for their friendship, and for making the last 5 years so enjoyable. For these reasons I am also grateful to Kristie Wendelberger, Bryan Dewsbury and Sat Gavassa, as well as many others.

I thank my brother Guy and my parents for their unconditional support, and for sticking with me through several periods during which my academic credentials didn't seem so hot! I have always been certain that they care only about my happiness, and for that I owe everything. With the upbringing I had, it would have been difficult to fail and, if I can provide the same environment for Leo, who know what he could achieve. 
Finally, I thank my wife Lindsay, and my son Leo for all of their love and support throughout this process. Here's to the many chapters to come. 


\section{ABSTRACT OF THE DISSERTATION}

THE ECOLOGY OF EXTRAFLORAL NECTAR IN SENNA MEXICANA VAR.

CHAPMANII

by

Ian Matthew Jones

Florida International University, 2016

Miami, Florida

Professor Suzanne Koptur, Major Professor

Extrafloral nectar (EFN) mediates food-for-protection mutualisms between plants and defensive insects. Senna mexicana var. chapmanii is a perennial legume native to the pine rockland habitats of south Florida. My dissertation focuses on how anthropogenic changes to the pine rocklands might affect EFN production by S. chapmanii, and the outcome of EFN mediated interactions. First, I investigated the influence of time of day, leaf damage, and leaf age on EFN production in S. chapmanii. Plants produced more nectar at night than during the day, and leaf damage resulted in increased EFN production. Furthermore, the response to leaf damage was greater when plants were damaged in the morning than when plants were damaged at night. Damage to young leaves elicited a stronger defensive response than damage to older leaves, in line with optimal defense theory. Second, I conducted a field experiment to determine the effects of ant activity, and light intensity, on herbivory rates, growth, and reproductive fitness in S. chapmanii. In shaded habitats, the presence of ants had no effect on herbivory rates, 
seed set, or plant size. In sunny habitats, however, plants with ants suffered less herbivore damage, produced more seeds, and grew larger over the duration of the one year study. Third, through a controlled greenhouse experiment I examined the effects of light intensity, and red/far-red light ratios, on EFN production in S. chapmanii. Plants in lightlimited conditions produced less EFN, and leaf damage elicited increased EFN production regardless of light conditions. Ratios of red/far-red light, however, did not affect EFN production in either damaged or undamaged plants. Finally, I conducted a field study to determine how ants affect reproductive fitness in S. chapmanii. Over a period of eight months I observed the effects of ants on the activity of herbivores, predators, pollinators, and pre-dispersal seed predators. Relative pollinator efficiency, and rates of pre-dispersal seed predation, were unaffected by ants. Plants with ants, however, were quicker to establish, grew larger, and produced floral displays that attracted more pollinators. In $S$. chapmanii ants affected plant reproductive fitness simply by facilitating growth and establishment, with coincidental effects on reproductive investment. 


\section{TABLE OF CONTENTS}

CHAPTER

PAGE

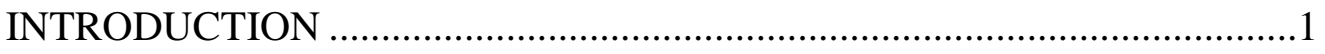

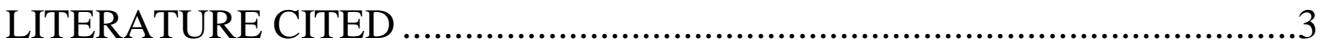

I. DYNAMIC EXTRAFLORAL NECTAR PRODUCTION: THE TIMING OF LEAF DAMAGE AFFECTS THE DEFENSIVE RESPONSE IN SENNA MEXICANA VAR. CHAPMANII (FABACEAE) ........................................5

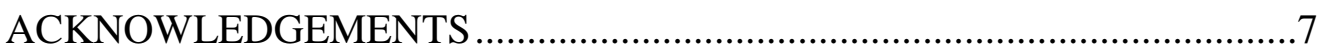

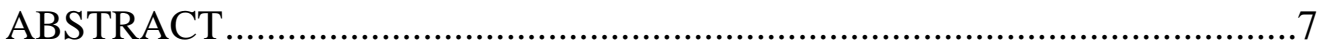

INTRODUCTION ............................................................................

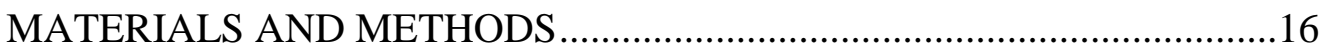

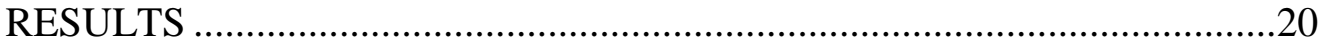

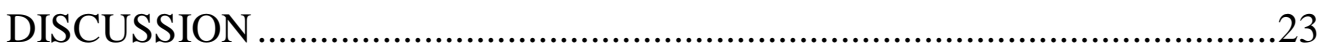

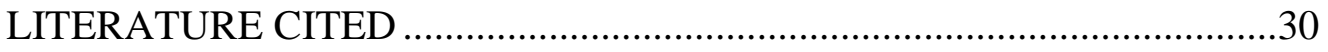

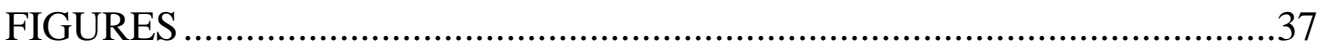

II. CHANGING LIGHT CONDITIONS IN PINE ROCKLAND HABITATS AFFECT THE INTENSITY AND OUTCOME OF ANT-PLANT

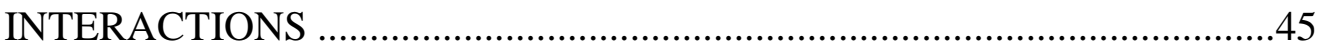

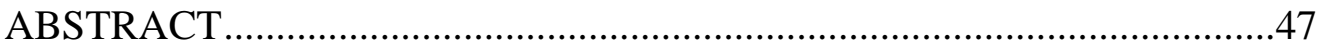

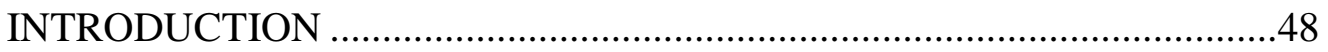

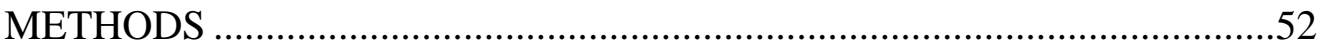

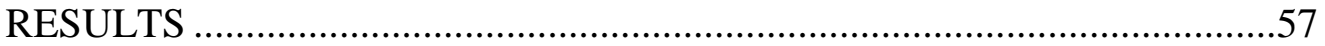

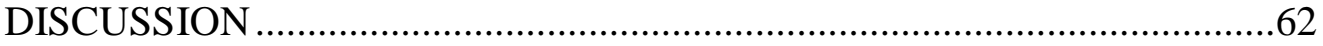

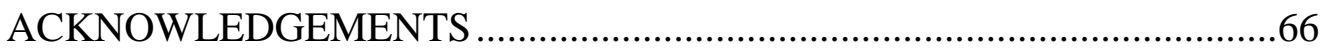

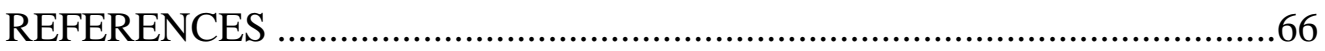

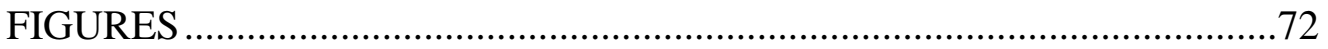

III. QUANTITY OVER QUALITY: LIGHT INTENSITY, BUT NOT RED/FAR-RED RATIO, AFFECTS EXTRAFLORAL NECTAR PRODUCTION IN SENNA MEXICANA VAR. CHAPMANII.......................76

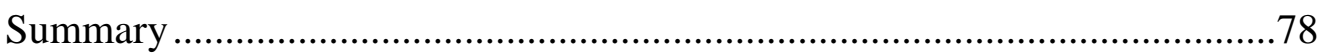

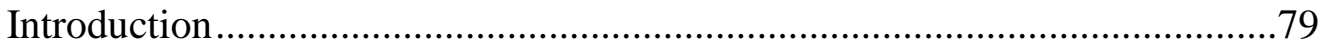

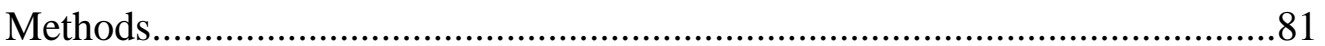

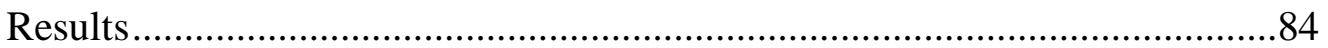

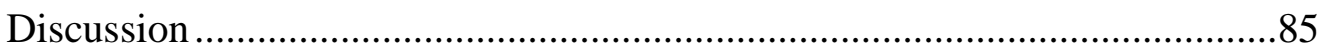

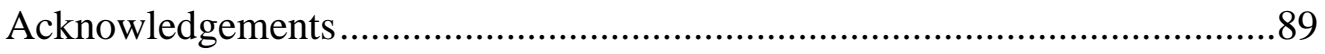

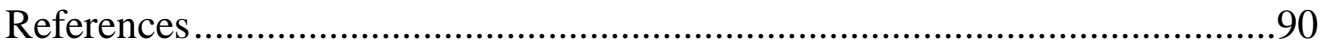

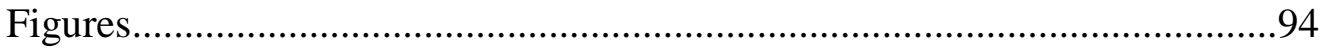




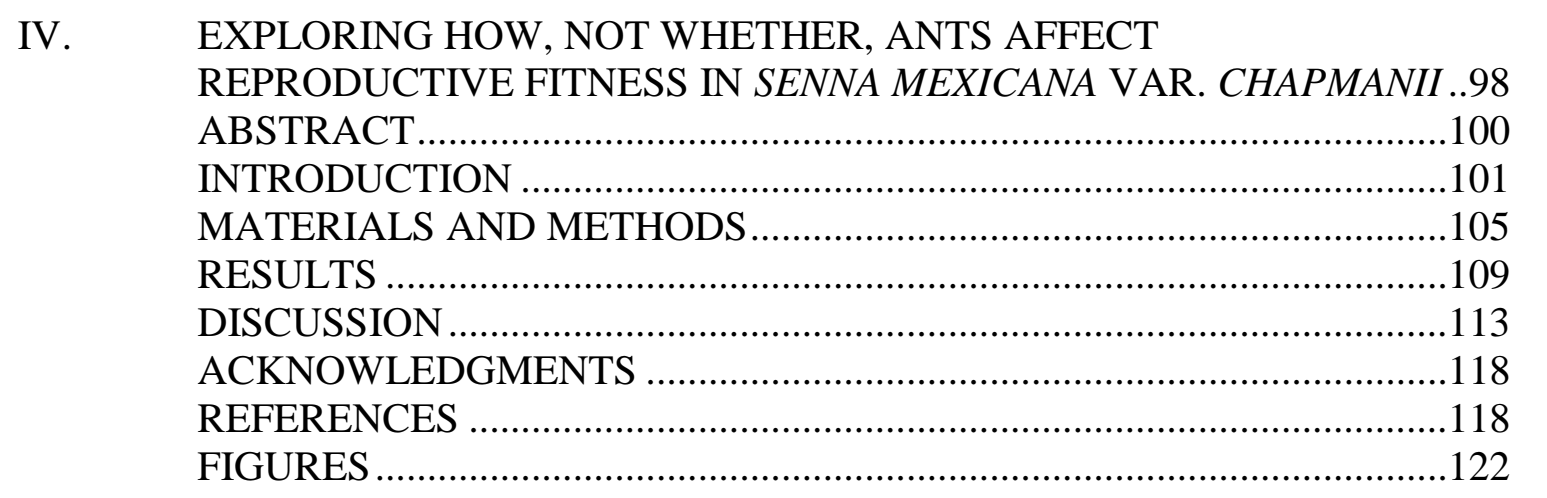

CONCLUSIONS AND FUTURE DIRECTIONS......................................129

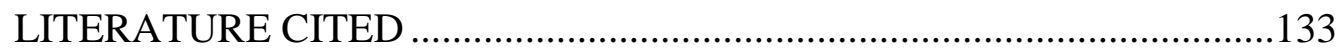

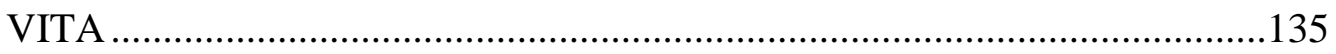




\section{LIST OF FIGURES}

FIGURE

PAGE

\section{CHAPTER I}

1.1 Extrafloral nectary of Senna chapmanii with nectar droplet. Nectary diameter =

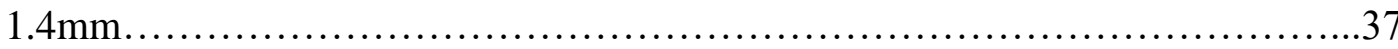

1.2 Sugar production in all plants in experiment 1 at night, and during the day. Bars indicate mean sugar accumulated during each 12 hour period. Letters indicate significant differences.........................................................

1.3 Mean sugar production in damaged versus control plants at 12 hour intervals post damage. Bars indicate mean sugar accumulated during each 12 hour period. Results for plants damaged at $7 \mathrm{am}$ and $7 \mathrm{pm}$ are combined, so each bar consists of measurements occurring at both time points. Overall patterns of EFN production in response to leaf damage can, therefore; be observed controlling for natural diurnal variations in nectar production. The dotted line indicates the time at which damage occurred. Stars indicate significant differences between damaged and control plants

1.4 Mean sugar production 12-24 hours post leaf damage in young and old seedlings damaged at $7 \mathrm{am}$ vs young and old seedlings damaged at $7 \mathrm{pm}$. Bars indicate mean sugar accumulated over each 12 hour period and, therefore, represent the average between one day time measurement and one night time measurement for each plant. Letters indicate significant differences.

1.5 Mean sugar production by plants with damage to young leaves, old leaves, or no leaf damage. Bars indicate mean sugar accumulated during each 12 hour period. Letters indicate significant differences

1.6 Mean nectar concentration in plants with damage to young leaves, old leaves, or no leaf damage. Bars indicate mean nectar concentration for each 12 hour period. Letters indicate significant differences............................. 42

1.7 Mean ant attendance on damaged and undamaged plants. Bars indicate the average number of ants observed on each plant, during each observation. Letters indicate significant differences

1.8 Mean ant recruitment on damaged and undamaged plants. Bars indicate the average number of recruitment events observed on each plant, during each observation. Letters indicate significant differences. 


\section{CHAPTER II}

2.1 Seed set in S. chapmanii plants from all 4 treatments. Bars represent mean seed set per plant over a period of one year. Error bars represent standard error. Different letters indicate significant differences............................72

2.2 Two-way ANOVAs to display the effects of light and the presence of ants on A: mean percentage herbivory rates. A significant interaction was observed between light and the presence of ants. Plants with no ants suffered significantly more herbivore damage than plants with ants present; B: mean plant growth rates. No interaction was observed between light and the presence of ants. No single treatment had a significant effect on plant growth rates; C: mean plant size. No interaction was observed between light and the presence of ants. No single treatment had a significant effect on overall plant size..........73

2.3 Temporal changes in plant size in the presence and absence of ants for A: all plants $(\mathrm{N}=40)$; B: plants in shaded habitats $(\mathrm{N}=20)$; $\mathrm{C}$ : plants in sunny habitats $(\mathrm{N}=20)$. Bars represent mean plant size during each two month period, and error bars represent standard error. Lower case letters indicate significant differences (seen only in $\mathrm{C}$ )

2.4 Temporal/ontogenetic variations in EFN production. Points indicate mean sugar production $(\mu \mathrm{g})$ across all 40 plants. Error bars represent standard error....75

\section{CHAPTER III}

3.1 Extrafloral nectary on the leaf rachis of Senna mexicana var. chapmanii. Photograph by Ian Jones

3.2 Light filter cylinder arrangement. The letter D indicates plants subjected to leaf

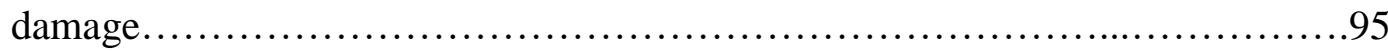

3.3 Mean percentage of light of different wavelengths (300-1000nm) transmitted through the three filter types. Light grey bands indicate red and far-red light wavelengths, while the dark grey band indicates crossover between the two. The sharp rise in percentage light transmission in film 1, starting at around 710nm, indicates the desired increase in R:FR light ratio within film 1 cylinders

3.4 Mean sugar production (mg) by damaged and undamaged plants subjected to 
three light treatments. Error bars indicate standard error. Letters indicate

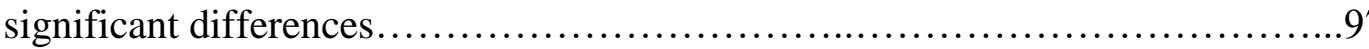

\section{CHAPTER IV}

4.1 Key herbivores on S. chapmanii plants with (Control) and without (Tanglefoot) ants. Bars represent mean numbers of herbivores per observation per plant. Error bars represent standard error.

4.2 A. Mean rates of pre-dispersal seed predation on S. chapmanii plants with (Control) and without (Tanglefoot) ants. Seed predation was calculated for each plant as the number of herbivorized seeds divided by the total number of developing seeds (fertilized ovules minus aborted seeds); B. Mean pollinator efficiency on S. chapmanii plants with and without ants. Pollinator efficiency was measured as the proportion of ovules fertilized for each plant; C. Mean effective fecundity of $S$. chapmanii plants with and without ants. Effective fecundity was calculated for each plant as the number of non-predated mature seeds divided by the total number of ovules. Error bars represent standard error in all cases

4.3 Mean number (A) and duration (B) of pollinator visits on S. chapmanii plants with and without ants. Error bars represent standard error. Stars indicate significant differences

4.4 Correlation between the number of active inflorescences on S. chapmanii plants at the time of observation and the number of pollinator visits. Circles represent the mean number of pollinator visits per observation, on plants with different numbers of inflorescences

4.5 Mean size of S. chapmanii plants with (Control) and without (Tanglefoot) ants for each month of the experiment. Plant size was estimated as the number of growing stems with ten or more leaves. Error bars represent standard error. Stars indicate significant differences

4.6 Reproductive fitness of S. chapmanii plants with (Control) and without (Tanglefoot) ants. Bars represent the means of weekly measurements taken over the course of the 8 month experiment. Error bars represent standard error..127

4.7 Extrafloral nectar production in S. chapmanii plants with (Control) and without (Tanglefoot) ants. Bars represent mean nectar production of all plants from bi-monthly measurements taken throughout the 8 month experiment. Error bars represent standard error 


\section{INTRODUCTION}

Extrafloral nectaries (EFNs), are sugar-secreting glands located outside of flowers, and have been reported on species belonging to 93 families and 332 genera (Koptur 1992, Marazzi et al. 2013). Extrafloral nectar provides plants with a form of indirect defense against herbivory, by attracting ants and other natural enemies (Janzen 1966, Koptur \& Lawton 1988, Heil et al. 2001, Heil 2015).

Plants known as myrmecophytes engage in obligate interactions with ants, and usually provide domatia and food bodies as well as EFN (e.g., Janzen 1966). A far greater number of plants, however, provide only EFN and engage in facultative interactions with ants. These plants are described as myrmecophiles, and their interactions with ants are less well understood (Rosumek et al. 2009; Heil 2015).

The threatened pine rockland habitats of south Florida contain a high proportion of myrmecophylic plants (around 27\%) (Koptur 1992b), but ant-plant interactions in these species have rarely been studied (but see: Rutter \& Rausher 2004). My dissertation describes a series of experiments designed to understand the ecology of EFN production in one such species, Senna mexicana var. chapmanii.

Ant-plant interactions mediated by EFN do not exist in isolation, but within a complex web of biotic interactions. With this in mind, I examine not only the overall impacts of ants on plant fitness, but their effects on other plant-insect interactions, both beneficial and antagonistic. I also examine the effects of abiotic factors on EFN mediated interactions. In particular I focus on the effects of changing light conditions in pine rockland habitats. 
Over the last century, much of the Florida pine rocklands have been destroyed. In the remaining fragments, light conditions are changing in predictable ways. Fires that would maintain the habitats characteristic open canopy are being supressed, and the species rich herb layer is experiencing increasing levels of shade (Possley et al. 2008). I sought to investigate how these changes might affect ant-plant interactions in $S$. chapmanii, and the many other EFN producing species in the pine rocklands.

In chapter I, I employ a combination of greenhouse and field experiments to explore the sources of variation in EFN production in S. chapmanii. Such variations are important as they affect the number and identity of visitors, and the effectiveness of plant defense. I investigate the influence of plant developmental stage, time of day, leaf age, and leaf damage on EFN production, and the observed patterns are compared with those predicted by optimal defense theory. Chapter I has been published in American Journal of Botany.

Chapter II describes a one year field study, examining the effects of ant activity and light intensity on the reproductive fitness of S. chapmanii. First, I determine the extent to which $S$. chapmanii benefits from ants in semi-natural conditions. Secondly, I discuss how changes in light conditions in pine rockland habitats may affect ant-plant interactions in S. chapmanii, and other EFN producing species. Chapter II has been submitted for publication in BIOTROPICA, and is formatted accordingly.

In chapter III, through a controlled greenhouse experiment, I investigate the effects of light conditions on EFN production in S. chapmanii. Light intensity, as well as ref/far red light ratios, are manipulated to determine how light availability, as well as 
informational light signals, affect resource allocation to defensive traits. Chapter III has been published in Ecology and Evolution.

Chapter IV describes an 8 month field experiment designed to study the process by which ants increase reproductive fitness in S. chapmanii. I observe the effects of ants on plant size and reproductive potential. I examine the effects of ants on rates of flowering, fruit set, and seed production. Finally, I observe the effects of ants on the activity and effectiveness of pollinators, and pre-dispersal seed predators. Chapter IV has been formatted for submission to Ecological Entomology.

\section{LITERATURE CITED}

Heil, M. 2015. Extrafloral nectar at the plant-insect interface: A spotlight on chemical ecology, phenotypic plasticity and food webs. Annual Review of Entomology 60: 213232.

Heil, M., Hilpert, A., Fiala, B., and Linsenmair, K.E. 2001. Nutrient availability and indirect (biotic) defence in a Malaysian ant-plant. Oecologia 126: 404-408.

Janzen, D.H. 1966. Coevolution of mutualism between ants and acacias in central America. Evolution 20: 249-275.

Koptur, S. 1992. Interactions between Insects and Plants Mediated by Extrafloral Nectaries. In Bernays, E. (ed.) CRC series on Insect/Plant Interactions. Volume 4, pp. 85-132.

Koptur, S., and Lawton, J.H. 1988. Interactions among vetches bearing extrafloral nectaries, their biotic protective agents, and herbivores. Ecology 69: 278-283.

Koptur, S. 1992b. Plants with Extrafloral Nectaries and Ants in Everglades Habitats. The Florida Entomologist 75: 38-50.

Marazzi, B., Bronstein, J.L., and Koptur, S. 2013. The diversity, ecology and evolution of extrafloral nectaries: current perspectives and future challenges. Annals of Botany 111: $1243-1250$. 
Possley, J., Woodmansee, S.W., and Maschinski, J. 2008. Patterns of plant composition in fragments of globally imperiled pine rockland forest: effects of soil type, recent fire frequency, and fragment size. Natural Areas Journal 28: 379-394.

Rosumek, F. B., Silveira, F.A.O., Neves, F.D., Barbosa, N.P.D., Diniz, L., Oki, Y., Pezzini, F., Fernandes, G.W., and Cornelissen, T. 2009. Ants on plants: a meta-analysis of the role of ants as plant biotic defenses. Oecologia 160: 537-549.

Rutter, M. T., and Rausher, M.D. 2004. Natural selection on extrafloral nectar production in Chamaecrista fasciculata: the costs and benefits of a mutualism trait. Evolution 58: 2657-2668. 


\section{CHAPTER I}

DYNAMIC EXTRAFLORAL NECTAR PRODUCTION: THE TIMING OF LEAF DAMAGE AFFECTS THE DEFENSIVE RESPONSE IN SENNA MEXICANA VAR. CHAPMANII (FABACEAE) 
Jones and Koptur - Dynamic extrafloral nectar production in Senna chapmanii

Dynamic extrafloral nectar production: The timing of leaf damage affects the defensive response in Senna mexicana var. chapmanii (Fabaceae) ${ }^{1}$

IAN M. JONES ${ }^{2}$ AND SUZANNE KOPTUR

Department of Biological Sciences, Florida International University, 11200 S.W. 8th

Street, Miami, Florida 33199

${ }^{2}$ Author for correspondence (e-mail: ijone002@fiu.edu).

${ }^{1}$ Manuscript received ; Revision accepted 
Acknowledgements: The authors thank A. Sinanan and Y. Lago for their help caring for plants and collecting data. Special thanks also go to B. Barrios, J. Clayborne, J. Gehring, C. Pimienta, and S. Zona for their constructive input. Thanks also to S. Zona for his generosity with greenhouse facilities. Finally, the authors would like to thank S. Kephart, M. Heil, and one anonymous reviewer for their helpful feedback on earlier versions of this manuscript. This work benefited from financial support from the Lloyd Kelly Foundation for Tropical Botany. This is contribution number to the Florida International University Program in Tropical Biology.

\begin{abstract}
Premise of the study: Extrafloral nectar (EFN) mediates food for protection mutualisms between plants and defensive insects. Understanding sources of variation in EFN production is important, as they may affect the number and identity of visitors, and the effectiveness of plant defense. We investigated the influence of plant developmental stage, time of day, leaf age, and leaf damage on EFN production in Senna mexicana var. chapmanii (Isely) H.S. Irwin \& Barneby. The observed patterns of variation in EFN production were compared with those predicted by optimal defense theory.

Methods: Greenhouse experiments with potted plants were conducted to determine how plant age, time of day, and leaf damage affected EFN production. A subsequent field study was conducted to determine how leaf damage, and the resulting increase in EFN production, affected ant visitation in S. chapmanii.
\end{abstract}


Key results: More nectar was produced at night, and by older plants. Leaf damage resulted in increased EFN production, and the magnitude of the response was greater in plants damaged in the morning than those damaged at night. Damage to young leaves elicited a stronger defensive response than damage to older leaves, in line with optimal defense theory. Damage to the leaves of $S$. chapmanii also resulted in significantly higher ant visitation in the field.

Conclusions: Extrafloral nectar is an inducible defense in S. chapmanii. Developmental variations in its production support the growth differentiation balance hypothesis while within-plant variations, and damage responses, support optimal defense theory.

Key words: Extrafloral nectar; optimal defense theory; plant defense.

\section{INTRODUCTION}

Extrafloral nectaries (EFNs) are glands that secrete nectar (solutions of sugar and other compounds) located outside of flowers, and have been reported on species belonging to 93 families and 332 genera (Koptur, 1992; Marazzi et al., 2013). One can find EFNs on almost any vegetative or reproductive plant structure (Bentley, 1977; Inouye and Taylor, 1979; Koptur, 1992), and these nectaries may serve diverse ecological functions (Baker et al., 1978; Becerra and Venable, 1989; Wagner and Kay, 2002;

Gonzalez-Teuber and Heil, 2009; Heil, 2011). Extrafloral nectar (EFN) may be consumed by a broad spectrum of arthropods but its discovery by ants, in particular, is known to benefit many plants by providing indirect defense against herbivores (Bentley, 1977; 
Koptur, 1992; Rosumek et al., 2009). Uncovering the factors that affect EFN production can help us to understand how plants regulate their investment in defense, and how they manage and maintain interactions with beneficial insects.

A host of studies have identified food for protection mutualisms between ants and plants (Koptur, 1992; Rosumek et al., 2009). In many cases, plants provide domatia and food bodies as well as EFN, and the resulting interactions may be obligate. Janzen (1966) famously observed that Acacia cornigera plants succumbed to herbivory when resident Pseudomyrmex ferruginea ants were experimentally removed. Plants that provide only EFN are normally involved only in facultative interactions with ants; however, significant fitness benefits have been reported nonetheless (Koptur, 1979; Koptur, 1984; Oliveira, 1997; Rudgers, 2004; Koptur et al., 2013).

Although indirect defenses are thought to be metabolically inexpensive in comparison with direct defenses, the secretion of nectar can undoubtedly be costly. Floral nectar production in Asclepias syriaca, for example, can consume up to $37 \%$ of daily assimilated carbon (Southwick, 1984). It is not surprising, therefore, that plants adjust nectar production over time, and in response to herbivory (Heil et al., 2000). Several studies addressing EFN secretion have demonstrated increased production in response to mechanical leaf damage (e.g., Stephenson, 1982; Koptur, 1989; Engel et al., 2001) and herbivory (Koptur, 1989; Agrawal and Rutter, 1998; Heil et al., 2001; Mondor and Addicott, 2003). Both the volume of nectar produced by each nectary (Heil et al., 2001), and the number of nectaries (Mondor and Addicott, 2003) have been seen to increase in damaged or herbivore infested plants. The ability to express defensive traits plastically confers several key evolutionary benefits to plants. Firstly, metabolic costs are reduced in 
cases where production is low, and secondly, more variable expression of defensive traits provides a barrier against the evolution of insect resistance (Heil, 2010).

In addition to responses to leaf damage, temporal variations in EFN production have also been observed, with different species exhibiting peak production at different times of day (Wickers, 1997; Heil et al., 2000; Raine et al., 2002; Barbosa et al., 2011). Such marked differences suggest that production patterns are not the result of a general physiological mechanism, but may be determined by particular selection pressures acting on each species (Tilman, 1978; Corbet and Delfosse, 1984; Kuo and Pate, 1985; Heil et al., 2000). The EFNs of Macaranga tanarius, for example, are dominated by ants during the night, and nectar robbing flies during the day (Heil et al., 2004a). The availability of suitable mutualists, as well as changing herbivore pressures, are likely factors in any costbenefit analysis for EFN production, and inevitably affect the outcome of ant-plant interactions. For example, Koptur (1979) removed EFNs from the common vetch, Vicia sativa, growing naturalized in California, and found that nectariless plants attracted fewer ants, suffered greater herbivore damage, and produced fewer fruit. The same species revealed a more complex situation in its native England, however, where ants visiting nectaries effectively protected the internally feeding pod-dwelling herbivores from their natural enemies (Koptur and Lawton, 1988). Such findings remind us that the costs and benefits of EFN production can only be truly understood in the context of the community.

In addition to diurnal variations, changes in EFN production occur over the course of plant development (Quintero et al., 2013). Investment in defensive traits should aim to maximize fitness benefits, while minimizing costs (McKey, 1974). As plants age the 
balance between costs and benefits may shift, and changes in the expression of defensive traits are predicted to occur (Elger et al., 2009). The effects of these ontogenetic variations on the dynamics of ant-plant interactions have only recently been explored (Boege and Marquis, 2005; Kwok and Laird, 2012; Quintero et al., 2013). Ontogenetic variations in plant indirect defences are expected to be shaped by plant limitations (resource allocation, architectural requirements, and anatomical constraints), as well as external drivers (herbivore pressures and the availability of suitable mutualists) (Quintero et al., 2013). Predicting such variations has relied on two prominent plant defense hypotheses: optimal defense theory (ODT; McKey, 1974), and the growth differentiation balance hypothesis (GDBH; Herms and Mattson, 1992). ODT predicts that plant parts, or developmental stages, that are of particularly high value, or that are highly vulnerable to herbivory, should exhibit heightened defences. The GDBH predicts that defences should be heightened in tissues, or life stages, in which the nutrient requirements for growth have been met. Only then will excess carbon from photosynthesis be allocated to the differentiation processes required for traits such as induced defences (Stamp, 2003). Predictions made using these hypotheses may be contradictory in some cases. For example, the seedling stage of many plants is particularly vulnerable to herbivory (Clark et al., 2012), and any loss of tissue results in a relatively high fitness cost (Coley and Barone, 1996; Heil et al., 2004b; Lambdon and Hassall, 2005; Radhika et al., 2008). Seedlings are also subject to high levels of competition, and are often carbon limited. As a result, ODT predicts an increased investment in defense at the seedling stage, while the GDBH predicts the reverse. 
Developmental changes in indirect defences may also be related to the types of interactions that they mediate. Myrmecophytic plants, providing both food and shelter for their insect mutualists, tend to produce these resources only once they reach a threshold size or stage, and they produce them in greater abundance as they age (Young et al. 1997; Itino et al. 2001). A meta-analysis conducted by Quintero et al. (2013) supports this pattern, and lends support to the GDBH. Conversely, in mymecophylic plants, which do not provide nesting sites for their mutualists, no consistent ontogenetic patterns have been observed. Doak et al. (2007) observed a marked decrease in EFN production with age in trembling aspen (Populus tremuloides, Salicaceae), while others have found EFN production to be increased in, or even limited to, mature stages (Koptur, 1979; Falcao et al., 2003; Kobayashi et al., 2008; Holland et al., 2009). More studies of myrmecophylic plants are required to understand the factors that affect plant resource allocation to defense.

Temporal changes in the type and intensity of plant defenses are predicted, not only over the development of the plant, but also within individual leaves. Young leaves are nutrient rich (Heil et al., 2004b; Lambdon and Hassall, 2005; Radhika et al., 2008), and are necessarily soft to allow for cell expansion (Yamawo et al., 2012). As a result, young leaves are particularly susceptible to herbivory, and should invest more heavily in defense according to ODT. Indeed, the leaves of Mallotus japonicus have been observed to shift from more costly direct defenses, such as trichomes, toxins, and secondary compounds, to relatively 'cheap' indirect defenses, such as EFN or food bodies, as they age (Yamawo et al., 2012). Any such changes in defensive strategy, however, may be 
influenced by plant life histories. Fast growing plants are expected to concentrate defensive investment in young leaves (McKey, 1974; van Dam et al., 1994), while slow growing plants, with greater leaf longevity, are likely to place equal importance on the defense of mature leaves (van Dam et al., 1996). Several studies have shown EFN production to vary with leaf age, and peak production most often occurs in young to middle aged leaves (Folgarait \& Davidson, 1995; Heil et al., 2000; Kobayashi et al., 2008; Radhika et al., 2008).

Over the last few decades, a rich literature has emerged on the role of EFN, the factors that affect its production, and the insect-plant interactions that it mediates. Despite how taxonomically widespread EFN is, and its importance as an indirect defense against herbivores, there are surprisingly few species for which the dynamics of its production are understood. Particularly little attention has been paid to temporal variations in EFN secretion, knowledge of which is imperative if we aim to understand how, and to what extent, plants manipulate their mutualists.

Here we conduct two greenhouse experiments and one field study to determine the dynamics of EFN production in Senna mexicana var. chapmannii (Jacq.) (hereafter referred to as $S$. chapmanii), a legume native to the pine rocklands of south Florida and the Caribbean (Lee and West, 2011). Senna is a genus within the subfamily Caesalpiniodeae, comprising around 350 species. Substantial diversification is thought to have occurred in the genus coinciding with the evolution of EFNs (Marazzi and Sanderson, 2010). Senna chapmanii is threatened in south Florida and grows primarily in the pine rocklands, themselves under pressure from saltwater intrusion and a host of 
anthropogenic factors (Noss, 2010). The plants bear single globe-shaped EFNs on the rachis between the first pair of leaflets (figure 1), as well as on the pedicels, which are commonly patrolled by ants (I. Jones, Florida International University, personal observation). Only nectaries on the rachis were sampled here, as none of the plants flowered during the study. Perennial legumes have often been used in experimental systems to investigate the ecological role of EFN (Heil, 2004; Choh et al., 2006; Rios et al., 2008; Jezorek et al., 2011). Harnessing biotic plant defences in these systems may represent an opportunity to increase agricultural production, or decrease the use of harmful and expensive pesticides.

Greenhouse experiments were conducted at Florida International University (FIU) to determine how factors such as plant age and time of day affect EFN production, and whether EFN production is inducible by leaf damage in S. chapmanii. In addition, experiments were designed to address two questions that have not previously been answered for any species: 1) Does the time of day at which leaf damage occurs affect the defensive response; and 2) Does damage to young and old leaves elicit the same degree of EFN induction?

Plants response to leaf damage may be influenced by changes in resource availability during the day. The timing of leaf damage may also inform the plants response by providing information regarding the source of the threat. We know that plants can manipulate EFN production in response to the presence of consumers (Heil et al., 2000; Heil et al., 2009), and that different types of damage can elicit different defensive responses (Schmidt et al., 2009; Sotelo et al., 2014), however, the effect of damage timing on inducible defenses has never been studied. 
Rates of EFN production are known to vary as leaves age (Folgarait \& Davidson, 1995; Heil et al., 2000; Kobayashi et al., 2008; Radhika et al., 2008) and, in some cases, developmental patterns of investment have been used to support ODT (Radhika et al., 2008; Holland et al., 2009). Damage to leaves is widely known to elicit increased EFN production in many plants (Stephenson, 1982; Koptur, 1989; Engel et al., 2001), however, responses to damage to leaves of different ages have never been compared. Greater EFN production in response to damage to young leaves would provide further support for ODT.

In this study, we report EFN production as the mean mass of sugar (mg) produced by each plant, as this provides the best representation of defensive investment. Previous studies have generally reported only nectar volume or concentration, both of which are affected by extraneous factors such as temperature and humidity. Where we refer to EFN production in the discussion, we refer to mean sugar production unless otherwise stated. In addition to greenhouse experiments, we conduct a field study to determine if leaf damage, and any subsequent rise in EFN production, actually leads to increased ant attendance in S. chapmanii. Though any increase in EFN production is assumed to confer greater defense, the effects of EFN on herbivory rates, and plant reproductive fitness, have largely been observed through the complete exclusion of ants, or the removal of EFN (Rosumek et al., 2009). Few studies have showed that the degree of ant defense is actually proportional to the quantity of EFN produced (but see Heil et al., 2001; Kost and Heil, 2005), and more evidence is required, particularly for species that mediate ant defense solely through food rewards. 


\section{MATERIALS AND METHODS}

\section{Experiment 1: Identifying temporal and developmental patterns of EFN}

secretion in S. chapmanii, and determining the effects of leaf damage, and damage

timing, on EFN production-S. chapmanii plants were grown from seeds, in a greenhouse at Florida International University (FIU). After three weeks, seedlings were transplanted into $0.6 \mathrm{~L}$ pots, and $1.5 \mathrm{~g}$ slow release fertilizer (Nutricote NPK, Florikan ESA LLC, 1579 Barber Road, Florida, USA) was added to each plant. Plants were maintained in the greenhouse until they reached one of two developmental stages, 1: young seedlings with 5-7 mature leaves, and 2: older seedlings with 10-12 mature leaves. Older plants were allowed to grow for 3-4 weeks longer (post-transplantation) than younger plants before experimentation. Using differently aged plants, within specific size ranges, allowed us to control for differences in plant growth rate, however variation in growth rates appeared low.

Thirty young plants were divided at random into treatment and control groups. Mechanical leaf damage (50\%) was inflicted on leaves 1-5 of the treatment plants (leaf 1 being the most apical mature leaf) by cutting each leaflet in half horizontally using scissors.

Extrafloral nectar production, from leaves 1-5 of each plant, was measured at $7 \mathrm{am}$ and $7 \mathrm{pm}$ every day for a period of 4 days ( 8 measurements). After each measurement, and 12 hours prior to the first measurement, plants were washed to remove any residual nectar, and dried with paper towels to prevent dilution of subsequent samples. Each 
measurement, therefore, represented 12 hours of nectar production either during the day (7pm), or during the night (7am).

Nectar volume was measured using 1,2, and 10 $\mu 1$ micropipettes, and its concentration determined using a handheld refractometer. Total sugar production by each plant was then calculated as described below. In order to determine baseline nectar production, measurements began at 7am, immediately prior to damage treatments. The experiment was later repeated (for a total of 60 plants) with initial nectar measurements, and subsequent damage treatments, occurring at $7 \mathrm{pm}$. As a result, combined results could be used to observe the response to leaf damage, controlling for natural diurnal variations in EFN production. Additionally, the two sets of experiments could be analyzed to compare the response to damage occurring at $7 \mathrm{am}$ and $7 \mathrm{pm}$. The experiment was repeated a further two times (60 plants) using older seedlings.

\section{Experiment 2: Determining the effects of damage to young versus old leaves.}

Does EFN production in S. chapmanii support optimal defense theory-Ninety $S$.

chapmanii plants were grown from seeds, as in experiment 1 , and were left to grow until they had at least 10-12 mature leaves.

Thirty plants were divided at random into three treatment groups. In group one, mechanical leaf damage (50\%) was inflicted on leaves 1-5 (the five youngest open leaves). In group 2, mechanical leaf damage (50\%) was inflicted on leaves 6-10 (older leaves further from the apical meristem). In group 3, the control group, no leaf damage was inflicted. Leaf damage was inflicted in groups 1 and 2 by removing $50 \%$ of each leaflet using scissors. Damage occurred at 7am on day 1 of the experiment. 
Extrafloral nectar production, by each plant, was measured every 12 hours (7am and $7 \mathrm{pm}$ ) for a period of 48 hours post treatment. Nectar measurements were carried out as in experiment 1 , recording total nectar volume, concentration, and sugar production from the nectaries of leaves 1-10.

\section{Experiment 3: Determining the effects of leaf damage on ant attendance in $S$.} chapmanii-One hundred S. chapmanii plants were grown from seeds as in experiment 1. Twenty plants with at least 10-12 mature leaves were then divided, at random, into two treatment groups, damaged and undamaged. In group 1, leaf damage was inflicted on leaves $1-5$ as in experiment 1 . Damage was inflicted at $7 \mathrm{pm}$ on day 1 of the experiment. Plants in treatment group 2 remained undamaged.

Immediately after leaf damage, the twenty plants were placed in pine rockland habitat within the FIU nature preserve. Pairs of plants (one from each treatment group) were placed side by side underneath fine mesh cages which excluded most insects, but not ants. These cages served to prevent herbivory, and protect against nectar robbers, both of which might affect the production and/or availability of EFN. The number and species of ants on each plant were then recorded at 5 time points during the following 24 hours $(10 \mathrm{pm}, 7 \mathrm{am}, 10 \mathrm{am}, 1 \mathrm{pm}, 4 \mathrm{pm})$. The number of ant recruitment events was also recorded for each plant. Ant recruitment was deemed to have occurred when 3 or more ants of the same species were observed on a single plant at the same time.

Calculating sugar content of EFN-Refractometers, used in experiments 1 and

2, were calibrated using a series of artificial nectar solutions. A sugar mix containing fructose (42\%), sucrose (23\%), maltose (21.5\%), and glucose (13.5\%) was formulated to 
closely resemble a generalized EFN. An $80 \%$ nectar solution was produced by dissolving $80 \mathrm{~g}$ of the sugar mix in $100 \mathrm{ml}$ distilled water. The resulting solution was then serially diluted to produce $70 \%, 60 \%, 50 \%, 40 \%, 30 \%, 20 \%$, and $10 \%$ solutions. By taking refractometer measurements of solutions with known sugar content, the following formula was established to calculate the sugar content (mg) of EFN produced by experimental plants.

mg sugar per $\mu 1$ nectar $=(($ Refractometer reading*0.00001729 $)+0.0000073) * 1000$

Statistical Analysis-For experiment 1, non-parametric Mann-Whitney U tests were utilized, as data were not normally distributed. Extrafloral nectar production in young and old seedlings was compared to determine if plant age affects EFN production. Data were aggregated by plant, so that the eight nectar measurements from each plant were reduced to one data point, the mean $(\mathrm{N}=120)$.

To determine if plants produce more nectar during the night or during the day, data were aggregated by plant and time $(\mathrm{N}=240)$. The eight observations for each plant were, therefore, reduced to two data points, mean nectar collected at 7am, and 7pm. Night-time and day-time sugar production were then compared in all plants.

In order to determine if EFN production increased in response to leaf damage, data were, again, aggregated by plant. Sugar production (mg) in damaged and control plants was compared for young plants $(\mathrm{N}=60)$, old plants $(\mathrm{N}=60)$, and all plants $(\mathrm{N}=120)$. 
To establish the length of time for which EFN production was increased after damage, data could not be aggregated. Sugar production in damaged and control plants were compared at $12,24,36,48,60,72$, and 84 hours post damage $(\mathrm{N}=120)$.

Finally, to determine if the time at which damage occurs affects plant response, data were aggregated by plant, and sugar production was compared between plants damaged at $7 \mathrm{am}$ and $7 \mathrm{pm}$. This analysis was repeated for young plants $(\mathrm{N}=30)$ and older plants $(\mathrm{N}=30)$. Only EFN collected 12 and 24 hours post treatment was included in this analysis, as this represented the peak in EFN response to leaf damage.

For experiment 2, Kruskal-Wallace H tests were used to compare EFN production among the three treatments $(\mathrm{N}=90)$, as data were not normally distributed. Post hoc analyses were then conducted separately using Mann-Whitney U tests between pairs of treatments $(\mathrm{N}=60)$. Holm's sequential Bonferroni adjustments were applied to control for type 1 errors.

For experiment 3, Mann-Whitney $\mathrm{U}$ tests were utilized, to determine if ant attendance and ant recruitment differed between damaged and undamaged plants $(\mathrm{N}=100)$.

\section{RESULTS}

Experiment 1-Old seedlings produced significantly more sugar that young seedlings both when damaged $(\mathrm{z}=-4.421, \mathrm{df}=28, P<0.001)$ and undamaged $(\mathrm{z}=-$ $3.319, \mathrm{df}=28, P=0.001)$. All plants consistently produced more sugar during the night 
$($ Median $=0.2923 \mathrm{mg})$ than during the day $($ Median $=0.0438 \mathrm{mg})(\mathrm{z}=-9.891, \mathrm{df}=238, P$ $<0.001)$. This was true for both damaged $(\mathrm{z}=-8.015, \mathrm{df}=118, P<0.001)$ and undamaged plants $(\mathrm{z}=-7.382, \mathrm{df}=118, P<0.001)($ figure 2$)$.

Both young and old seedlings subjected to $50 \%$ leaf damage, produced significantly more sugar than undamaged plants (young: $\mathrm{z}=-4.938$, $\mathrm{df}=58, P<0.001$; old: $\mathrm{z}=-5.396, \mathrm{df}=58, P<0.001)$. In young seedlings, sugar production was significantly higher in damaged plants compared with control plants $12(\mathrm{z}=-5.042, \mathrm{df}=$ $58, P<0.000), 24(\mathrm{z}=-4.337, \mathrm{df}=58, P<0.001)$, and $36(\mathrm{z}=-2.653, \mathrm{df}=58, P=0.008)$ hours post treatment. In older seedlings, damaged plants produced significantly more sugar $12(\mathrm{z}=-3.722, \mathrm{df}=58, P<0.001), 24(\mathrm{z}=-3.187, \mathrm{df}=58, P=0.001)$ and $72(\mathrm{z}=-$ $2.233, \mathrm{df}=58, P=0.026$ ) hours post treatment. When young and old seedlings were analyzed together, damaged plants produced significantly more sugar than control plants at every time point except $60(\mathrm{z}=-1.643, \mathrm{df}=118, P=0.1)$ hours post treatment (figure $3)$.

The time at which leaf damage occurred did not have an effect on plant response in young seedlings $(\mathrm{z}=-0.684, \mathrm{df}=58, P=0.512)$. However, older seedlings damaged at 7 am produced significantly more sugar that those damaged at $7 \mathrm{pm}$ in the 24 hours after leaf damage. $(\mathrm{z}=-1.970, \mathrm{df}=58, P=0.049)$ (figure 4).

Experiment 2-The Kruskal-Wallis comparison among treatments showed that the location of plant damage affected EFN production. Subsequent Mann-Whitney U tests, with Bonferoni adjustments, showed that plants with 50\% damage to young leaves produced significantly more sugar than plants with $50 \%$ damage to old leaves $(\mathrm{z}=-2.935$, 
df $=58, P=0.003)$, and control plants $(\mathrm{z}=-2.676$, df $=58, P=0.007)$. Plants with 50\% damage to old leaves did not produce more sugar than control plants $(\mathrm{z}=-0.643$, df $=58$, $P=0.520)$ (Figure 5). Plants with damage to young leaves also produced a higher volume of nectar than control plant $(\mathrm{z}=-4.391, \mathrm{df}=58, P<0.001)$, and plants with damage to old leaves $(\mathrm{z}=-4.539$, df $=58, P<0.000)$. The volume of nectar produced by plants with damage to old leaves was not greater than that of control plants $(\mathrm{z}=-0.488, \mathrm{df}=58, P$ $=0.626)$. The mean concentration of EFN produced by plants with young leaf damage was also significantly higher than that produced by plants with old leaf damage $(\mathrm{z}=$ 2.935, $\mathrm{df}=58, \mathrm{p}=0.003)$, and control plants $(\mathrm{z}=-2.676, \mathrm{df}=58, \mathrm{p}=0.007)$ (figure 6). Nectar concentration was not increased in plants suffering damage to older leaves in comparison to controls $(\mathrm{z}=-0.555, \mathrm{df}=58, \mathrm{p}=0.579)$.

Experiment 3-The total number of ants observed was significantly higher on damaged plants than on undamaged plants $(\mathrm{z}=-3.468$, $\mathrm{df}=98, \mathrm{P}=0.001)$ (figure 7$)$. The number of ant recruitment events was also greater on damaged versus undamaged plants $(\mathrm{z}=-2.716, \mathrm{df}=98, \mathrm{P}=0.007)$ (figure 8 ). Nine ant species were observed on damaged plants while only six were observed on undamaged plants. Of the 299 ant visits observed, over $90 \%$ could be attributed to three species, Brachymyrmex obscurior Forel, Wasmannia auropunctata Roger, and Paratrechina longicornis (Latreille). 


\section{DISCUSSION}

Extrafloral nectar is an extremely widespread, often inducible trait that mediates food for protection interactions between plants and ants. Although the ecological role of EFN as a form of biotic defense against herbivores is well supported (Bentley, 1977; Koptur, 1992; Rosumek et al., 2009), far less is known about how plants control EFN secretion. Here we examine the effects of time of day, plant age, leaf damage, and the timing of leaf damage on EFN production in S. chapmanii.

Time of day — All plants produced significantly more nectar during the night than during the day. Overall, EFN production was over 5 times higher during the night (figure 2), and even damaged plants produced less nectar during the day than control plants produced at night. Nocturnal peaks in EFN production have been observed in several other studies (Bentley 1977; Heil et al., 2000), but diurnal patterns of EFN production vary greatly among species (Heil et al., 2000; Raine et al., 2002). In most cases, patterns seem to correspond with consumer activity (Tilman, 1978; Corbet and Delfosse, 1984; Kuo and Pate, 1985; Heil et al., 2000). More observations of herbivore and ant activity, in natural growing conditions, are required to determine the selection pressures that drive nocturnal EFN production in S. chapmanii.

Leaf damage - Both young and old seedlings produced significantly more EFN in response to leaf damage, providing further support for the assumption that EFN functions as an inducible defensive response. Numerous studies have reported increased EFN production in response to leaf damage (Stephenson, 1982; Koptur, 1989; Agrawal and Rutter, 1998; Engel et al., 2001; Heil et al., 2001; Mondor and Addicott, 2003; Choh 
and Takabayashi, 2006; Lach et al., 2009). In most cases, however; only the volume or concentration of nectar is reported, and the period of elevation is no greater than 48 hours. Here we report elevated sugar production in S. chapmanii for up to 84 hours post leaf damage. Inducible EFN production has been seen less commonly in tropical and subtropical plants (but see Heil et al., 2000), and it has been suggested that tropical plants, often subjected to greater herbivore pressures than their temperate counterparts, tend to express indirect defenses constitutively (Bixenmann et al., 2011).

The production of EFN in S. chapmanii in response to leaf damage was strongly dependent on the age of the damaged leaves, with damage to young leaves resulting in significantly greater sugar production. This weighting of defensive investment towards more valuable, and vulnerable tissues, provides strong support for ODT. Damage to young leaves is thought to have a greater impact on future plant fitness, as they have already caused high construction costs, but have not yet contributed significantly to the plants pool of photosynthetic products (Harper, 1989). Several authors have used ODT to predict patterns of EFN production. Holland et al. (2009) observed constitutive EFN production in the fruits of cactus, Pachycereus schottii, but only inducible production in less valuable flower buds. Radhika et al. (2008) showed not only that EFN production was greater in young leaves of lima bean and castor, but that carbohydrate assimilates were transported from older to younger leaves in order to facilitate this investment. No authors, to our knowledge, have previously measured EFN production after controlled damage to tissues of different ages. Our results, therefore, provide new support for ODT, and further evidence of the costs of inducible plant defenses. 
Extrafloral nectar production in S. chapmanii was almost exclusive to the youngest mature leaves and, although this was not explicitly measured, the response to leaf damage did not appear to be systemic. Damage to leaves 6-10 had no impact on nectar production in leaves 1-5. This relationship requires further study before any conclusions can be drawn for $S$. chapmanii, however, a lack of systemic response has been noted in other species (Swift and Lanza, 1993; Heil et al., 2000).

Damage to young leaves of $S$. chapmanii elicited an increase not only in the overall quantity of sugar secreted, but also the volume and concentration of EFN. Many studies have shown changes in nectar quantity in response to damage (eg., Stephenson, 1982; Koptur, 1989; Agrawal and Rutter, 1998), but few have reported changes in nectar quality. The extent to which plants can manipulate EFN composition is an active area of research. The concentration of carbohydrates in EFN is known to vary widely (Heil et al., 2000; Bluthgen et al., 2004), and changes in concentration play a crucial role in determining the identity and behavior of its consumers (Heil, 2011). Nectar composition can even affect prey choice in some ants (Wilder and Eubanks, 2010), and it is suggested that plants may manipulate the nutritional value of nectar in order to encourage defensive mutualists to feed on their most damaging herbivores. While plants are known to manipulate nectar concentration (Heil, 2011), this has rarely been observed in response to short term ecological cues. A few species, however, have been reported to manipulate nectar composition in response to the identity of visitors (Heil et al., 2009). Our results indicate that $S$. chapmanii can manipulate nectar concentration in response to the location of leaf damage. 
Plant age - Baseline extrafloral nectar (EFN) production was higher in older versus younger $S$. chapmanii seedlings. Older seedlings also demonstrated a larger increase in EFN production in response to leaf damage. These findings may indicate an age-dependent shift in the balance of costs and benefits associated with EFN production in S. chapmanii. It should also be considered, however, that the observed increase in EFN production with plant age may be a function of the availability of sucrose in the phloem. Millán-Cañongo et al. (2014) found that spatiotemporal patterns of EFN production in Ricinus communis were mirrored by the activity of the plant hormone jasmonic acid (JA), and the enzyme cell-wall invertaze (CWI). In experimentally shaded leaves, EFN production, but not the activity of JA or CWI, was greatly reduced. These findings highlight the importance of sucrose availability as a limiting factor for EFN production. In our experiments, older seedlings possessed a higher photosynthetic capacity, and damage treatments represented a smaller percentage loss of leaf tissue. The increased EFN production that we observed in older seedlings may, therefore, have resulted from greater availability of photosynthetic assimilates.

Our observations of the relationship between plant age and EFN production provide support for the GDBH. Older plants have greater photosynthetic potential, and may satisfy nutrient requirements for growth with more to spare (Herms and Mattson, 1992; Stamp, 2003). The present study, however, observed only immature life stages, and work is ongoing to examine ontogenetic changes in EFN production throughout the lifespan of S. chapmanii in more detail. 
Timing of leaf damage - Although many factors are known to affect patterns of EFN production, interactions among these factors have rarely been considered. We have clearly shown that EFN production in S. chapmanii increases in response to leaf damage, and that it follows a predictable diurnal rhythm. We supplemented these findings by asking the question: Does the time of day at which damage occurs affect plant response? Our results clearly suggest that the answer is yes. Older seedlings damaged at $7 \mathrm{am}$ produced significantly more nectar in the 24 hours that followed, than those damaged at $7 \mathrm{pm}$. Plant responses to attack are known to vary based on the severity of damage (Koptur, 1989), and even the feeding guild of the attacker (Schmidt et al., 2009; Sotelo et al., 2014). It is not surprising, therefore, that defensive responses seem to also be sensitive to diurnal rhythms. The mechanisms behind this phenomenon deserve further study. The timing of leaf damage may provide the plant with useful cues as to the source and severity of the threat. Alternatively, or additionally, plants may face changing resource limitations over the course of 24 hours. Wickers (1997), for example, suggested that diurnal patterns of EFN production in Inga thibaudiana result from changes in water availability. Indeed, in experiment 1 we observed a steady reduction in EFN production rates over 84 hours (figure 3), probably due to declining water availability over the course of the experiment. Plants were watered 24 hours prior to damage treatments, and water was replenished through light spraying after each nectar measurement. In future, plants should be watered fully after each nectar measurement, to minimize any reduction in water availability during the course of the study. 
One potential limitation in all three experiments was that damaged and control plants remained in close proximity throughout the study. Exposure to herbivore infested conspecifics has been observed to stimulate EFN production in several plants (Choh et al., 2006; Heil and Silva Bueno, 2007; Li et al., 2012). Our results, however, indicate that this is not the case in S. chapmanii. Indeed, future studies should explore the possibility that defensive investment in $S$. chapmanii may be down-regulated in response to highly invested neighbors.

The effects of leaf damage on ant attendance-Leaf damage, and a resulting increase in EFN production, resulted in higher ant attendance in S. chapmanii. Extrafloral nectar is widely known to mediate food for protection mutualisms between ants and plants, and many plants have been shown to derive significant fitness benefits from these interactions (Koptur, 1979; Oliveira, 1997; Rudgers, 2004; Koptur et al., 2013). The majority of studies, however, have utilized an all-or-nothing exclusion of ants, or of EFN (Rosumek et al., 2009), and few have demonstrated a correlation between investment in EFN production and the intensity of ant-plant interactions (but see Heil et al., 2001; Kost and Heil, 2005). Volatile organic chemicals (VOCs) produced by damaged plants may also have affected ant attendance, however; our experimental design placed damaged plants and control plants in close proximity, so it is likely that the effects of long distance chemical cues would be seen in both treatments. Volatile chemicals within EFN itself, however, have been shown to affect ant attraction over short distances. Choice tests, conducted using the EFN of Acacia myrmecophytes, showed that ants preferred nectar over sugar solutions based on odor alone (Gonzalez-Teuber and Heil, 2009). In addition 
to overall ant attendance, we observed a significantly higher number of recruitment events on damaged S. chapmanii plants. While individual ants feeding at EFNs might represent chance encounters, recruitment events may better demonstrate manipulation of ant behavior by $S$. chapmanii.

\section{CONCLUSIONS}

Variations in EFN production may be ontogenetically programmed, and/or occur in response to a host of abiotic and biotic factors. Observing these variations in controlled experiments can help us to understand patterns of plant investment in defense, the costs

of those defenses, and how plants maintain mutualisms with ants. Ontogenetic changes in EFN production support GDBH in $S$. chapmanii. Older seedlings produce more EFN, probably as a result of increased availability of sucrose in the phloem. Changes in EFN production within individual leaves, however, provided strong support for ODT. Younger leaves produced significantly more EFN, in line with per-unit area tissue value and vulnerability to attack.

Our most important findings, however, relate to the response of S. chapmanii plants to leaf damage. Older seedlings damaged at 7am produced significantly more nectar over 24 hours, than those damaged at $7 \mathrm{pm}$. The ability of plants to fine tune their investment in indirect defenses in response to the timing of plant damage may have evolved in response to patterns of herbivore or mutualist activity. Alternatively, contrasting diurnal and nocturnal responses may reflect patterns of resource availability. 
Damage to young leaves elicited a significant increase in EFN production, while damage to older leaves had no effect. In addition, EFN volume and concentration was increased in response to young leaf damage. These results provide further support for ODT, and suggest that $S$. chapmanii can manipulate EFN production with a high degree of sensitivity. This ability likely affords the plants better protection from herbivores, while optimizing their use of resources. Few studies have considered the effects of leaf damage on EFN quality, and the present study considers only carbohydrate concentration. More extensive analyses are required to determine nectar composition in S. chapmanii, and discern how nectar constituents vary temporally, and in response to leaf damage. We contribute to an improved understanding of plant resource allocation, and the dynamics of defensive traits. Such an understanding is directly applicable in agricultural settings, where the loss of crops to herbivores, and the overuse of pesticides, cause social and environmental problems worldwide.

\section{LITERATURE CITED}

Agrawal, A. A., and Rutter. M. T. 1998. Dynamic anti-herbivore defense in in ant-plants: the role of induced responses. Oikos 83: 227-236.

Baker, D. A., L. J. Hall, and Thorpe. J. R. 1978. A study of the extrafloral nectaries of Ricinus communis. New Phytologist 81. 129-137.

Barbosa, D. L., J. J. A. Van Loon, and M. Dicke. 2011. The effects of herbivore-induced plant volatiles on interactions between plants and flower-visiting insects. Phytochemistry 72: 1647-1654.

Becerra, J. X. I., and D. L. Venable. 1989. Extrafloral nectaries: a defence against anthomoptera mutualisms? Oikos 55. 276-280. 
Bentley, B. L. 1977. The protective function of ants visiting the extrafloral nectaries of Bixa orellana (Bixaceae). Journal of Ecology 65: 27.

Bixenmann, R. J., P. D. Coley, and T. A. Kursar. 2011. Is extrafloral nectar production induced by herbivores or ants in a tropical facultative ant-plant mutualism? Oecologia 165: 417-425.

Bluthgen, N., G. Gottsberger, and K. Fiedler. 2004 Sugar and amino acid composition of ant attended nectar and honeydew sources from an Australian rainforest. Austral Ecology 29: 418-429.

Boege, K., and R. J. Marquis. 2005. Facing herbivory as you grow up: the ontogeny of resistance in plants. Trends in Ecology and Evolution 20: 441-448.

Choh, Y., S. Kugimiya, J. Takabayashi. 2006. Induced production of extrafloral nectar in intact Lima bean plants in response to volatiles from spider mite-infested conspecific plants as a possible indirect defence against spider mites. Oecologia 147: 455-460.

Choh, Y., and J. Takabayashi. 2006. Herbivore-induced extrafloral nectar production in lima bean plants enhanced by previous exposure to volatiles from infested conspecifics. Journal of Chemical Ecology 32: 2073-2077.

Clark, C. J., J. R. Poulsen, and D. J. Levey. 2012. Vertebrate herbivory impacts seedling recruitment more than niche partitioning or density-dependent mortality. Ecology 93: 554-564.

Coley, P. D., and J. A. Barone. 1996. Herbivory and plant defenses in tropical forests. Annual Review of Ecology and Systematics 27: 305-335.

Corbet, S. A., and E. S. Delfosse. 1984. Honeybees and the nectar of Echium plantagineum L. in south-eastern Australia. Australian Journal of Ecology 9: 125-139.

Doak, P., D. Wagner, and A. Watson. 2007. Variable extrafloral nectary expression and its consequences in quaking aspen. Canadian Journal of Botany 85: 1-9.

Elger, A., D. G. Lemoine, M. Fenner, and M. E. Hanley. 2009. Plant ontogeny and chemical defence: older seedlings are better defended. Oikos 118: 767-773.

Engel, V., M. K. Fischer, F. L. Wackers, and W. Volkl. 2001. Interactions between extrafloral nectaries, aphids and ants: are there competition effects between plant and homopteran sugar sources? Oecologia 129: 577-584.

Falcao, P. F., G. F. D. Melo-de-Pinna, I. R. Leal, and J. S. Almeida-Cortez. 2003. Morphology and anatomy of extrafloral nectaries in Solanum stramonifolium (Solanaceae). Canadian Journal of Botany 81: 859-864.

Folgarait, P. J., and D. W. Davidson. 1995. Myrmecophytic Cecropia: antiherbivore defenses under different nutrient treatments. Oecologia. 104: 189-206. 
Gonzalez-Teuber, M., and M. Heil. 2009. Nectar chemistry is tailored for both attraction of mutualists and protection from exploiters. Plant Signaling and Behaviour 4. 809-813.

Harper, J. L. 1989. The value of a leaf. Oecologia 80: 53-58.

Heil, M. 2004. Induction of two indirect defences benefits lima bean (Phaseolus lunatus, Fabaceae) in nature. Journal of Ecology 92: 527-536.

Heil, M. 2010. Plastic defense expression in plants. Evolutionary Ecology 24. 555-569.

Heil, M. 2011. Nectar: generation, regulation and ecological functions. Trends in Plant Science 16: 4. 191-200.

Heil, M., B. Fiala, B. Baumann, and K. E. Linsenmair. 2000. Temporal, spatial and biotic variations in extrafloral nectar secretion by Macaranga tanarius. Functional Ecology 14: 749-757.

Heil, M., T. Koch, A. Hilpert, B. Fiala, W. Boland, and K. E. Linsenmair. 2001. Extrafloral nectar production of the ant-associated plant, Macaranga tanarius, is an induced, indirect, defensive response elicited by jasmonic acid. Proceedings of the National Academy of Sciences, USA 98: 1083-1088.

Heil, M., A. Hilpert, R. Kruger, and K. E. Linsenmair. 2004. Competition among visitors to extrafloral nectaries as a source of ecological costs of an indirect defence. Journal of Tropical Ecology 20: 201-208.

Heil, M., D. Feil, A. Hilpert, and K. E. Linsenmair. 2004. Spatiotemporal patterns in indirect defense of a South-East Asian and-plant support the optimal defense hypothesis. Journal of Tropical Ecology 20: 573-580.

Heil, M., and J. C. Silva Bueno. 2007. Within-plant signaling by volatiles leads to induction and priming of an indirect plant defense in nature. Proceedings of the National Academy of Sciences, USA 104. 5467-5472.

Heil, M., M. Gonzalez-Teuber, L. W. Clement, S. Kautz, M. Verhaagh, and J. C. Silva Bueno. 2009. Divergent investment strategies of Acacia myrmecophytes and the coexistence of mutualists and exploiters. Proceedings of the National Academy of Sciences USA 106: 18091-18096.

Herms, D .A., and W. J. Mattson. 1992. The dilemma of plants - to grow or defend. Quarterly Review of Biology 67: 283-335.

Holland, J. N., A. A. Chamberlain, and K. C. Horn. 2009. Optimal defence theory predicts investment in extrafloral nectar resources in an ant-plant mutualism. Journal of Ecology 97: 89-96.

Inouye, D. W., and O. R. Taylor. 1979. A temperate region plant-ant-seed predator system: consequences of extrafloral nectary secretion by Helianthella quinquenervis. Ecology 65: 618. 
Itino, T., T. Itioka, A. Hatada, A. A. Hamid. 2001. Effects of food rewards offered by ant-plant Macaranga on the colony size of ants. Ecological Research 16: 775-786.

Janzen, D. H. 1966. Coevolution of mutualism between ants and acacias in central America. Evolution 20: 249-275.

Jezorek, H., P. Stiling, and J. Carpenter. 2011. Ant predation on an invasive herbivore: can an extrafloral nectar-producing plant provide associational resistance to Opuntia individuals? Biological Invasions 13: 2261-2273.

Kobayashi, S., T. Asai, Y. Fujimoto, and S. Kohshima. 2008. Anti-herbivore structures of Paulownia tomentosa: morphology, distribution, chemical constituents and changes during shoot and leaf development. Annals of Botany-London 101: 1035-1047.

Koptur, S. 1979. Facultative mutualism between weedy vetches bearing extrafloral nectaries and weedy ants in California. American Journal of Botany 66(9): 1016-1020.

Koptur, S. 1984. Experimental evidence for defense of Inga (Mimosoideae) saplings by ants. Ecology 65: 1787-1793.

Koptur, S., and J. H. Lawton. 1988. Interactions among vetches bearing extrafloral nectaries, their biotic protective agents, and herbivores. Ecology 69: 278-283.

Koptur, S. 1989. Is extrafloral nectar production an inducible defence? Pp 323-339 in J. Bock and Y. Linhart, editors. Evolutionary ecology of plants. Westview Press, Boulder, Colorado, USA.

Koptur, S. 1992. Extrafloral nectary-mediated interactions between insects and plants. Pp 81-129 in Bernays. E. A. (ed). Insect-plant interactions. Vol IV. CRC Press. Boca Raton.

Koptur, S., M. Palacios-Rios, C. Diaz-Castelazo, W. P. Mackay, and V. Rico-Gray. 2013. Nectar secretion on fern fronds associated with lower levels of herbivore damage: field experiments with a widespread epiphyte of Mexican cloud forest remnants. Annals of Botany 111: 1277-1283.

Kost, C., and M. Heil. 2005. Increased availability of extrafloral nectar reduces herbivory in Lima bean plants (Phaseolus lunatus, Fabaceae). Basic and Applied Ecology 6: 237248.

Kuo, J., and PJ. S. Pate. 1985. The extrafloral nectaries of cowpea (Vigna unguiculata (L.) Wapp). 1. Morphology, anatomy and fine-structure. Planta 166: 15-27.

Kwok, K. E., and R. A. Laird. 2012. Plant age and the inducibility of extrafloral nectaries in Vicia faba. Plant Ecology 213(11): 1823-1832.

Lach, L., R. J. Hobbs, and J. D. Majer. 2009. Herbivory-induced extrafloral nectar increases native and invasive ant worker survival. Population Ecology 51: 237-243. 
Lambdon, P. W., and M. Hassall. 2005. How should toxic secondary metabolites be distributed between leaves of a fast-growing plant to minimize the impact of herbivory? Functional Ecology 19: 299-305.

Lee, D., and S. West. 2011. Wayside trees of tropical Florida. Mebane, NC. Tellus Books.

Li, T., J. K. Holopainen, H. Kokko, A. I Tervahauta, J. D. Blande. 2012. Herbivore induced aspen volatiles temporally regulate two different indirect defences in neighbouring plants. Functional Ecology 26(5): 1176-1185.

Marazzi, B., and M. J. Sanderson. 2010. Large-scale patters of diversification in the widespread legume genus Senna and the evolutionaryrole of extrafloral nectaries. Evolution 64:3570-3592.

Marazzi, B., J. L. Bronstein, and S. Koptur. 2013. The diversity, ecology and evolution of extrafloral nectaries: current perspectives and future challenges. Annals of Botany 111: $1243-1250$.

McKey, D. 1974. Adaptive patterns in alkaloid physiology. American Naturalist. 108: 305-320.

Millán-Cañongo, C., D. Orona-Tamayo, and M. Heil. 2014. Phloem sugar flux and jasmonic acid-responsive cell wall invertase control extrafloral nectar secretion in Rivinus communis. Journal of Chemical Ecology 40: 760-769.

Mondor, E. B., and J. F. Addicitt. 2003. Conspicuous extra-floral nectaries are inducible in Vicia faba. Ecology Letters 6: 495-497.

Noss, R. F. 2010. Between the devil and the deep blue sea: Florida's unenviable position with respect to sea level rise. Climate Change 107(1-2): 1-16.

Oliveira, P. S. 1997. The ecological function of extrafloral nectaries: Herbivore deterrence by visiting ants and reproductive output in Caryocar brasiliense (Caryocaraceae). Functional Ecology 11: 323-330.

Quintero, C., K. E. Barton, and K. Boege. 2013. The ontogeny of plant indirect defences. Perspectives in Plant Ecology, Evolution and Systematics 15: 245-254.

Radhika, V, C. Kost, S. Bartram, M. Heil, and W. Boland. 2008. Testing the optimal defence hypothesis for two indirect defences: extrafloral nectar and volatile organic compounds. Planta 228: 449-457.

Raine, N. E., P. Willmer, and G. N. Stone. 2002. Spatial structuring and floral avoidance behaviour prevent ant-pollinator conflict in a Mexican ant-acacia. Ecology 83: 30863096. 
Rios, R. S., R. J. Marquis, and J. C. Flunker. 2008. Population variation in plant traits associated with ant attraction and herbivory in Chamaecrista fasciculata (Fabaceae). Oecologia 156: 577-588.

Rosumek, F. B., F. A. O. Silveira, F. D. Neves, N. P. D. Barbosa, L. Diniz, Y. Oki, F. Pezzini, G. W. Fernandes, and T. Cornelissen. 2009. Ants on plants: a meta-analysis of the role of ants as plant biotic defenses. Oecologia 160: 537-549.

Rudgers, J. A. 2004. Enemies of herbivores can shape plant traits: selection in a facultative ant-plant mutualism. Ecology 85: 192-205.

Schmidt, L., U. Schurr, U. S. R. Rose. 2009. Local and systemic effects of two herbivores with different feeding mechanisms on primary metabolism of cotton leaves. Plant, Cell and Environment 32: 893-903.

Sotelo, P., E. Perez, A. Najar-Rodriguez, A. Walter, and S. Dorn. 2014. Brassica plant responses to mild herbivore stress elicited by two specialist insects from different feeding guilds. Journal of Chemical Ecology 40 (2): 136-149.

Southwick, E. E. 1984. Photosynthate allocation to floral nectar: a neglected energy investment. Ecology 65: 1775-1779.

Stamp, N. 2003. Out of the quagmire of plant defense hypotheses. Quarterly Review of Biology 78: 23-55.

Stephenson, A. G. 1982. Iridoid glycosides in the nectar of Catalpa speciosa are unpalatable to nectar thieves. Journal of Chemical Ecology 8: 1025-34.

Swift, S., and J. Lanza. 1993. How do Passiflora vines produce more extrafloral nectar after simulated herbivory. Bulletin of the Ecological Society of America 74: 451.

Tilman, D. 1978. Cherries, ants and tent caterpillars: timing of nectar production in relation to susceptibility of caterpillars to ant predation. Ecology 59: 686-692.

Van Dam, N. M., R. Verpoorte, and E. van der Meijden. 1994. Extreme differences in pyrrolizidine alkaloid levels between leaves of Cynoglossum officinale. Phytochemistry 37: 1013-1016.

Van Dam, N. M., T. J. de Jong, Y. Iwasa, and T. Kubo. 1996. Optimal distribution of defenses: are plants smart investors? Functional Ecology 10: 128-136.

Wagner, D., and A. Kay. 2002. Do extrafloral nectaries distract ants from visiting flowers? An experimental test of an overlooked hypothesis. Evolutionary Ecology Research 4. 293-305.

Wickers, S. 1997. Study of nectariferous secretion in a pioneer plant, Inga thibaudiana, in relation with ants. Acta Botanica Gallica 144: 315-26. 
Wilder, S. M., M. D. Eubanks. 2010. Extrafloral nectar content alters foraging preferences of a predatory ant. Biology Letters 6: 177-179.

Yamawo, A., N. Suzuki, J. Tagawa, and Y. Hada. 2012. Leaf ageing promotes the shift in defence tactics in Mallotus japonicas from direct to indirect defence. Journal of Ecology 100: 802-809.

Young, T. P., C. H. Stubblefield, and L. A. Isbell. 1997. Ants on swollen thorn acacias: species coexistence in a simple system. Oecologia 109: 98-107. 


\section{FIGURES}

Figure 1.1: Extrafloral nectary of Senna chapmanii with nectar droplet. Nectary diameter $=1.4 \mathrm{~mm}$.

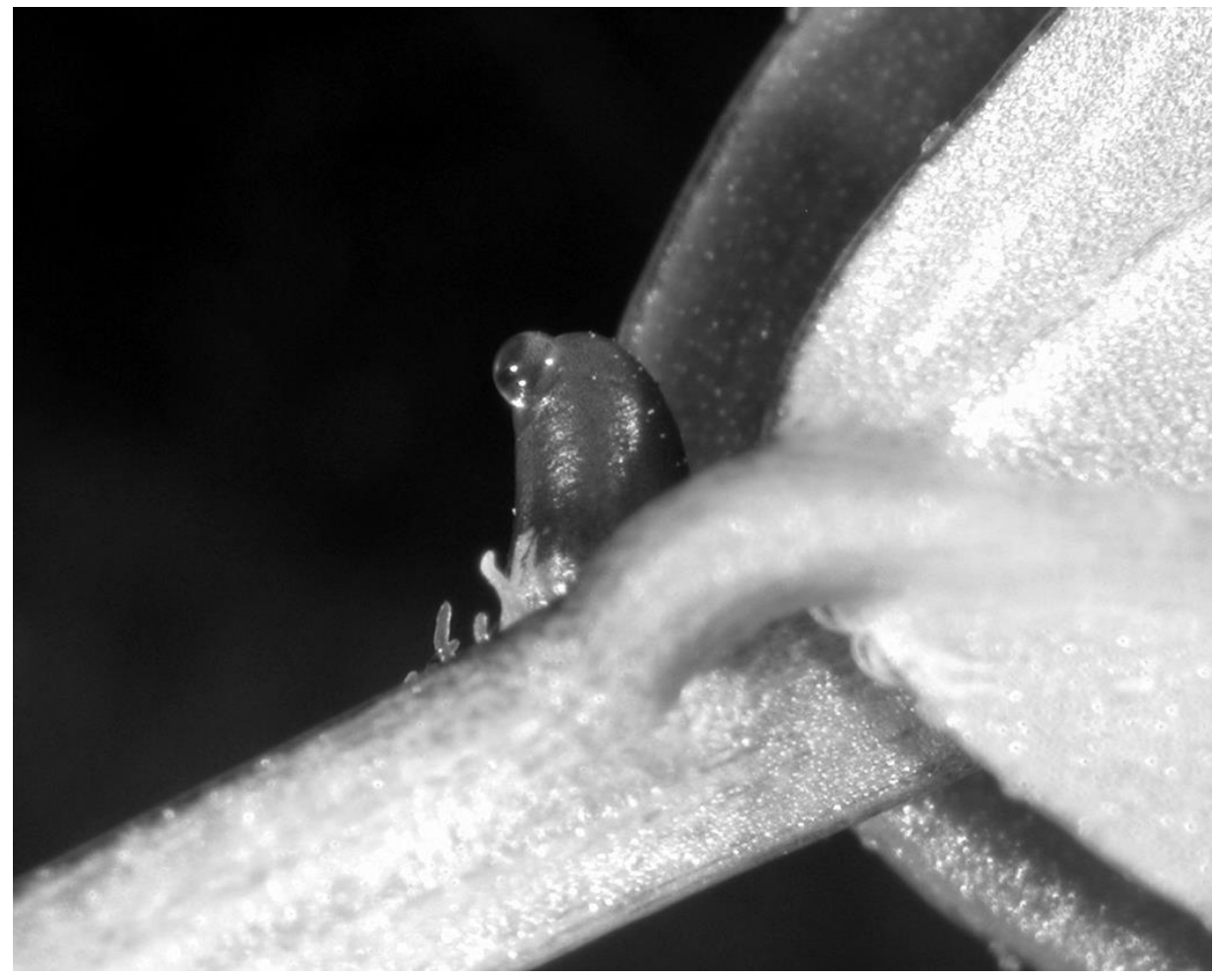


Figure 1.2: Sugar production in all plants in experiment 1 at night, and during the day.

Bars indicate mean sugar accumulated during each 12 hour period. Letters indicate significant differences.

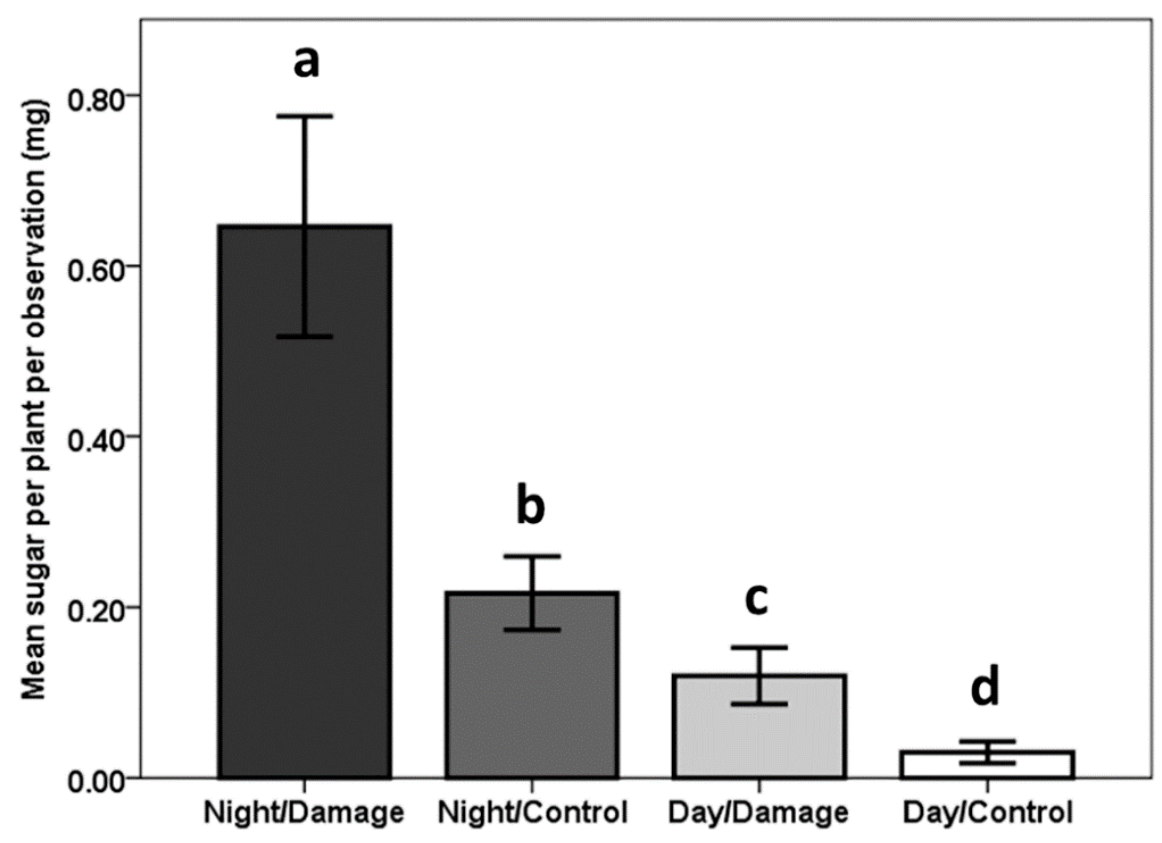


Figure 1.3: Mean sugar production in damaged versus control plants at 12 hour intervals post damage. Bars indicate mean sugar accumulated during each 12 hour period. Results for plants damaged at $7 \mathrm{am}$ and $7 \mathrm{pm}$ are combined, so each bar consists of measurements occurring at both time points. Overall patterns of EFN production in response to leaf damage can, therefore; be observed controlling for natural diurnal variations in nectar production. The dotted line indicates the time at which damage occurred. Stars indicate significant differences between damaged and control plants.

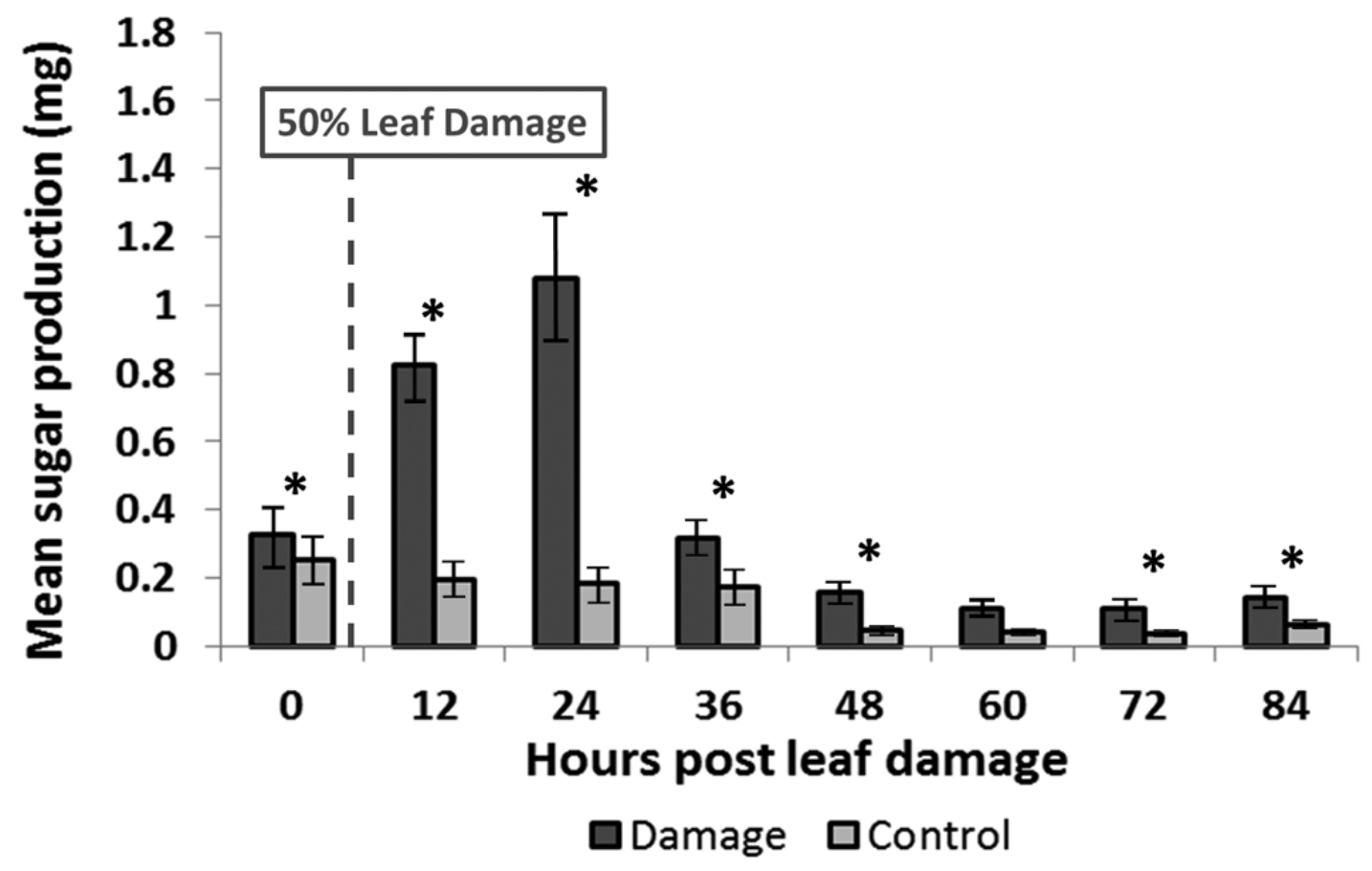


Figure 1.4: Mean sugar production 12-24 hours post leaf damage in young and old seedlings damaged at $7 \mathrm{am}$ vs young and old seedlings damaged at $7 \mathrm{pm}$. Bars indicate mean sugar accumulated over each 12 hour period and, therefore, represent the average between one day time measurement and one night time measurement for each plant. Letters indicate significant differences.

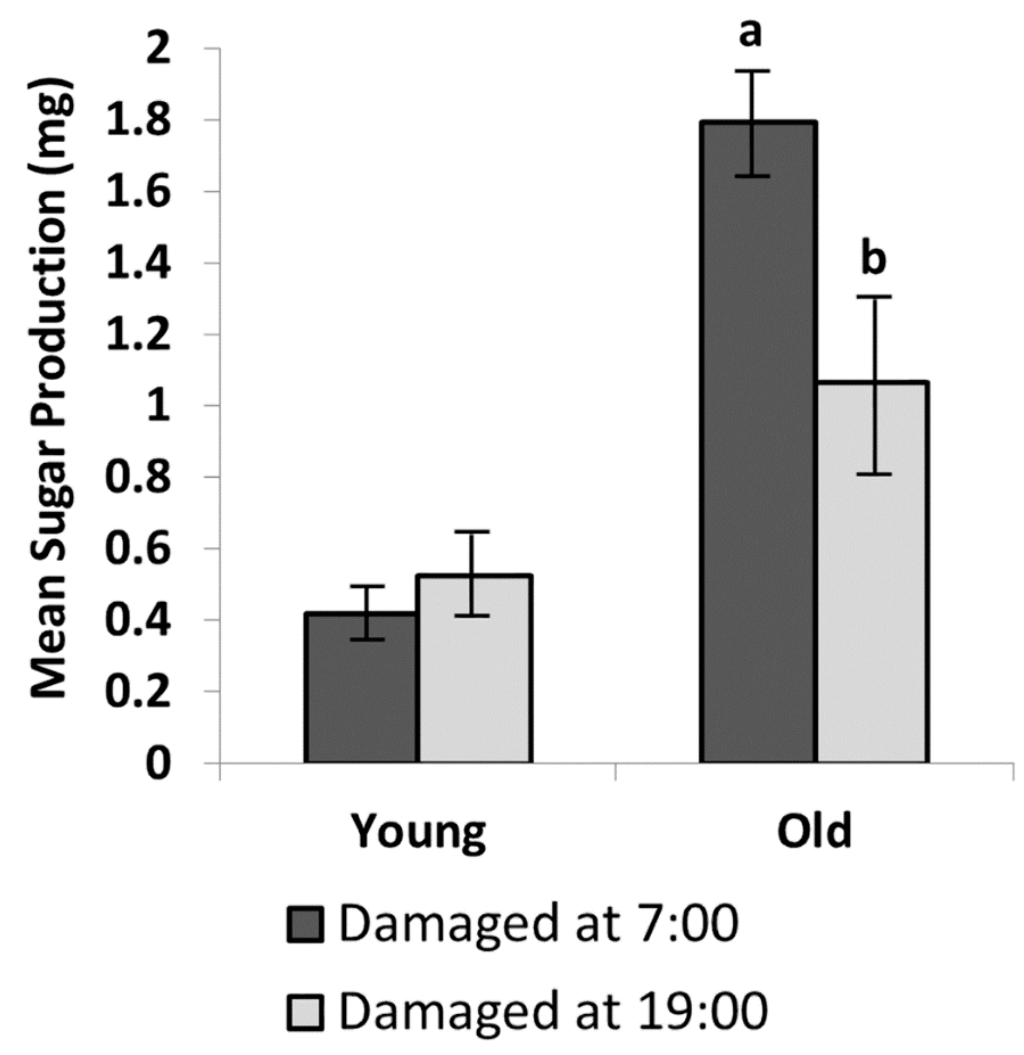


Figure 1.5: Mean sugar production by plants with damage to young leaves, old leaves, or no leaf damage. Bars indicate mean sugar accumulated during each 12 hour period. Letters indicate significant differences.

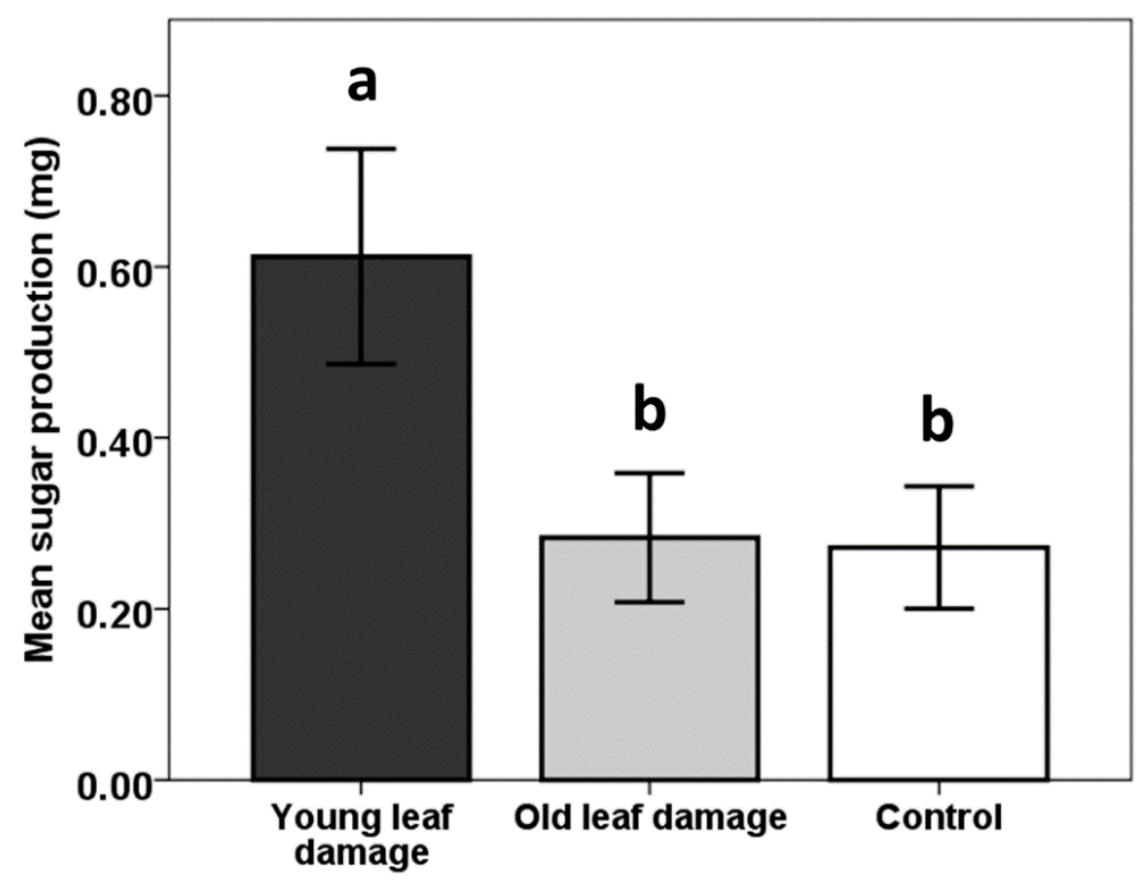


Figure 1.6: Mean nectar concentration in plants with damage to young leaves, old leaves, or no leaf damage. Bars indicate mean nectar concentration for each 12 hour period. Letters indicate significant differences.

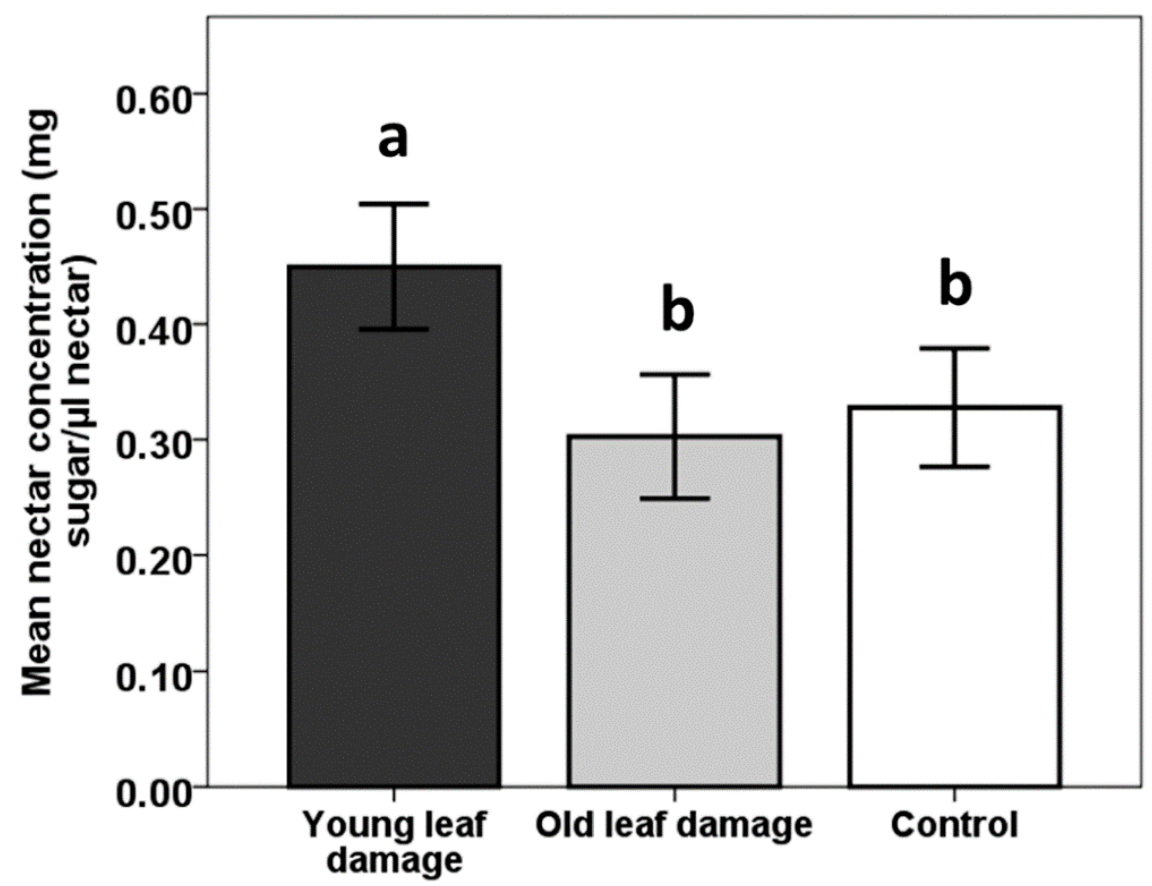


Figure 1.7: Mean ant attendance on damaged and undamaged plants. Bars indicate the average number of ants observed on each plant, during each observation. Letters indicate significant differences.

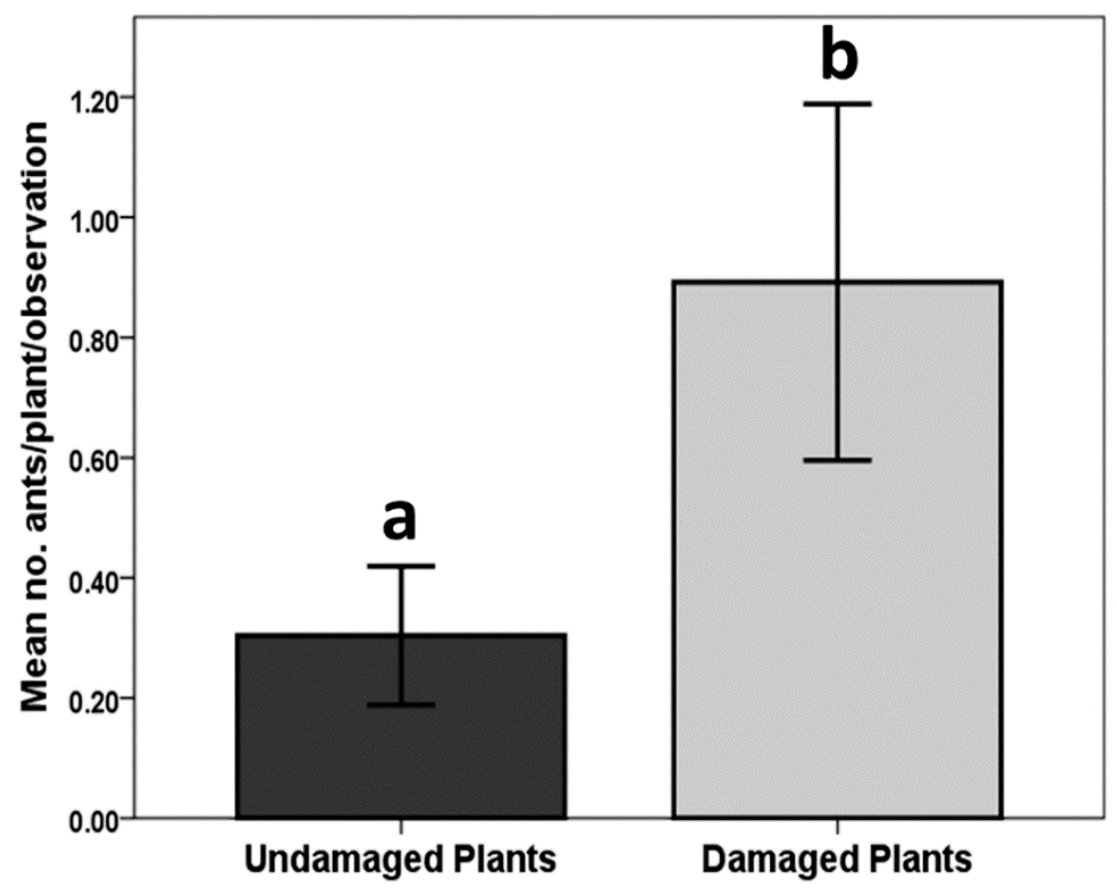


Figure 1.8: Mean ant recruitment on damaged and undamaged plants. Bars indicate the average number of recruitment events observed on each plant, during each observation. Letters indicate significant differences.

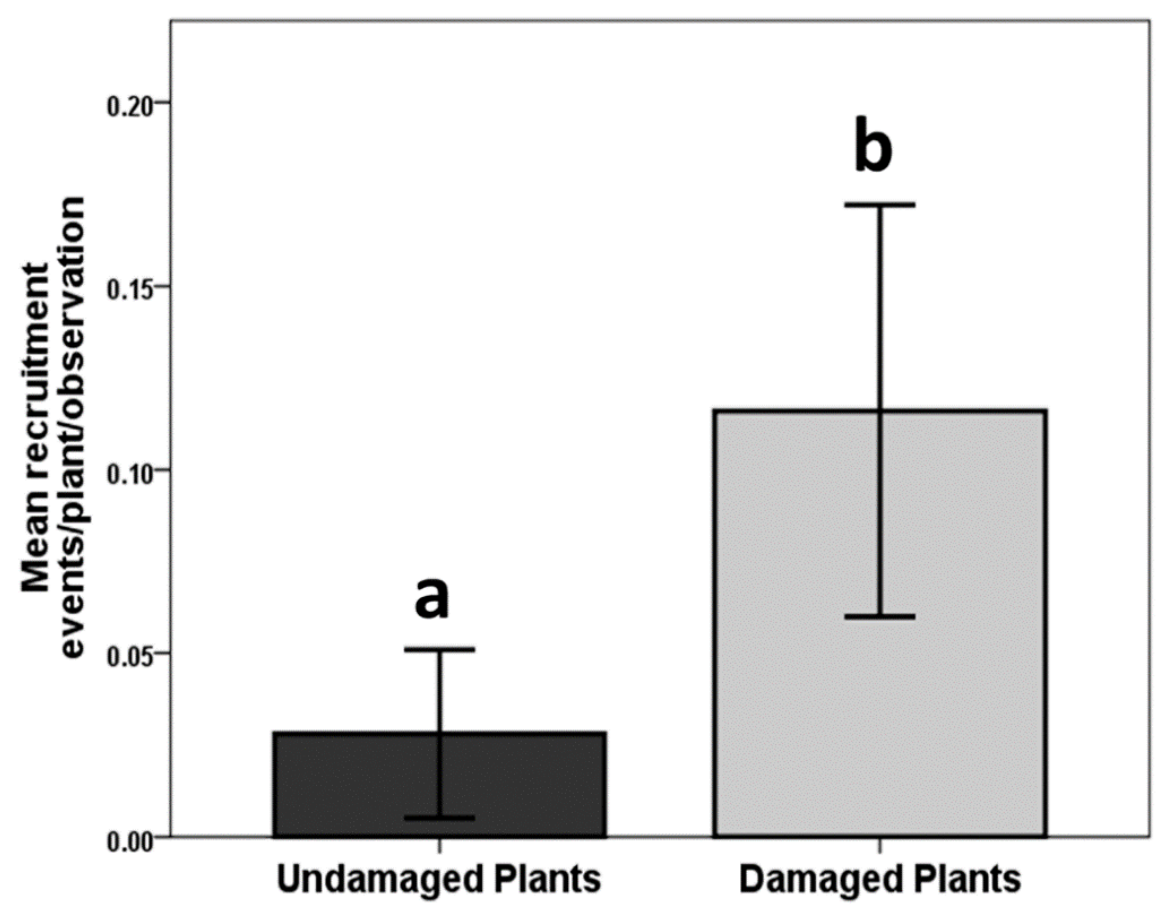


CHAPTER II

CHANGING LIGHT CONDITIONS IN PINE ROCKLAND HABITATS AFFECT THE INTENSITY AND OUTCOME OF ANT-PLANT INTERACTIONS 
Jones et al. - Ant-Plant Interactions in Changing Habitats

\section{Changing Light Conditions in Pine Rockland Habitats Affect the Intensity and} Outcome of Ant-Plant Interactions

LRH: Jones, Koptur, Gallegos, Tardanico, Trainer, and Peña

RRH: Ant-Plant Interactions in Changing Habitats

Ian M. Jones ${ }^{1}$, Suzanne Koptur, Hilma R. Gallegos, Joseph P. Tardanico, Patricia A. Trainer, and Jorge Peña ${ }^{2}$

${ }^{1}$ Department of Biological Sciences, Florida International University, 11200 S.W. 8th

Street, Miami, Florida 33199

${ }^{2}$ Tropical Research and Education Center, University of Florida, Homestead FL 33031

${ }^{1}$ Corresponding Author: ijone002@fiu.edu

Received ___ revision accepted ___ 


\begin{abstract}
Extrafloral nectar (EFN) mediates food-for-protection mutualisms between plants and ants. Such mutualisms exist within a complex web of biotic interactions, and in a framework provided by the abiotic environment. Both biotic and abiotic factors, therefore, affect the outcome of ant-plant interactions. We conducted an experiment to determine the effects of ant activity, and light intensity, on herbivory rates, growth, and reproductive fitness in the subtropical perennial legume, Senna mexicana var. chapmanii, a perennial legume native to south Florida pine rockland habitats.
\end{abstract}

Forty plants were divided among four treatments in a factorial experimental design with two independent variables: ant activity and light intensity. Plants were divided equally between sunny and shady habitats, and ants were excluded from half of the plants in each habitat type.

In shaded habitats, the presence of ants had no effect on herbivory rates, seed set, or plant size. In sunny habitats, however, plants with ants suffered less herbivore damage, produced more seeds, and grew larger than plants without ants over the duration of the one year study.

Ants represent an important biotic defense against herbivores in S. chapmanii; however, their effects on plant fitness depend on light conditions. Pine rockland habitats in south Florida have been widely destroyed or mismanaged. In fragments that remain, disruption of fire regimes has led to increased canopy closure and shading of the understory. These changes will likely negatively impact ant-plant interactions. We 
highlight the importance of conservation efforts to preserve the pine rocklands and their many native plant species.

Key Words: Extrafloral nectar; Florida; plant defenses; Senna mexicana var. chapmanii.

\section{EXTRAFLORAL NECTARIES (EFNS), SUGAR-SECRETING GLANDS LOCATED OUTSIDE OF} FLOWERS, HAVE BEEN REPORTED ON SPECIES BELONGING TO 93 FAMILIES AND 332 GENERA (Koptur 1992, Marazzi et al. 2013). These glands are structurally diverse, and may be found on almost any vegetative or reproductive plant structure (Bentley 1977, Inouye and Taylor 1979, Koptur 1992). A wide range of ecological functions have been suggested for EFNs (Baker et al. 1978, Becerra \& Venable 1989, Wagner \& Kay 2002, GonzalezTeuber \& Heil 2009, Heil 2011), however, they are most noted for providing indirect defense against herbivory by attracting natural enemies of herbivores (Janzen 1966, Koptur \& Lawton 1988, Heil et al. 2001, Heil 2015). Ants represent the most common visitors to EFNs, and have regularly been observed to benefit host plant fitness (Bentley 1977, Koptur 1992, Rosumek et al. 2009, Heil 2015).

A host of studies have identified food-for-protection mutualisms between ants and plants (Koptur 1992, Rosumek et al. 2009, Koptur et al. 2015). Plants, known as myrmecophytes, may provide domatia and food bodies as well as EFN, and engage in obligate interactions with ants. Janzen (1966), for example, observed that Acacia cornigera plants succumbed to herbivory when resident Pseudomyrmex ferruginea ants were experimentally removed. A far greater number of plants, however, provide only EFN and engage in facultative interactions with ants. These plants are described as 
myrmecophiles and, although their interactions with ants are more varied in their outcomes (Rosumek et al. 2009), significant fitness benefits have been reported in many plants (Koptur 1979, Oliveira 1997, Rudgers 2004, Kost \& Heil 2005, Leal et al. 2006, Koptur et al. 2013).

In a number of myrmecophiles the experimental exclusion of ants has resulted in reduced herbivory and an increase in plant reproductive fitness (Cuautle \& Rico-Gray 2003, Heil 2004, Rutter \& Rausher 2004, Leal et al. 2006). In the majority of these studies, however, plant fitness has been observed a relatively short time after ant exclusion, usually within one growing season (but see Torres-Hernandez et al. 2000, Rudgers 2004). In reality, the fitness benefits gained by plants as a result of reduced herbivory may not occur in the same growing season. Studies conducted over longer periods are required to account for potential lag-times between the deterrence of herbivores by ants and changes in plant reproductive fitness.

In one such long-term study, Torres-Hernandez et al. (2000) evaluated the effects of different ant species on the reproductive fitness of Turnera ulmifolia over a period of two years. Plants associated with ants suffered lower levels of herbivory than plants without ants, but the level of protection provided by ants, and the effects on plant reproductive fitness, depended on the size and species of ants concerned. Furthermore, when ants were excluded, visits from other predators such as bees and wasps increased, and these insects offered greater protection for the plant than did some ant species. The outcome of facultative ant-plant mutualisms, therefore, are strongly dependent on community-level dynamics. 
Ant-plant mutualisms do not function in isolation, but within a framework imposed by abiotic factors (Kersch \& Fonseca 2005). Increased nutrient availability in Macaranga triloba, for example, has been observed to increase EFN production and ant attendance, leading to reduced herbivory rates (Heil et al. 2001). Soil moisture levels have also been shown to affect EFN production and subsequent ant visitation in Mallotus japonicus (Yamawo et al. 2012). Light may be a particularly important factor influencing ant-plant mutualisms, as it not only represents a crucial part of resource availability, but may also serve as an indicator of insect activity (Karban et al. 1999).

Extrafloral nectar production has been observed to increase in response to high light intensity (Yamawo \& Hada 2010, Jones and Koptur 2015b). Furthermore the induction of EFN production, either through treatment with jasmonic acid (Radhika et al. 2010) or through leaf damage (Izaguirre et al. 2013), has been found to be dependent on light intensity and quality. Few studies have considered the effects of light conditions on EFN-mediated ant-plant interactions in natural growing conditions, and those that exist have yielded mixed results. In Stryphnodendron microstachyum, plants shaded by the forest canopy were exposed to more herbivores than plants growing in open pasture. In response these shaded plants produced more EFN and attracted more ants than plants in full sun (de la Fuente \& Marquis 1999). Conversely, Cecropia trees exposed to increased sunlight, in forest gaps, more efficiently attract mutualistic ants than plants growing in the shade (Davidson \& Fisher 1991). In the most comprehensive study of its type, Kersch and Fonseca (2005) found that the presence of ants on Inga vera resulted in significant fitness benefits in sunny habitats, but not in the shade. It is clear from these studies that the outcome of insect-plant interactions may be conditional upon light conditions. It is 
likely that plants fare best from their interactions with ants when growing in the ecological conditions to which they are adapted.

Temporal variations in the number and outcome of EFN-mediated ant-plant interactions are particularly poorly understood (but see Wickers 1997, Rico-Gray et al. 1998, Moya-Raygoza \& Larsen 2001, Diaz-Castelazo et al. 2004, Moya-Raygoza 2005, Chavarro-Rodriguez et al. 2013, Lange et al. 2013). Diurnal/nocturnal patterns of EFN production vary enormously among plant species (Heil et al. 2000, Raine et al. 2002), and are often adapted to consumer activity (Tilman 1978, Corbet \& Delfosse 1984, Kuo \& Pate 1985, Heil et al. 2000). Such marked differences suggest that EFN production patterns are not the result of a generalized physiological mechanism, but may be affected by particular selection pressures acting on each species (Tilman 1978; Corbet and Delfosse 1984; Kuo and Pate 1985; Heil et al. 2000). The EFNs of Macaranga tanarius, for example, are dominated by ants during the night, and nectar robbing flies during the day (Heil et al. 2004). Competition among visitors can represent an important ecological cost of EFN production (Heil et al. 2004). Herbivore pressures, as well as the availability of suitable mutualists may also vary markedly between day and night. These factors are likely important in determining patterns of EFN production.

Senna mexicana var. chapmanii (hereafter referred to as Senna chapmanii) (Fabaceae), is an herbaceous low-lying shrub native to the pine rocklands of south Florida and the Caribbean. The species bears single globe-shaped EFNs on the rachis between the first pair of leaflets, as well as on the pedicels, which are commonly patrolled by ants (Jones \& Koptur 2015, Koptur et al. 2015). We have previously shown that ants remove key herbivores from S. chapmanii (Koptur et al. 2015). We have also 
demonstrated that EFN production in S. chapmanii occurs predominantly at night (Jones and Koptur 2015). Pine rockland habitats contain a high proportion (around 27\%) of extrafloral nectary-bearing plants (Koptur 1992), but ant-plant interactions have been studied in detail only in a few species (e.g..Rutter \& Rausher 2004). Much of the Florida pine rocklands have been destroyed in recent history and, in the remaining habitat fragments, light conditions are changing in predictable ways as a consequence of the suppression of fires that would maintain the open canopy that characterizes the habitat (Possley et al. 2008). We have shown that light intensity significantly affects EFN production in S. chapmanii (Jones and Koptur 2015b). Here we sought to investigate how changing light conditions might affect ant-plant interactions in S. chapmanii, as a model for the potential effects on the many other EFN producing species in the pine rocklands.

We conducted a one-year field study to observe EFN mediated ant-plant interactions in S. chapmanii. We manipulated ant activity and light intensity to determine the effects of both factors on plant size, growth rate, herbivory, and seed set. We also observed how EFN mediated ant-plant interactions varied at night and during the day. The intensity of mutualistic interactions varies considerably in space and time (Bentley 1976, Barton 1986, Rico-Gray et al. 1998, Mayo-Raygoza \& Larsen 2001, Bronstein et al. 2003, Kersch \& Fonseca 2005). Here we contribute to a growing literature, which aims to understand the causes of such variations.

\section{METHODS}

A one-year field study was carried out at the University of Florida's Tropical Research and Education Center (TREC) in Homestead, Florida (25 30'27.52N, 
8³0'13.67"W), between April 2013 and March 2014. The climate is subtropical, with average minimum and maximum temperatures of $3.2-24.8^{\circ} \mathrm{C}$ in January and $22.7-32.4^{\circ} \mathrm{C}$ in July. Elevation is roughly $2.5 \mathrm{~m}$ asl, and mean annual precipitation is $1496 \mathrm{~mm}$ (Koptur et al. 2015). The study site consisted of flat calcareous limestone rocklands that had been rock-plowed for agriculture. We utilized an $8000 \mathrm{~m}^{2}$ plot, previously overgrown with exotic pest plants, which had been mostly cleared of all vegetation except for a few stands of large native trees. Adjacent to the western edge of the plot there is a fragment of pine rockland habitat, a protected natural area.

Senna chapmanii plants were grown from seed in a greenhouse at Florida International University. Seeds were collected from multiple individuals in a single population on Big Pine Key (under Research Permit \# FFO4RFKD-2014-0, National Wildlife Refuge System - National Key Deer Refuge). After 3 months, forty plants were transplanted into the experimental site, in an evenly spaced array, with each plant at least $4 \mathrm{~m}$ from its nearest neighbor. Sites were chosen to ensure an equal number of plants in sunny vs shaded habitats. Light conditions at each plant location were later characterized as described below.

Plants were mulched with wood chips, and watered for two months until they were established. Plants were then divided into a factorial experimental design with two independent variables, ant activity and light intensity (sun vs shade). Ten plants were allocated to each of four treatments: (1) sunny habitats with ants present; (2) sunny habitats with ants excluded; (3) shady habitats with ants present; (4) shady habitats with 
ants excluded. Ant exclusion treatments were assigned systematically to ensure even distribution of treatments across the site.

Ants were excluded by painting a sticky gel (Tanglefoot $\left.{ }^{\mathrm{TM}}\right)$ around the base of the stem. Tanglefoot was reapplied on an as-needed basis, to maintain the efficacy of antexclusion treatments. Light intensity was measured at the apex of each plant at the beginning of the study, using a digital illuminance meter (Dr.Meter LX1330B, Union City, CA 94587). Light was measured three times throughout the day (9:00am, 12:00pm, and 3:00pm), on a clear day with no cloud cover, and mean light intensity was calculated for each plant location. Mean illuminance ranged from 7,800-51,366Lux in the shade and 59,600-98,000Lux in sunny habitats.

Insect activity was observed on each plant during weekly surveys. Plant size, growth rate, and reproductive fitness, as well as percentage herbivore damage, was measured every two weeks. Extrafloral nectar production (volume and concentration) was measured every two months.

INSECT ACTIVITY - Every week, a single branch was chosen from each plant as a census locale. The chosen branch was observed for a period of two minutes, and the number and species of ants and herbivores were recorded. Voucher specimens were collected where necessary, for identification, and stored at Florida International University (FIU). Insect observations were conducted during the day (10:00am-3:00pm), and at night (8:00pm1:00am) on an alternating basis, in order to compare diurnal and nocturnal patterns of insect activity. 
PLANT REPRODUCTIVE FITNESS— Every two weeks, throughout the study, the number of open flowers and the number of mature fruits were counted on each plant. Mature fruit were collected and returned to the laboratory at FIU where the seeds of each fruit were counted and weighed. Where we refer to plant reproductive fitness in the results and discussion, we refer to seed set unless otherwise stated.

HERBIVORY RATES- Every two weeks, throughout the study, a single branch with an intact growing tip was chosen from each plant. A jewelry tag was fastened beneath the most recently matured leaf. After two weeks, percentage herbivore damage was estimated for each new leaf above the jewelry tag, and the mean percentage was taken as the overall bi-weekly herbivory score for that plant. On rare occasions, all of the leaves above the jewelry tag were removed by herbivores. In these cases a herbivory score of $100 \%$ was given.

PLANT GROWTH RATES- Prior to the commencement of the study, 200 leaves at various developmental stages were collected from the experimental plants. Leaves were measured (length in $\mathrm{cm}$ ) before being placed in a drying oven for 48 hours, and dry biomass was recorded for each leaf. A significant regression equation was found $(\mathrm{F}(1,198)=424.416), \mathrm{P}<0.001)$ with an $\mathrm{R}^{2}$ of 0.682 . The following formula was established to estimate the dry biomass of a leaf from its length:

$$
\text { Leaf dry biomass }(\mathrm{g})=\text { Leaf length }(\mathrm{cm}) * 0.0188
$$

During the study, every two weeks, a single branch with an intact growing tip was chosen from each plant in order to measure vegetative growth rates. A jewelry tag was 
placed beneath the most recently matured leaf, and the length of that leaf was measured. After two weeks the number of mature leaves above the jewelry tag was counted, and the length of each leaf was measured again. The total dry biomass of the leaves above the jewelry tag was calculated at the beginning and end of each two week period. Where we refer to plant growth in the results, we refer to the mean increase in dry biomass of individual branches over a two week period.

PLANT SIZE — Every two weeks, throughout the study, the size of each plant was estimated by counting the number of branches. Branches were classified as any growing stem with ten or more leaves.

EXTRAFLORAL NECTAR PRODUCTION— At two-month intervals throughout the study, extrafloral nectar (EFN) production was measured in each plant. A single branch was selected from each plant, and any insects present were removed by hand. Nectaries were then washed by lightly spraying with water. Leaves were then dried with paper towel, and branches were sealed within fine mesh bags to exclude insects. Bags were placed on branches at $7 \mathrm{pm}$, and removed 12 hours later for nectar measurements at $7 \mathrm{am}$.

For each plant, combined nectar volume from the five most recently matured leaves on the chosen branch was measured using 1,2 , and $10 \mu 1$ micropipettes. Nectar concentration was measured using a handheld refractometer, and total sugar production was estimated from the combination of these measurements (see Jones \& Koptur, 2015). In the results, EFN is expressed as total sugar production. 
STATISTICAL ANALYSIS - Insect observation data were not normally distributed, even after transformation. The effects of Tanglefoot and light intensity on ant and herbivore abundance were, therefore, tested independently using non-parametric Mann-Whitney U tests. Ant and herbivore abundance during day and night-time observations were also compared using Mann-Whitney U tests.

Plant reproductive fitness data (seed set) were also not normally distributed even after transformation. The interaction between Tanglefoot and light intensity, therefore, could not be tested. The effects of Tanglefoot (presence/absence of ants), and light intensity on seed set were tested independently using non-parametric Mann-Whitney U tests.

The effects of Tanglefoot (presence/absence of ants) and light intensity on herbivory rates, plant growth rates, and plant size were tested using two-way ANOVA, and additional within treatment comparisons were conducted using independent sample ttests.

\section{RESULTS}

ANT ACTIVITY - Overall ant abundance was significantly higher on plants without Tanglefoot than on Tanglefoot treated plants $(\mathrm{N}=40, \mathrm{df}=38, \mathrm{U}=11, \mathrm{z}=-5.114, \mathrm{P}<0.001)$, indicating that Tanglefoot successfully excluded ants from treatment plants. On plants with Tanglefoot, a mean of 0.17 ants were observed per observation (1080 observations), and ants were present in only 185 observations (17.1\%). On these occasions, ant numbers 
on a single branch ranged from 1 to 11 . On plants without Tanglefoot, a mean of 1.34 ants were observed per observation (1080 observations), and ants were present in 606 observations (56.1\%). When ants were present, numbers ranged from 1 to 18 .

Ants were significantly more abundant on plants in sunny habitats than those in the shade $(\mathrm{N}=40, \mathrm{df}=38, \mathrm{U}=117.5, \mathrm{z}=-2.232, \mathrm{P}=0.024)$. No significant differences were seen between the total number of ants observed at night and during the day $(\mathrm{N}=80, \mathrm{df}=78$, $\mathrm{U}=797.5, \mathrm{z}=-0.024, \mathrm{P}=0.981$ ), however, clear diurnal/nocturnal patterns were observed within individual ant species. Brachymyrmex obscurior was significantly more abundant during the day than at night $(\mathrm{N}=80, \mathrm{df}=78, \mathrm{U}=559.5, \mathrm{z}=-2.332, \mathrm{P}=0.020)$, Camponotus floridanus was more abundant at night than during the day $(\mathrm{N}=80, \mathrm{df}=78, \mathrm{U}=536.5, \mathrm{z}=-$ 2.586, $\mathrm{P}=0.01$ ), and Cardiocondyla emeryi was more abundant during the day than during the night $(\mathrm{N}=80, \mathrm{df}=78, \mathrm{U}=0.579, \mathrm{z}=-2.293, \mathrm{P}=0.022)$.

Six ant species made up the vast majority of observations, B. obscurior (38.04\%), C. floridanus (19.37\%), Solenopsis invicta (19.02\%), Camponotus sexguttatus (10.23\%), C. emeryi (9.2\%), and Pheidole moerens (2.7\%). The remaining $1.44 \%$ of observations included 4 species, of which sightings were rare enough to be deemed unimportant for plant fitness.

HERBIVORE ACTIVITY - Overall herbivore numbers were not affected by the presence or absence of Tanglefoot $(\mathrm{N}=40, \mathrm{df}=38, \mathrm{U}=193, \mathrm{z}=-0.190, \mathrm{P}=0.862)$. There were also no differences in the abundance of herbivores between plants in sunny and shady habitats $(\mathrm{N}=40, \mathrm{df}=38, \mathrm{U}=161, \mathrm{z}=-1.057, \mathrm{P}=0.301)$. 
Herbivore numbers did not vary between day and night $(\mathrm{N}=80, \mathrm{df}=78, \mathrm{U}=633.5$, $\mathrm{z}=-1.609, \mathrm{P}=0.108)$, however, differences in diurnal and nocturnal activity were observed in several key herbivore groups. Psyllids were observed in higher abundance during the day than at night $(\mathrm{N}=80, \mathrm{df}=78, \mathrm{U}=547.0, \mathrm{z}=-2.451, \mathrm{P}=0.014)$, while both leafhoppers $(\mathrm{N}=80, \mathrm{df}=78, \mathrm{U}=440.5, \mathrm{z}=-3.585, \mathrm{P}<0.001)$ and sulphur butterfly caterpillars $(\mathrm{N}=80$, $\mathrm{df}=78, \mathrm{U}=524.0, \mathrm{z}=-3.023, \mathrm{P}=0.003$ ) were more abundant at night than during the day.

A total of 725 herbivores were observed over 2160 observations (a mean of 0.34 herbivores per observation). The most common herbivores were psyllids $(412,56.83 \%)$, leafhoppers $(114,15.72 \%)$, sulphur caterpillars $(57,7.86 \%)$, and scale insects $(45$, $6.21 \%$ ). The remaining $13.35 \%$ of observations were made up of a wide range of taxa, including other Hemiptera (60, 8.28\%), weevils and other Coleoptera (31, 4.28\%), and other lepidopteran larvae $(6,0.83 \%)$.

THE EFFECTS OF SUNLIGHT AND ANTS ON PLANT REPRODUCTIVE FITNESS - Light intensity did not affect seed set overall, although the difference was nearly significant $(\mathrm{N}=40$, $\mathrm{df}=38, \mathrm{U}=134, \mathrm{z}=-1.955, \mathrm{P}=0.051$ ), with plants in sunny habitats producing more seeds. The presence of ants did not affect seed set overall $(\mathrm{N}=40, \mathrm{df}=38, \mathrm{U}=146.5, \mathrm{z}=-1.585$, $\mathrm{P}=0.113$ ), however, in sunny habitats, plants with ants produced significantly more seeds than plants from which ants were excluded $(\mathrm{N}=20, \mathrm{z}=-2.656, \mathrm{U}=16.0, \mathrm{P}=0.009)$. In shady habitats ants had no effect on seed production $(\mathrm{N}=20, \mathrm{z}=-0.326, \mathrm{U}=46.5, \mathrm{P}=0.796)$. In the presence of ants, plants in sunny habitats produced significantly more seeds than plants in shady habitats $(\mathrm{N}=20, \mathrm{z}=-2.774, \mathrm{U}=15.0, \mathrm{P}=0.007)$. In the absence of ants, sunlight had no impact on seed set $(\mathrm{N}=20, \mathrm{z}=-0.000, \mathrm{U}=50.0, \mathrm{P}=1.000)$ (Figure 1). 
THE EFFECTS OF SUNLIGHT AND ANTS ON HERBIVORY - A two-way ANOVA revealed a significant interaction effect, indicating that the effects of sunlight and ants on herbivory rates were not independent $(\mathrm{N}=40, \mathrm{df}=36, \mathrm{~F}=6.905, \mathrm{P}=0.013)$. Light, alone did not affect herbivory rates $(\mathrm{N}=40, \mathrm{df}=36, \mathrm{~F}=0.018, \mathrm{P}=0.894)$; however, plants with ants excluded suffered significantly higher levels of herbivory overall $(\mathrm{N}=40, \mathrm{df}=36, \mathrm{~F}=8.085, \mathrm{P}=0.007)$ (Figure 2A).

In sunny habitats, plants with no ants suffered significantly more herbivory than plants with ants present $(\mathrm{N}=20, \mathrm{df}=18, \mathrm{t}=-3.979, \mathrm{~F}=0.204, \mathrm{P}=0.001)$. In shady habitats, the presence of ants had no effect on herbivory rates $(\mathrm{N}=20, \mathrm{df}=18, \mathrm{t}=-0.149, \mathrm{~F}=0.621$, $\mathrm{P}=0.884)$.

THE EFFECTS OF SUNLIGHT AND ANTS ON PLANT GROWTH RATES- A two-way ANOVA revealed no significant interaction between light and the presence of ants $(\mathrm{N}=40, \mathrm{df}=36$, $\mathrm{F}=0.540, \mathrm{P}=0.467)$. Neither light $(\mathrm{N}=40, \mathrm{df}=36, \mathrm{~F}=0.010, \mathrm{P}=0.921)$ nor the presence of ants $(\mathrm{N}=40, \mathrm{df}=36, \mathrm{~F}=2.320, \mathrm{P}=0.136)$ significantly affected plant vegetative growth rates (Figure 2B).

EFFECTS OF SUNLIGHT AND ANTS ON PLANT SIZE- A two way ANOVA revealed no interaction effect between sunlight and the presence of ants $(\mathrm{N}=40, \mathrm{df}=36, \mathrm{~F}=2.696$, $\mathrm{P}=0.109)$. Plants in sunny habitats were not significantly larger than those in shady habitats $(\mathrm{N}=40, \mathrm{df}=36, \mathrm{~F}=2.240, \mathrm{P}=0.143)$, and the presence of ants did not have a significant impact on plant size overall $(\mathrm{N}=40, \mathrm{df}=36, \mathrm{~F}=2.254, \mathrm{P}=0.142)$ (Figure 2C). When plants in sunny habitats were considered alone, however, plants with ants present grew significantly larger than plants with ants excluded $(\mathrm{N}=20, \mathrm{df}=18, \mathrm{t}=2.345, \mathrm{P}=0.031)$. 
Plants with ants present increased in size during the course of the study, while plants without ants decreased in size. Overall comparisons of plant size in the presence and absence of ants, however, revealed no significant differences $(\mathrm{N}=40, \mathrm{df}=38, \mathrm{~F}=$ 3.670, $\mathrm{t}=1.447, \mathrm{P}=0.156$ ), even when analyzed by season (Spring: $\mathrm{N}=40, \mathrm{df}=38, \mathrm{~F}=$ 1.573, $\mathrm{t}=0.37, \mathrm{P}=0.970 ;$ Summer: $\mathrm{N}=40, \mathrm{df}=38, \mathrm{~F}=0.515, \mathrm{t}=1.547, \mathrm{P}=0.130$; Fall: $\mathrm{N}=40$, $\mathrm{df}=38, \mathrm{~F}=3.403, \mathrm{t}=1.603, \mathrm{P}=0.117$; Winter: $\mathrm{N}=40, \mathrm{df}=38, \mathrm{~F}=3.616, \mathrm{t}=1.573, \mathrm{P}=0.124$ ) (Figure 3A).

When plants in the shade were considered alone, the presence of ants neither affected plant size overall $(\mathrm{N}=20, \mathrm{df}=18, \mathrm{~F}=0.096, \mathrm{t}=-0.095, \mathrm{P}=0.926)$, or in any individual season (Spring: $\mathrm{N}=20, \mathrm{df}=18, \mathrm{~F}=1.040, \mathrm{t}=-0.202, \mathrm{P}=0.844$; Summer: $\mathrm{N}=20$, $\mathrm{df}=18, \mathrm{~F}=0.104, \mathrm{t}=0.3, \mathrm{P}=0.767$; Fall: $\mathrm{N}=20, \mathrm{df}=18, \mathrm{~F}=0.002, \mathrm{t}=-0.236, \mathrm{P}=0.816$; Winter: $\mathrm{N}=20, \mathrm{df}=18, \mathrm{~F}<0.001, \mathrm{t}=-0.189, \mathrm{P}=0.852$ ) (Figure 3B).

When plants in sunny habitats were considered alone, plants with ants were not larger than plants without ants $(\mathrm{N}=20, \mathrm{df}=18, \mathrm{~F}=3.670, \mathrm{t}=1.447, \mathrm{P}=0.156)$. When analyzed by season, however, plants with ants present were significantly larger by the summer $(\mathrm{N}=20, \mathrm{df}=18, \mathrm{~F}=0.129, \mathrm{t}=2.134, \mathrm{P}=0.047)$, and remained larger during Fall $(\mathrm{N}=20, \mathrm{df}=18, \mathrm{~F}=0.934, \mathrm{t}=2.660, \mathrm{P}=0.016)$ and winter $(\mathrm{N}=20, \mathrm{df}=18, \mathrm{~F}=3.024, \mathrm{t}=2.128$, $\mathrm{P}=0.047$ ) than plants without ants (Figure 3C).

EXTRAFLORAL NECTAR PRODUCTION— Neither the presence of ants $(\mathrm{N}=40, \mathrm{df}=38, \mathrm{z}=-$ 0.135, $\mathrm{U}=195, \mathrm{P}=0.904)$ nor light intensity $(\mathrm{N}=40, \mathrm{df}=38, \mathrm{z}=-2.656, \mathrm{U}=142, \mathrm{P}=0.121)$ had a significant effect on EFN production. Per leaf EFN production was observed to decrease steadily throughout the course of the study (Figure 4). 


\section{DISCUSSION}

Our results show that ants can act as a highly effective biotic defense against herbivores in Senna chapmanii, and that the outcome of these ant-plant interactions depends on light conditions. Plants with ants in sunny habitats suffered less herbivore damage, produced more seeds, and grew larger than plants from which ants were excluded. In shaded habitats, however, no such differences were seen. That plants received greater benefits from their ant partners in sunny habitats was not surprising, as ant activity was significantly higher in the sun than in the shade. Among plants from which ants were excluded, those in sunny habitats suffered more herbivore damage, and produced fewer seeds than those in shady habitats. These results suggest that plants in sunny habitats faced greater herbivore pressures than plants in the shade; however, we observed no significant differences in herbivore activity between sunny and shady habitats.

Light conditions may affect the outcome of ant-plant interactions in a number of ways. Firstly, light conditions are known to affect ant activity, with many species occurring in higher abundance in sunny microhabitats (Varon et al. 2007). The tropical fire ant, Solenopsis geminata, for example, is particularly abundant in unshaded areas in Costa Rican coffee plantations (Perfecto \& Vandermeer 1996). In addition to ant activity, light conditions have been found to affect EFN production in several species (Radhika et al. 2010, Yamawo \& Hada 2010, Izaguirre et al. 2013), including S. chapmanii (Jones and Koptur 2015b). Yamawo and Hada (2010), for example, found that EFN production in Mallotus japonicus was increased at high light intensities. Furthermore, Izaguirre et al. 
(2013) observed that EFN production in passion fruit (Passiflora edulis) is downregulated in response to changes in light spectral quality that signal the proximity of other plants. Although we did not observe increased EFN production in plants in sunny habitats, our results suggest that light conditions significantly impacted the outcome of ant-plant interactions, predominantly due to localized variations in ant activity.

We observed no difference in overall ant activity between daytime and nighttime observations, despite the fact that we know that EFN production in $S$. chapmanii is significantly increased at night (Jones and Koptur 2015). We did, however, observe diurnal/nocturnal variations in the activity of some individual ant species. Indeed, the two most abundant species, B. obscurior and C. floridanus, were more abundant during the daytime and nighttime respectively, perhaps indicating some degree of temporal resource partitioning. Overall, however, our results suggest that, for $S$. chapmanii, spatial rather than temporal variations in ant activity have a greater impact on the outcome of ant-plant interactions.

Most studies of the effects of ants on plant fitness have been limited by their duration. Heil et al. (2001) compared the effects of ant exclusion on herbivory rates in three Macaranga species. After 2 months, herbivory rates had increased by an average of less than $2 \%$ compared to control (ants present) plants. Within one year, however, plants with ants excluded lost between $70-80 \%$ of their leaf area. These findings suggest that long-term studies (of at least one year) are required to accurately determine the effects of ants on herbivory rates. In many existing studies, plant fitness is estimated only a short time after ant exclusion, often within the same growth season. The true effects of 
herbivory on plant fitness may be cumulative, as damage can affect not only short term reproductive investment but also plant size, thereby reducing future reproductive potential (Rosumek et al. 2009). Here we addressed these shortcomings in two ways. Firstly, an experiment duration of one calendar year surpasses that of most studies, and represents more than a snapshot in a relatively short-lived plant. Secondly, we recorded changes in plant size over the course of the study, as a measure of future reproductive potential. In sunny habitats, plants with ants grew steadily larger over the course of the year than plants without ants, while plants without ants gradually decreased in size. These observations provide further evidence that ants are more effective plant bodyguards for $S$. chapmanii in sunny habitats, and suggest that the gap in reproductive fitness between plants with and without ants would only widen over time.

It should be noted that we have focused only on foliar herbivory, which may be misleading as ants can be equally important in defending reproductive structures (Falcao et al. 2014, Heil 2015). Indeed, EFN production has been observed to increase during fruit production in several species (Holland et al. 2009, Falcao et al. 2014). During our study we regularly saw ants patrolling developing fruit, an activity that may account for much of the difference in seed set between plants with and without ants. Future work should focus on the effects of ants on the activity of pre-dispersal seed predators.

Bi-monthly measurements revealed a gradual reduction in EFN production over the course of the study. These measurements were taken between April and February, and we have observed a similar pattern in a subsequent field study, during which measurements were taken between October and May (Jones et al. unpublished data). 
These results suggest that the decline in EFN production with age in S. chapmanii represents an ontogenetic rather than a seasonal or phenological pattern. Previous studies of the ontogeny of EFN secretion, particularly among myrmecophylic plants, have yielded mixed results. Doak et al. (2007) observed a marked decrease in EFN production with age in trembling aspen (Populus tremuloides, Salicaceae), while others have found EFN production to be increased in, or even limited to, mature stages (Koptur 1979, Falcao et al. 2003, Kobayashi et al. 2008, Holland et al. 2009). Our results suggest that ant-plant interactions may be most important for establishment and early growth in $S$. chapmanii. Future studies could observe establishment rates of S. chapmanii saplings in natural growing conditions, in the presence and absence of ants.

Understanding the effects of small scale changes in light conditions is particularly important for plants in pine rockland habitats, which are threatened in south Florida (Possley et al. 2008). Over the last century, more than $98 \%$ of pine rockland habitat in south Florida (with the exception of Everglades National Park) has been destroyed for agriculture and urban development (Barrios et al. 2011). Because of their close proximity to dense human populations, the remaining pine rockland fragments are frequently mismanaged. In particular, the fires that are necessary to maintain healthy pine rocklands are often suppressed (Possley et al. 2008). Pine rockland habitats are characterized by an open canopy, with high levels of light reaching the diverse, endemic-rich herb layer. In the absence of fire, trees and shrubs quickly grow, and many understory species are shaded out, decreasing plant diversity. While the transition to a closed canopy hammock environment will inevitably threaten many pine rockland species, our results suggest that 
even minor changes in habitat structure could have devastating effects on the fitness of low lying herbaceous species, particularly those that rely on mutualistic ants for defense.

ACKNOWLEDGMENTS: The authors thank S. Zona for his generosity with greenhouse facilities. Help with insect specimen identification came from M. Deyrup and J. Clayborn. Constructive input on the manuscript was also provided by J. Theobald, and J. Richards. Financial support was provided in the form of three research grants from the Lloyd Kelly foundation for tropical botany. Statistical consultation was provided by A. Matamala. This is contribution number ...?... to the Florida International University Program in Tropical Biology.

\section{REFERENCES}

BAKER, D. A., L. J. HALL, AND J. R. THORPE. 1978. A study of the extrafloral nectaries of Ricinus communis. New Phytologist 81. 129-137.

Barrios, B., G. ARELlano, AND S. Koptur. 2011. The effects of fire and fragmentation on occurrence and flowering of a rare perennial plant. Plant Ecology 212: 1057-1067.

BARTON, A. M. 1986. Spatial variation in the effect of ants on an extrafloral nectary plant. Ecology 67:495-504.

BECERRA, J. X. I., AND D. L. VENABLE. 1989. Extrafloral nectaries: a defence against anthomoptera mutualisms? Oikos 55. 276-280.

BeNTLEY, B. L. 1976. Plants bearing extrafloral nectaries and associated ant community-interhabitat differences in reduction of herbivore-damage. Ecology 57: $815-820$.

BENTLEY, B. L. 1977. The protective function of ants visiting the extrafloral nectaries of Bixa orellana (Bixaceae). Journal of Ecology 65: 27. 
Bronstein, J. L., W. G. Wilson, AND W. E. Morris. 2003. Ecological dynamics of mutualistic/antagonist communities. American Naturalist 162: 24-39.

CUAUTLE, M., AND V. Rico-Gray. 2003. The effect of wasps and ants on the reproductive success of the extrafloral nectaried plant Turnera ulmifolia (Turneraceae). Functional Ecology 17: 417-423.

Corbet, S. A., AND E. S. Delfosse. 1984. Honeybees and the nectar of Echium plantagineum L. in south-eastern Australia. Australian Journal of Ecology 9: 125-139.

Chavarro-Rodriguez, N., C. Diaz-CAStelazo, And V. Rico-Gray. 2013. Characterization and functional ecology of the extrafloral nectar of Cedrela odorata in contrasting growth environments in central Veracruz, Mexico. Botany 91: 695-701.

DAVIDSON, D. W., AND B. L. FISCHER. 1991. Symbiosis of ants with Cecropia as function of light regime. Pages 289-309 in C. R. Huxley and D. F. Cutler, editors. Ant-plant interactions. Oxford University Press, New York, New York, USA.

DE LA FuENTE, M. A. S., AND R. J. MARQUIS. 1999. The role of ant-tended extrafloral nectaries in the protection and benefit of a neotropical rainforest tree. Oecologia 118: 192-202.

Díaz-Castelazo, C. V. Rico-Gray, P. S. Oliveira, And M. Cuautle. 2004. Extrafloral nectary - mediated ant - plant interactions in the coastal vegetation of Veracruz, Mexico: Richness, occurrence, seasonality, and ant foraging patterns. Ecoscience 11: 472-481.

DOAK, P., D. WAGNER, AND A. WATSON. 2007. Variable extrafloral nectary expression and its consequences in quaking aspen. Canadian Journal of Botany 85: 1-9.

Falcao, P. F., G. F. D. Melo-De-Pinna, I. R. Leal, And J. S. AlmeidA-Cortez. 2003. Morphology and anatomy of extrafloral nectaries in Solanum stramonifolium (Solanaceae). Canadian Journal of Botany 81: 859-864.

FALCÃO, J. C. F., W. DÁTTILO., T. J. Izzo. 2014. Temporal variation in extrafloral nectar secretion in different ontogenic stages of the fruits of Alibertia verrucosa $\mathrm{S}$. Moore (Rubiaceae) in a Neotropical savanna. Journal of Plant Interactions 9: 137-142.

GonZAlez-Teuber, M., AND M. HeIL. 2009. Nectar chemistry is tailored for both attraction of mutualists and protection from exploiters. Plant Signaling and Behaviour 4: 809-813.

HeIL, M. 2004. Induction of two indirect defences benefits lima bean (Phaseolus lunatus, Fabaceae) in nature. Journal of Ecology 92: 527-536.

HEIL, M. 2011. Nectar: generation, regulation and ecological functions. Trends in Plant Science 16: 4. 191-200. 
HeIL, M. 2015. Extrafloral nectar at the plant-insect interface: A spotlight on chemical ecology, phenotypic plasticity and food webs. Annual Review of Entomology 60: 213232.

Heil, M., B. Fiala, B. Baumann, And K. E. Linsenmair. 2000. Temporal, spatial and biotic variations in extrafloral nectar secretion by Macaranga tanarius. Functional Ecology 14: 749-757.

Heil, M., A. Hilpert, B. Fiala, And K. E. LinsenMaIR. 2001. Nutrient availability and indirect (biotic) defence in a Malaysian ant-plant. Oecologia 126: 404-408.

Heil, M., A. Hilpert, R. Kruger, AND K. E. Linsenmair. 2004. Competition among visitors to extrafloral nectaries as a source of ecological costs of an indirect defence. Journal of Tropical Ecology 20: 201-208.

Holland, J. N., A. A. Chamberlain, And K. C. Horn. 2009. Optimal defence theory predicts investment in extrafloral nectar resources in an ant-plant mutualism. Journal of Ecology 97: 89-96.

INOUYE, D. W., AND O. R. TAYLOR. 1979. A temperate region plant-ant-seed predator system: consequences of extrafloral nectary secretion by Helianthella quinquenervis. Ecology 65: 618.

Izaguirre, M. M., C. A. Mazza, M. S. Astigueta, A. M Ciarla, And C. L. Ballare. 2013. No time for candy: passionfruit (Passiflora edulis) plants down-regulate damageinduced extra floral nectar production in response to light signals of competition. Oecologia 173: 213-221.

JANZEN, D. H. 1966. Coevolution of mutualism between ants and acacias in central America. Evolution 20: 249-275.

JONES, I. M, AND S. KOPTUR. 2015. Dynamic extrafloral nectar production: The timing of leaf damage affects the defensive response in Senna mexicana var. chapmanii (Fabaceae). American Journal of Botany 102: 58-66.

JONES, I. M, AND S. KOPTUR. 2015b. Quantity Over Quality: Light Intensity, but not Red/Far-Red Ratio, Affects Extrafloral Nectar Production in Senna mexicana var. chapmanii. Functional Ecology. In Press

Karban, R., A. A. Agrawal, J. S. Thaler, And L. S. Adler. 1999. Induced plant responses and information content about risk of herbivory. Trends in Ecological Evolution 14: 443-447.

KERSCH, M. F, AND C. R. FOnSECA. 2005. Abiotic factors and the conditional outcome of an ant-plant mutualism. Ecology 86: 2117-2126. 
Kobayashi, S., T. Asai, Y. FuJIMOTO, AND S. KohShima. 2008. Anti-herbivore structures of Paulownia tomentosa: morphology, distribution, chemical constituents and changes during shoot and leaf development. Annals of Botany 101: 1035-1047.

KOPTUR, S. 1979. Facultative mutualism between weedy vetches bearing extrafloral nectaries and weedy ants in California. American Journal of Botany 66: 1016-1020.

KoptUR, S. 1992. Interactions between Insects and Plants Mediated by Extrafloral Nectaries. In Bernays, E. (ed.) CRC series on Insect/Plant Interactions. Volume 4, pp. 85-132.

KoPTUR, S. 1992. Plants with Extrafloral Nectaries and Ants in Everglades Habitats. The Florida Entomologist 75: 38-50.

KOPTUR, S., AND J. H. LAWTON. 1988. Interactions among vetches bearing extrafloral nectaries, their biotic protective agents, and herbivores. Ecology 69: 278-283.

Koptur, S., M. Palacios-Rios, C. Diaz-Castelazo, W. P. Mackay, and V. RicoGRAY. 2013. Nectar secretion on fern fronds associated with lower levels of herbivore damage: field experiments with a widespread epiphyte of Mexican cloud forest remnants. Annals of Botany 111: 1277-1283.

KoptuR, S., I. M. JoneS., AND J. E. PenA. 2015 The Influence of Host Plant Extrafloral Nectaries on Multitrophic Interactions: An Experimental Investigation. PLOSone. In Press.

Kost, C., M. HeIL. 2005. Increased availability of extrafloral nectar reduces herbivory in lima bean plants (Phaseolus lunatus, Fabaceae). Basic Applied Ecology 6: 237-48.

KUO, J., AND P. J. S. PATE. 1985. The extrafloral nectaries of cowpea (Vicia unguiculata (L.) Wapp). 1. Morphology, anatomy and fine-structure. Planta 166: 15-27.

LANGE, D., W. DÁTTILO., AND K. DEL-CLARO. 2013. Influence of extrafloral nectary phenology on ant-plant mutualistic networks in a neotropical savanna. Ecological Entomology 38: 463-469.

LeAL, I. R., E. Fischer, C. Kost, M. TABARelLi, AND R. WiRTH. 2006. Ant protection against herbivores and nectar thieves in Passiflora coccinea flowers. Ecoscience 13: 431438.

MARAZZI, B., J. L. BRONSTEIN, AND S. KoptUR. 2013. The diversity, ecology and evolution of extrafloral nectaries: current perspectives and future challenges. Annals of Botany 111: 1243-1250.

MoYA-RAYGOZA, G. 2005. Relationships between the ant Brachymyrmex obscurior (Hymenoptera, Formicidae) and Acacia pennatula (Fabaceae). Insectes Sociaux 52: 105107. 
MOYA-RAYGOZA, G., AND K. J. LARSEN. 2001. Temporal resource switching by ants between honeydew produced by the fivespotted gamma grass leafhopper (Dalbulus quinquenotatus) and nectar produced by plants with extrafloral nectaries. American Midland Naturalist 146: 311-320.

OLIVEIRA, P. S. 1997. The ecological function of extrafloral nectaries: Herbivore deterrence by visiting ants and reproductive output in Caryocar brasiliense (Caryocaraceae). Functional Ecology 11: 323-330.

Perfecto, I., AND J. VANDERMEeR. 1996. Microclimatic changes and the indirect loss of ant diversity in a tropical agroecosystem. Oecologia 108: 577-582.

Possley, J., S. W. WoOdMANSEE, AND J. MASChINSKI. 2008. Patterns of plant composition in fragments of globally imperiled pine rockland forest: effects of soil type, recent fire frequency, and fragment size. Natural Areas Journal 28: 379-394.

RAdHIKA, V., C. Kost, A. Mithofer, AND W. BOLAND. 2010. Regulation of extrafloral nectar secretion by jasmonates in lima bean is light dependent. Proceedings of the National Academy of Sciences, USA 107: 17228-17233.

Raine, N. E., P. WiLlmeR, AND G. N. StONE. 2002. Spatial structuring and floral avoidance behaviour prevent ant-pollinator conflict in a Mexican ant-acacia. Ecology 83: 3086-3096.

Rico-Gray, V., J. G. Garcia-Franco, M. Palacios-Rios, C. Diaz-Castelazo, V. PARRA-TABLA, AND J. A. NAVARRO. 1998. Geographical and seasonal variation in the richness of ant-plant interactions in Mexico. Biotropica 30: 190-200.

Rosumek, F. B., F. A. O. Silveira, F. D. Neves, N. P. D. Barbosa, L. Diniz, Y. Oki, F. PEZZINI, G. W. FERNANDES, AND T. CORNELISSEN. 2009. Ants on plants: a meta-analysis of the role of ants as plant biotic defenses. Oecologia 160: 537-549.

RUDGERS, J. A. 2004. Enemies of herbivores can shape plant traits: Selection in a facultative ant-plant mutualism. Ecology 85: 192-205.

RUTTER, M. T., AND M. D. RAUSHER. 2004. Natural selection on extrafloral nectar production in Chamaecrista fasciculata: the costs and benefits of a mutualism trait. Evolution 58: 2657-2668.

TILMAN, D. 1978. Cherries, ants and tent caterpillars: timing of nectar production in relation to susceptibility of caterpillars to ant predation. Ecology 59: 686-692.

Torres-Hernandez, L., V. Rico-Gray, C. Castillo-Guevara, and J. A. Vergara. 2000. Effect of nectar-foraging ants and wasps on the reproductive fitness of Turnera ulmifolia (Turneraceae) in a coastal sand dune in Mexico. Acta Zoologica Mexicana 81: 13-21. 
Varon, E. H., P. Hanson, J. T. Longino, O. Borbon, M. Carballo, and L. Hilje. 2007. Temporal and spatial distribution of ants in a light gradient in a coffee agroforestry system, Turrialba, Costa Rica. Revista de Biologia Tropical 55: 943-956.

WAGNER, D., AND A. KAY. 2002. Do extrafloral nectaries distract ants from visiting flowers? An experimental test of an overlooked hypothesis. Evolutionary Ecology Research 4: 293-305.

WICKERS, S. 1997. Study of nectariferous secretion in a pioneer plant, Inga thibaudiana, in relation with ants. Acta Botanica Gallica 144: 315-26.

YAMAWO, A, AND Y. HADA. 2010. Effects of light on direct and indirect defences against herbivores of young plants of Mallotus japonicus demonstrate a trade off between two indirect defence traits. Annals of Botany 106: 143-148.

YAMAWO, A., Y. HADA, AND N. SUZUKI. 2012. Variations in direct and indirect defenses against herbivores on young plants of Mallotus japonicus in relation to soil moisture conditions. Journal of Plant Research 125: 71-76. 


\section{FIGURES}

FIGURE 2.1: Seed set in S. chapmanii plants from all 4 treatments. Bars represent mean seed set per plant over a period of one year. Error bars represent standard error. Different letters indicate significant differences.

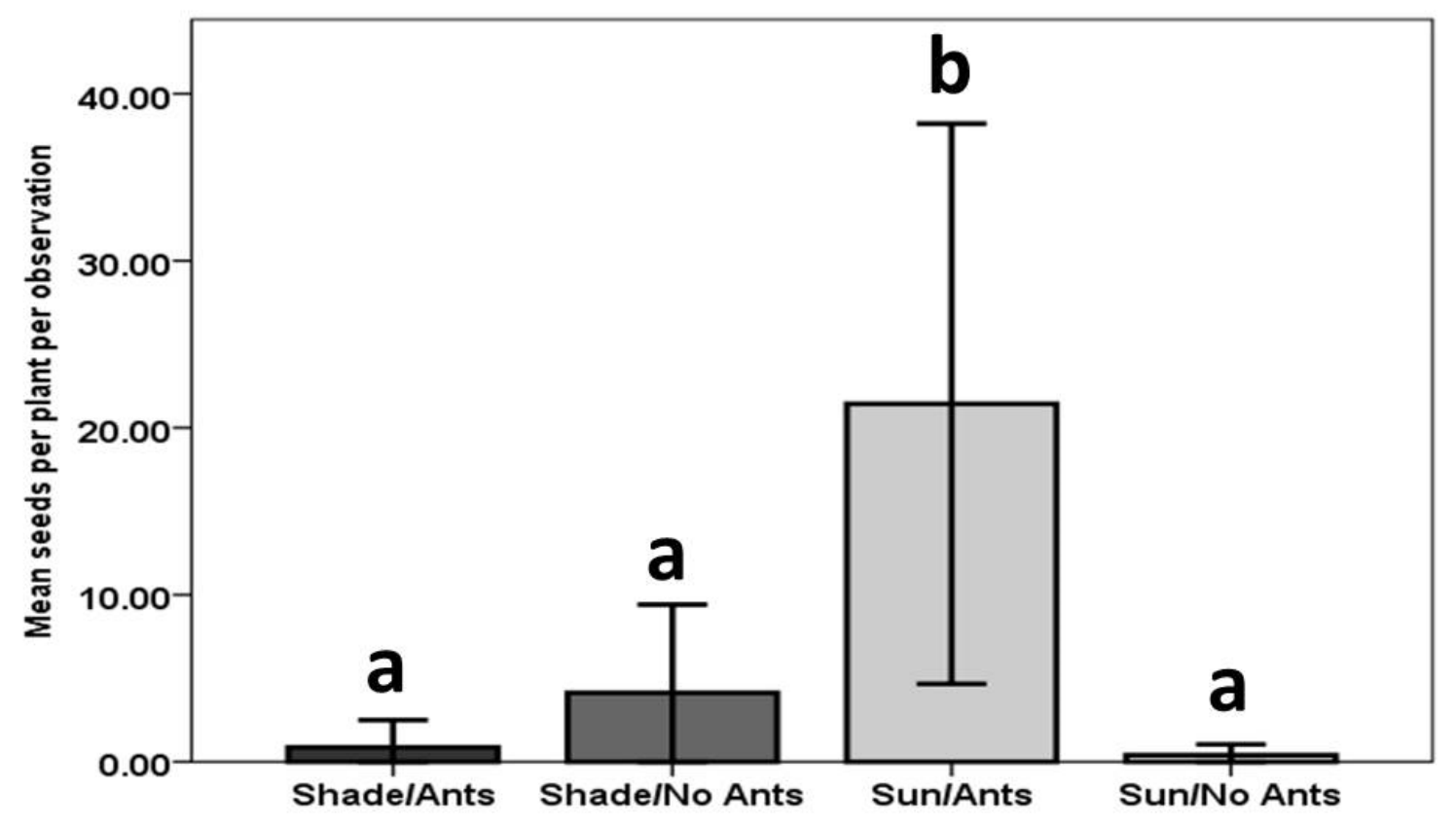


FIGURE 2.2: Two-way ANOVAs to display the effects of light and the presence of ants on A: mean percentage herbivory rates. A significant interaction was observed between light and the presence of ants. Plants with no ants suffered significantly more herbivore damage than plants with ants present; B: mean plant growth rates. No interaction was observed between light and the presence of ants. No single treatment had a significant effect on plant growth rates; C: mean plant size. No interaction was observed between light and the presence of ants. No single treatment had a significant effect on overall plant size.
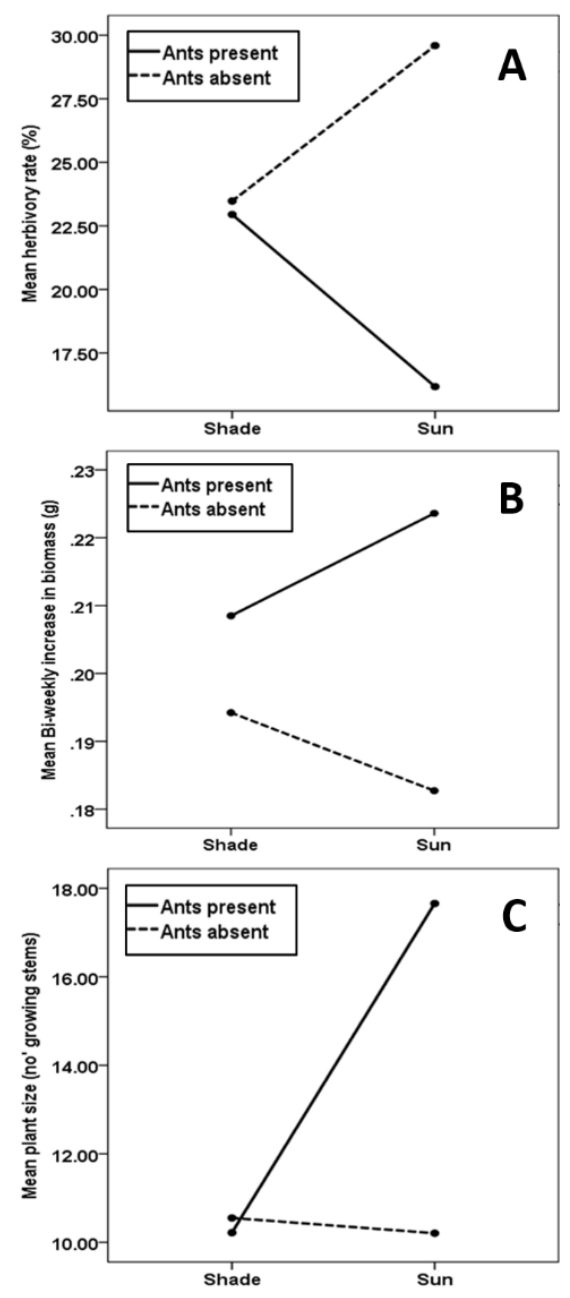
FIGURE 2.3: Temporal changes in plant size in the presence and absence of ants for A: all plants $(\mathrm{N}=40)$; B: plants in shaded habitats $(\mathrm{N}=20)$; $\mathrm{C}$ : plants in sunny habitats $(\mathrm{N}=20)$. Bars represent mean plant size during each two month period, and error bars represent standard error. Lower case letters indicate significant differences (seen only in C).
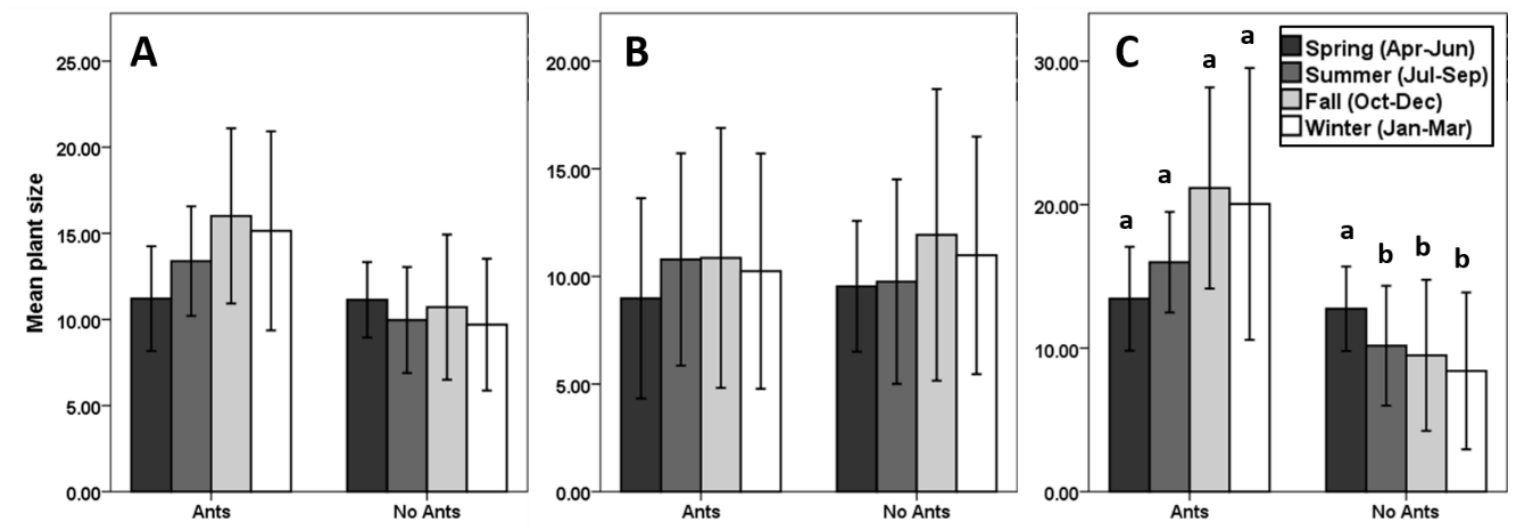
FIGURE 2.4: Temporal/ontogenetic variations in EFN production. Points indicate mean sugar production $(\mu \mathrm{g})$ across all 40 plants. Error bars represent standard error.

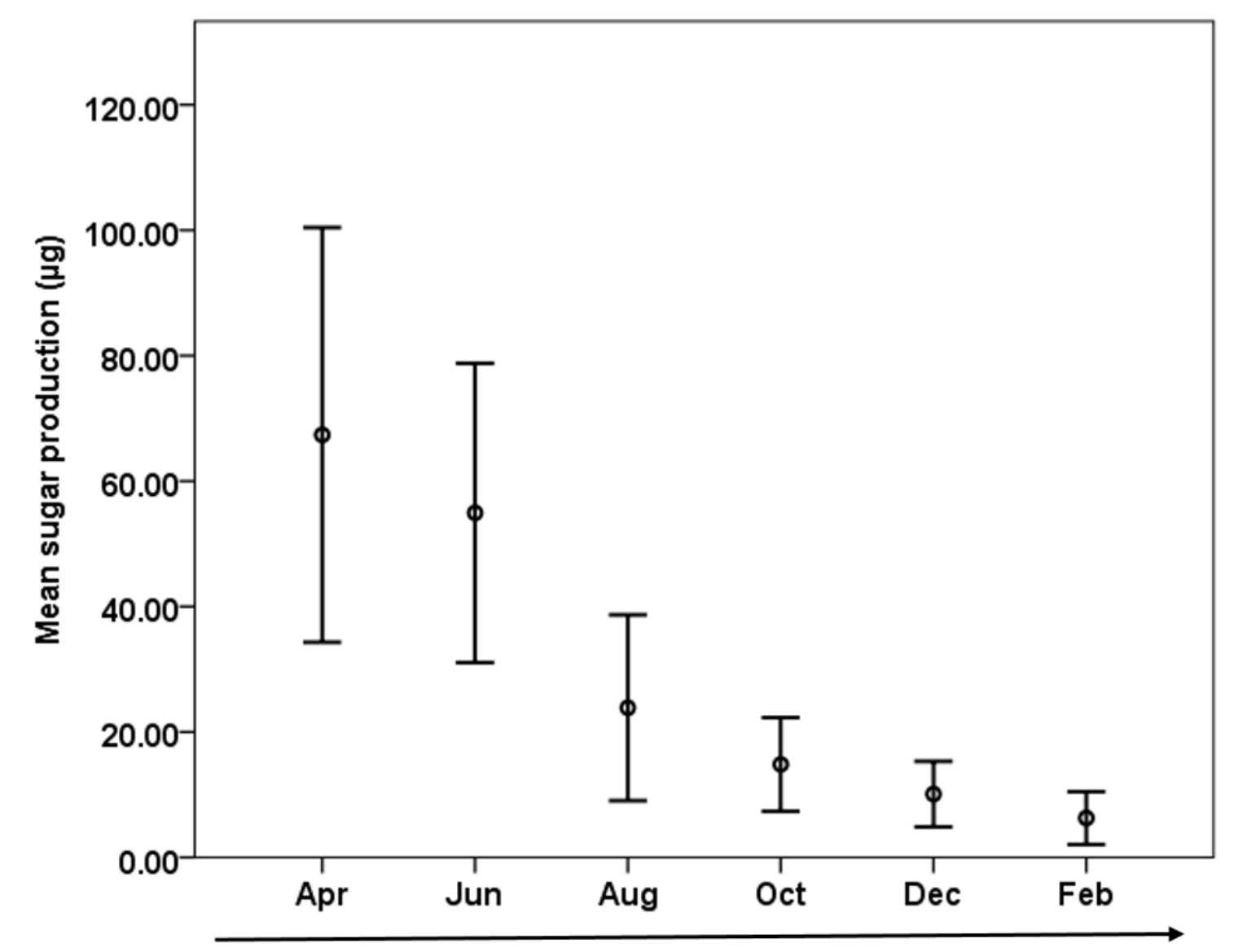

Month/Plant age 


\section{CHAPTER III}

QUANTITY OVER QUALITY: LIGHT INTENSITY, BUT NOT RED/FAR-RED

RATIO, AFFECTS EXTRAFLORAL NECTAR PRODUCTION IN SENNA

MEXICANA VAR. CHAPMANII 
Jones and Koptur - Light and extrafloral nectar production

Quantity Over Quality: Light Intensity, but not Red/Far-Red Ratio, Affects

Extrafloral Nectar Production in Senna mexicana var. chapmanii

IAN MATTHEW JONES*A, SUZANNE KOPTUR

${ }^{a}$ Department of Biological Sciences, Florida International University, Miami, USA

*Corresponding author: ijone002@fiu.edu 


\section{Summary}

1. Extrafloral nectar (EFN) mediates food-for-protection mutualisms between plants and insects, and provides plants with a form of indirect defense against herbivory. Understanding sources of variation in EFN production is important because such variations affect the number and identity of insect visitors and the effectiveness of plant defense.

2. Light represents a potentially crucial tool for regulating resource allocation to defense, as it not only contributes energy but may help plants to anticipate future conditions. Low red/far-red (R/FR) light ratios can act as a signal of the proximity of competing plants. Exposure to such light ratios has been shown to promote competitive behaviors that coincide with reduced resource allocation to direct chemical defenses. Little is known, however, about how such informational light signals might affect indirect defenses such as EFN, and the interactions that they mediate.

3. Through controlled greenhouse experiments we investigated the effects of light intensity, and R/FR light ratios, on EFN production in Senna mexicana var. chapmanii. Plants in light-limited conditions produced significantly less EFN, and leaf damage elicited increased EFN production regardless of light conditions. Ratios of R/FR light, however, did not appear to affect EFN production in either damaged or undamaged plants.

4. Understanding the effects of light on indirect defenses is of particular importance for plants in the threatened pine rockland habitats of south Florida, where light 
conditions are changing in predictable ways following extensive fragmentation and subsequent mismanagement. Around $27 \%$ of species in these habitats produce EFN, and may rely on insect communities for defense.

Key-words: Extrafloral nectar; Fabaceae; plant defenses; resource allocation; Senna mexicana var. chapmanii.

\section{Introduction}

Extrafloral nectaries (EFNs) are nectar-secreting glands located outside of flowers, and have been observed on a huge diversity of species, spanning over 93 families and 332 genera (Koptur 1992; Marazzi et al. 2013). These nectaries may serve diverse ecological functions (Baker et al. 1978; Becerra \& Venable 1989; Wagner \& Kay 2002; Heil 2011), but primarily they are known to provide indirect defense against herbivores by attracting predatory insects, predominantly ants (Bentley 1977; Koptur 1992; Rosumek et al. 2009; Heil 2015). Despite their unquestionable importance, relatively little is known about the factors that regulate EFN production. Uncovering these factors can help us understand how plants regulate their investment in defense, and how they manage and maintain interactions with beneficial insects.

Light conditions are likely to be particularly influential in controlling the expression of plant defensive traits, as light not only represents a crucial aspect of resource availability, but may also serve as an indicator of insect activity (Karban et al. 1999), or future competition (Izaguirre et al. 2006). Plants are well known to sense 
changes in spectral signals (for example: Weller et al. 1997; Adams et al. 2001). Far-red light, for example, is a component of the solar spectrum $(710-850 \mathrm{~nm})$ that is heavily reflected by plant tissues (Izaguirre et al. 2006). Increases in far-red radiation, relative to the red portion of sunlight (620-750nm), can be detected through the photoreceptor, phytochrome B (Ballaré 1990; 2014). A low red/far-red (R/FR) light ratio is known to indicate the close proximity of competitors for many plants (Ballaré 1999, 2014).

Plants exposed to low R/FR light conditions often express a suite of competitionfocused traits collectively known as the shade-avoidance syndrome (Ballaré 1999; Pierik et al. 2013; Ballaré 2014). Responses associated with the shade-avoidance syndrome include increased stem elongation, reduced lateral branching, and a reduction in resource allocation to defensive traits (Izaguirre et al. 2006). The expression of several direct plant defenses such as phenolic compounds (Moreno et al. 2009), and latex (Rasmann, Johnson \& Agrawal 2009; Agrawal et al. 2012), are known to be reduced in low R/FR light.

Far less is known about the effects of light conditions on the expression of indirect plant defenses such as EFN. Light intensity is known to affect trade-offs between indirect defenses in Mallotus japonicus (Yamawo \& Hada 2010); however, only the effects of light intensity, and not light quality, were observed and so we know little about how these plants may respond to informational light signals. In lima beans (Phaseolus lunatus), the induction of EFN production with jasmonic acid (JA) has been shown to be dependent on light intensity, and on the ratio of R/FR wavelengths (Radhika et al. 2010). Izaguirre et al. (2013) also observed EFN production in passion fruit (Passiflora edulis) in carefully manipulated light conditions. Plants (and plant parts) exposed to low R/FR 
light conditions exhibited reduced EFN production, compared to those exposed to higher $\mathrm{R} / \mathrm{FR}$ light ratios, particularly in response to simulated herbivory.

Pine rockland habitats contain a high proportion of EFN-bearing plants (27\%) (Koptur 1992), but the dynamics of EFN production in these species has rarely been studied (but see Rutter \& Rausher 2004; Jones \& Koptur 2015). Senna mexicana var. chapmanii (hereafter referred to as Senna chapmanii) is a herbaceous legume native to the pine rocklands of south Florida and the Caribbean. We have already shown that $S$. chapmanii plants produce more EFN in response to leaf damage (Jones \& Koptur 2015). We have also observed that plants in shady conditions are less well defended by ants than those in direct sunlight (Jones et al. unpublished data).

In this study, we investigated the effects of light intensity and R/FR light ratio on EFN production in S. chapmanii. Both artificially defoliated and undamaged plants were tested. We expected EFN production would be increased in response to leaf damage and high light intensity, but reduced in response to low R/FR light ratios. Understanding the factors that control EFN production is important, because such variations affect the number and identity of insect visitors, and the effectiveness of plant defense.

\section{Methods}

To control $S$. chapmanii light environments, film cylinders $(50 \mathrm{~cm}$ in circumference and $60 \mathrm{~cm}$ in height) were constructed using three calibrated light filtration films. Film 1 (treatment film) was a metal sputter-coated film designed to mimic shading 
by other plants by reducing photosynthetically active radiation (PAR) by approximately $80 \%$, and reducing the ratio of R/FR light. Film 2 (control film), a dye-impregnated film, was designed to reduce PAR by approximately $80 \%$, but without impacting R:FR light ratio. Films 1 and 2 were supplied by the 3M Corporation (St. Paul, Minnesota, 55144, USA), and have been used previously to test the effects of irradiance and spectral quality on forest tree seedling development (Lee et al. 1996). Film 3 was a clear acetate film which allowed approximately 90\% PAR transmission, and had no impact on R:FR light ratio. Film 3 was supplied by BLICK art materials (Galesburg, Illinois, 61402, USA), and controlled for the effects of the cylinders themselves. Twenty four film cylinders ( 8 of each type) were placed on a greenhouse bench. The open bottom of each cylinder was placed around the plant pot, and the top end was sealed closed using clear tape. Cylinders composed of the three film types were placed alternately in three rows running east to west (figure 2).

To determine the actual light environments within the film cylinders, the intensity and spectral distribution of light within the greenhouse was measured using a radiospectrometer (Unispec-DC, PP SYSTEMS, Amesbury, Massachusetts, USA). These measurements were then compared with measurements taken inside the film cylinders 1 , 2, and 3. Percentage transmittance of light through each film type, at a range of wavelengths (300-1000nm), was then calculated. Three of each filter type were tested (figure 3).

Senna chapmanii was grown from seeds in the greenhouse on the Modesto Maidique campus at Florida International University. After 3 weeks, seedlings were 
transplanted into $0.6-\mathrm{L}$ pots, and 1.5g of slow release fertilizer (Nutricote NPK; Florikan, Sarasota, Florida, USA) was added to each plant. Plants were maintained in the greenhouse until they had at least 10 mature leaves. Experiments were conducted from June-August 2014.

Twenty-four plants were placed randomly in the cylinders (figure 2). After 48 hours inside the cylinders, 12 plants (4 from each cylinder type) were subjected to $50 \%$ leaf damage. Leaf damage was inflicted by removing $50 \%$ of each leaflet using scissors. The same damage treatments were used in a previous study (Jones \& Koptur 2015), and induced a highly significant increase in EFN production in S. chapmanii. The remaining 12 plants were left undamaged. The experiment, therefore, had two independent variables, light quality and leaf damage.

Extrafloral nectar production, by each plant, was measured 12 and 24 hours after leaf damage as the increase in EFN production by $S$. chapmanii in response to leaf damage has been shown to be greatest during this period (Jones \& Koptur 2015). Leaf damage was inflicted at $7 \mathrm{am}$, so nectar measurements took place at $7 \mathrm{pm}$ on the day of leaf damage, and at 7am the following morning. Taking measurements in the morning, and at night, allowed us to calculate a mean EFN production for each plant, controlling for natural diurnal variations in EFN production. Nectar volume was measured using 1, 2, and $10 \mu \mathrm{L}$ micropipettes, and its concentration determined using a handheld refractometer. Total sugar production by each plant was then calculated as described by Jones and Koptur (2015). The experiment was repeated 6 times, using a total of 144 plants. 
We report EFN production as the mean mass of sugar $(\mathrm{mg})$ produced by each plant, as this provides the best representation of defensive investment. Previous studies have often reported only nectar volume or concentration, both of which are affected by environmental factors such as temperature and humidity. Where we refer to EFN production in the discussion, we refer to mean sugar production.

Statistical Analysis: Kruskal-Wallace H tests were used to compare EFN production between the three light treatments in damaged and undamaged plants. Post hoc comparisons between pairs of light treatments were then conducted separately using Mann-Whitney U tests. Holm's sequential Bonferroni adjustments were applied to control for type 1 errors. Damaged and undamaged plants within each light treatment were compared using Mann-Whitney U tests.

\section{Results}

Radiospectrometer readings confirmed that light conditions inside the cylinders were as expected (figure 3). Film 1 admitted between 10\% and 30\% of light in photosynthetically active wavelengths, but transmittance rose to almost $90 \%$ in the farred wavelength band. Film 1, therefore, adequately mimicked shading by other plants, as compared to film 2, which admitted around $20 \%$ of light in photosynthetically active wavelengths, with transmittance rising only slightly in the far-red band. Film 3, the clear film, admitted around $90 \%$ of light across all wavelengths (figure 3). 
In all three light treatments, damaged plants produced more EFN than undamaged plants (Film 1: $\mathrm{z}=-2.492, \mathrm{df}=46, P=0.013$; Film 2: $\mathrm{z}=-2.474, \mathrm{df}=46, P=0.013$;

Film 3: $\mathrm{z}=-2.062, \mathrm{df}=46, P=0.039)$. Light treatments significantly affected EFN production in both damaged $($ Chi Square $=18.355, \mathrm{df}=2, P<0.001)$ and undamaged plants (Chi Square $=23.014, \mathrm{df}=2, P<0.001)$ (figure 4$)$.

Among damaged plants, those in clear tubes (film 3) produced significantly more EFN than those in $70 \%$ shade with reduced R/FR light ratio $(\mathrm{z}=-3.843, \mathrm{df}=46, P<$ $0.001)$, and those in $70 \%$ shade $(\mathrm{z}=-3.350, \mathrm{df}=46, P=0.001)$. There was no difference in sugar production between plants in 70\% shade with reduced R/FR light ratio, and those in $70 \%$ shade $(\mathrm{z}=-1.012, \mathrm{df}=46, P=0.311)$ (figure 4$)$.

Among undamaged plants, those in clear tubes (film 3) produced significantly more EFN than those is $70 \%$ shade with reduced $\mathrm{R} / \mathrm{FR}$ light ratio $(\mathrm{z}=-4.245, \mathrm{df}=46, P$ $<0.001)$, and those in $70 \%$ shade $(\mathrm{z}=-3.343, \mathrm{df}=46, P=0.001)$. There was no difference in sugar production between plants in 70\% shade with reduced R/FR light ratio, and those in $70 \%$ shade $(\mathrm{z}=-1.343, \mathrm{df}=46, P=0.179)$ (figure 4$)$.

\section{Discussion}

Extrafloral nectar is an extremely widespread, often inducible trait that mediates food-for-protection interactions between plants and ants. Although the ecological role of EFN is well established (Bentley 1977; Koptur 1992; Rosumek et al. 2009), far less is 
known about how changes in environmental conditions, even over small scales, may affect its production and, therefore, the outcomes of the interactions it mediates.

Plants in all three light treatments produced more EFN in response to leaf damage. Inducible EFN nectar production has been reported in many species (Stephenson 1982; Koptur 1989; Agrawal \& Rutter, 1998; Engel et al. 2001; Heil et al. 2001; Mondor \& Addicott 2003; Choh \& Takabayashi 2006; Lach et al. 2009; Heil 2015). Indeed, increased EFN production in response to leaf damage has been observed previously in $S$. chapmanii (Jones \& Koptur 2015). We observe for the first time, however, that this induced response is maintained in light-limited conditions, albeit at a lower level. It should be noted that, in the present study, we observed the effects of mechanical leaf damage and not true herbivory. Plants have been observed to respond to the oral secretions of specific herbivores (Kessler et al. 2010), and responses to damage have been shown to vary based on herbivore feeding guild (Schmidt et al. 2009; Sotelo et al. 2014). Future work, therefore, should focus on the effects of damage inflicted by key herbivores.

Light intensity had a significant impact on EFN production, as both damaged and undamaged plants produced more EFN at high light intensities. It might seem intuitive that a reduction in the availability of photosynthetically active light would reduce the level of resources available for defense. Indeed, some so called 'green nectaries' may be isolated from phloem tissue, and produce nectar only at a rate that can be supported by their own photosynthesis (Lüttge 2013). The resource availability hypothesis (RAH), however, suggests that low nutrient environments may promote greater investment in 
defensive traits, compared to nutrient rich environments where plants must grow quickly in order to compete (Coley et al. 1985; Endara \& Coley, 2011). The relationship between nutrient availability and defense is, therefore, complex, and assumptions that increased resources should lead to a greater investment in defense may be misplaced.

The carbon-nutrient balance hypothesis $(\mathrm{CNBH})$ suggests that when a given resource limits plant growth, other resources, found in relative excess, may be allocated towards defenses (Bryant et al., 1983). For example, in light-rich and nutrient-poor conditions plants are expected to invest in carbon-based defenses, while in shaded but nutrient-rich conditions plants should invest more heavily in nitrogen-based defenses (Lerdau \& Coley, 2002). Yamawo and Hada (2010) found that light intensity affected the trade-off between two indirect defenses in Mallotus japonicus. In low light conditions, both the size and the productivity of EFNs were reduced, but the production of pearl bodies was increased. These results seem to support $\mathrm{CNBH}$, as pearl bodies are rich in protein and represent a significant nitrogen investment (Heil et al. 2004). Our observations that EFN production in S. chapmanii is reduced in low light conditions seem to reflect resource availability and contradict RAH. However, it remains possible that reduced EFN production may coincide with an increased investment in nitrogen-based defensive compounds such as alkaloids. Future studies should seek to understand these dynamics, in S. chapmanii and other species.

The simplest and most elegant explanation for the observed pattern of EFN production may come from Millán-Cañongo et al. (2014), who observed reduced EFN production in shaded leaves of Ricinus communis. Changes in EFN production were 
shown to be mediated by cell wall invertase, an enzyme involved in the unloading of sucrose from the phloem into the nectary. Light conditions did not appear to affect cell wall invertase activity, so it was suggested that reduced EFN production was a result of lower sucrose content available in the phloem (Millán-Cañongo et al. 2014).

Changes in R/FR light ratio had no effect on EFN production in S. chapmanii. Plants exposed to low R/FR light ratios produced slightly less EFN in both damaged and undamaged plants, but the differences were not significant. These results were surprising as light spectral quality has been observed to affect EFN production significantly in both lima beans (Radhika et al. 2010) and passion fruit (Izaguirre et al. 2013). It is possible that our shade treatments reduced overall light intensity to such an extent that the effects of light spectral quality were tempered. This seems unlikely, however, as Radhika et al. (2010) showed that R/FR light ratio affected JA induced EFN production even at low light intensities. Our results suggest that $S$. chapmanii down-regulates indirect defenses in response to shade, but that it does not do so in response to specific spectral signals that indicate competition.

This study contributes to an improved understanding of plant resource allocation, and the dynamics of defensive traits. Spatiotemporal patterns of EFN production are often adapted to optimize plant defense (Tilman 1978; Heil 2015). These patterns, however, are driven by simple physiological mechanisms that respond to environmental conditions (Heil 2015). We add to a growing understanding of how changing environmental conditions affect indirect plant defenses, and the interactions that they support. 
Understanding how EFN production responds to changing light conditions is of particular importance in pine rockland habitats, where roughly $27 \%$ of plants bear EFNs (Koptur 1992b). Over the last century, roughly $98 \%$ of pine rockland habitat in south Florida (with the exception of Everglades National Park) has been destroyed for agriculture and urban development (Barrios et al. 2011). Due to their close proximity to dense human populations, the remaining fragments are frequently mismanaged. In particular, the fires that are necessary to maintain healthy pine rocklands are often suppressed (Possley et al. 2008). Pine rockland habitats are characterized by an open canopy, with high levels of light reaching the species-rich herb layer. In the absence of fire, trees and shrubs quickly become overgrown, and understory plants are shaded. With this experiment we hoped to create a clearer understanding of how changing light conditions in the pine rocklands might affect insect-plant interactions, and the fitness of plants that rely on these interactions for defense.

\section{Acknowledgements}

The authors thank H. Gallegos for help caring for plants and collecting data, S. Zona for his generosity with greenhouse facilities, and D. Gann for help collecting radiospectrometer data. We are indebted to J. Richards and D. Lee for the use of light filters, for valuable advice on the design of the experiment, and for their comments on the manuscript. Constructive input was also provided by B. Barrios, J. Clayborne, S. Pena, A. Salas, N. Palermo, M. Ellenby, C. Pimienta, B. Harris, and S. Zona. We also thank A. Moore, M. Heil, and two anonymous reviewers for their helpful feedback on earlier 
versions of this manuscript. This work benefited from financial support from the Lloyd Kelly Foundation for Tropical Botany. This is contribution number ...? ?... to the Florida International University Program in Tropical Biology.

\section{References}

Adams, S.R., Pearson S., \& Hadley P. (2001) Improving quantitative flowering models through a better understanding of the phases of photoperiod sensitivity. Journal of Experimental Botany, 52, 655-662.

Agrawal, A.A., \& Rutter M.T. (1998) Dynamic anti-herbivore defense in in ant-plants: the role of induced responses. Oikos, 83, 227-236.

Agrawal, A., Kearney E., Hastings A., \& Ramsey T. (2012) Attenuation of the jasmonate burst, plant defensive traits, and resistance to specialist monarch caterpillars on shaded common milkweed (Asclepias syriaca). Journal of Chemical Ecology, 38, 893-901.

Baker, D.A., Hall L.J. \& Thorpe J.R. (1978) A study of the extrafloral nectaries of Ricinus communis. New Phytologist, 81, 129-137.

Ballare, C.L., Scopel A.L. \& Sanchez R.A. (1990) Far-red radiation reflected from adjacent leaves- an early signal of competition in plant canopies. Science, 247, 4940. 329-332.

Ballare, C.L. (1999) Keeping up with the neighbours: phytochrome sensing and other signalling mechanisms. Trends in Plant Science, 4, 97-102.

Ballare, C.L. (2011) Jasmonate-induced defenses: a tale of intelligence, collaborators and rascals. Trends in Plant Science, 16, 249-257.

Ballare, C.L. (2014) Light regulation of plant defense. Annual Review of Plant Biology, $65,335-363$.

Barrios, B., Arellano G. \& Koptur S. (2011) The effects of fire and fragmentation on occurrence and flowering of a rare perennial plant. Plant Ecology, 212, 1057-1067.

Becerra, J.X.I. \& Venable D.L. (1989) Extrafloral nectaries: a defence against anthomoptera mutualisms? Oikos, 55, 276-280.

Bentley, B.L. (1977) The protective function of ants visiting the extrafloral nectaries of Bixa orellana (Bixaceae). Journal of Ecology, 65, 27. 
Bryant, J.P., Chapin III F.S. \& Klein D.R. (1983) Carbon/nutrient balance of boreal plants in relation to vertebrate herbivory. Oikos, 40, 257-368.

Choh, Y., \& Takabayashi J. (2006) Herbivore-induced extrafloral nectar production in lima bean plants enhanced by previous exposure to volatiles from infested conspecifics. Journal of Chemical Ecology, 32, 2073-2077.ijone

Coley, D.P., Bryant J.P. \& Chapin S. (1985) Resource availability and plant antiherbivore defense. Science, 230, 895-899.

Endara, M.J., \& Coley P.D. (2011) The resource availability hypothesis revisited: a metaanalysis. Functional Ecology, 25, 389-398.

Engel, V., Fischer M.K., Wackers F.L. \& Volkl W. (2001) Interactions between extrafloral nectaries, aphids and ants: are there competition effects between plant and homopteran sugar sources? Oecologia, 129, 577-584.

Heil, M., Koch T., Hilpert A., Fiala B., Boland W. \& Linsenmair K.E. (2001) Extrafloral nectar production of the ant-associated plant, Macaranga tanarius, is an induced, indirect, defensive response elicited by jasmonic acid. Proceedings of the National Academy of Sciences (USA), 98, 1083-1088.

Heil, M., Baumann B., Krüger R., Linsenmair K.E. (2004) Main nutrient compounds in food bodies of Mexican Acacia ant-plants. Chemoecology, 14, 45-52.

Heil, M. (2011) Nectar: generation, regulation and ecological functions. Trends in Plant Science, 16, 4. 191-200.

Heil, M. (2015) Extrafloral nectar at the plant-insect interface: A spotlight on chemical ecology, phenotypic plasticity, and food webs. Annual Review of Entomology, 60, 213232.

Izaguirre, M.M., Mazza C.A., Astigueta M.S., Ciarla A.M., Ballare C.L. (2013) No time for candy: passion fruit (Passiflora edulis) plants down-regulate damage-induced extra floral nectar production in response to light signals of competition. Oecologia, 173, 213221.

Jones, I.M., \& Koptur S. (2015) Dynamic extrafloral nectar production: The timing of leaf damage affects the defensive response in Senna mexicana var. chapmanii (Fabaceae). American Journal of Botany, 102, 58-66.

Karban, R., Agrawal A.A., Thaler J.S., \& Adler L.S. (1999) Induced plant responses and information content about risk of herbivory. Trends in Ecological Evolution, 14, 443447.

Kessler, D., Diezel D., \& Baldwin I.T. (2010) Changing pollinators as a means of escaping herbivores. Current Biology, 20, 237-242. 
Koptur, S. (1989) Is extrafloral nectar production an inducible defence? Pp 323-339 in J. Bock and Y. Linhart, editors. Evolutionary ecology of plants. Westview Press, Boulder, Colorado, USA.

Koptur, S. (1992) Extrafloral nectary-mediated interactions between insects and plants. Pp 81-129 in Bernays. E. A. (ed). Insect-plant interactions. Vol IV. CRC Press. Boca Raton.

Koptur, S. (1992) Plants with Extrafloral Nectaries and Ants in Everglades Habitats. The Florida Entomologist, 75 (1), 38-50.

Lach, L., Hobbs R.J. \& Majer J.D. (2009) Herbivory-induced extrafloral nectar increases native and invasive ant worker survival. Population Ecology, 51, 237-243.

Lee, D.W., Baskaran K., Mansor M., Mohamad H., Yap S.K. (1996) Irradiance and spectral quality affect Asian tropical rain forest tree seedling development. Ecology, 77, $568-580$.

Lerdau, M., \& Coley P. (2002) Benefits of the carbon-nutrient balance hypothesis. Oikos, 98, 534-536.

Lüttge, U. (2013) Green nectaries: the role of photosynthesis in secretion. Botanical Journal of the Linnean Society, 173, 1-11.

Marazzi, B., Bronstein J.L. \& Koptur S. (2013) The diversity, ecology and evolution of extrafloral nectaries: current perspectives and future challenges. Annals of Botany, 111 (6), 1243-1250.

Millán-Cañongo, C., Orona-Tamayo D. \& Heil M. (2014) Phloem sugar flux and jasmonic acid-responsive cell wall invertase control extrafloral nectar secretion in Ricinus communis. Journal of Chemical Ecology, 40, 760-769.

Mondor, E.B., \& Addicott J.F. (2003) Conspicuous extra-floral nectaries are inducible in Vicia faba. Ecology Letters, 6, 495-497.

Moreno, J.E., Tao Y., Chory J. \& Ballare C.L. (2009) Ecological modulation of plant defense via phytochrome control of jasmonate sensitivity. Procedures of the National Academy of Science, 106, 4935-4940.

Pierik, R., Mommer L. \& Voesenek L.A.C.J. (2013) Molecular mechanisms of plant competition: neighbour detection and response strategies. Functional Ecology, 27, 841853.

Possley, J., Woodmansee S.W. \& Maschinski J. (2008) Patterns of plant composition in fragments of globally imperiled pine rockland forest: effects of soil type, recent fire frequency, and fragment size. Natural Areas Journal, 28 (4), 379-394. 
Radhika, V., Kost C., Mithofer A. \& Boland W. (2010) Regulation of extrafloral nectar secretion by jasmonates in lima bean is light dependent. Proceedings of the National Academy of Sciences, USA, 107, 17228-17233.

Rasmann, S., Johnson M.D. \& Agrawal A.A. (2009) Induced responses to herbivory and jasmonate in three milkweed species. Journal of Chemical Ecology, 35, 1326-34.

Rosumek, F.B., Silveira F.A.O., Neves F.D., Barbosa N.P.D., Diniz L., Oki Y., Pezzini F., Fernandes G.W. \& Cornelissen T. (2009) Ants on plants: a meta-analysis of the role of ants as plant biotic defenses. Oecologia, 160, 537-549.

Rutter, M.T., \& Rausher M.D. (2004) Natural selection on extrafloral nectar production in Chamaecrista fasciculata: the costs and benefits of a mutualism trait. Evolution, 58, 2657-2668.

Schmidt, L., Schurr U. \& Rose U.S.R. (2009) Local and systemic effects of two herbivores with different feeding mechanisms on primary metabolism of cotton leaves. Plant, Cell and Environment, 32, 893-903.

Sotelo, P., Perez E., Najar-Rodriguez A., Walter A. \& Dorn S. (2014) Brassica plant responses to mild herbivore stress elicited by two specialist insects from different feeding guilds. Journal of Chemical Ecology, 40 (2), 136-149.

Stephenson, A.G. (1982) Iridoid glycosides in the nectar of Catalpa speciosa are unpalatable to nectar thieves. Journal of Chemical Ecology, 8, 1025-34.

Tilman, D. (1978) Cherries, ants and tent caterpillars: timing of nectar production in relation to susceptibility of caterpillars to ant predation. Ecology, 59, 686-692.

Wagner, D., \& Kay A. (2002) Do extrafloral nectaries distract ants from visiting flowers? An experimental test of an overlooked hypothesis. Evolutionary Ecology Research, 4, 293-305.

Weller, J.L., Murfet I.C. \& Reid J.B. (1997) Pea Mutants with Reduced Sensitivity to Far-Red Light Define an Important Role for Phytochrome A in Day-Length Detection. Plant Physiology, 114, 1225-1236.

Yamawo, A., \& Hada Y. (2010) Effects of light on direct and indirect defenses against herbivores of young plants of Mallotus japonicus demonstrate a trade-off between two indirect defence traits. Annals of Botany, 106, 143-148. 


\section{Figures}

Figure 3.1: Extrafloral nectary on the leaf rachis of Senna mexicana var. chapmanii. Photograph by Ian Jones.

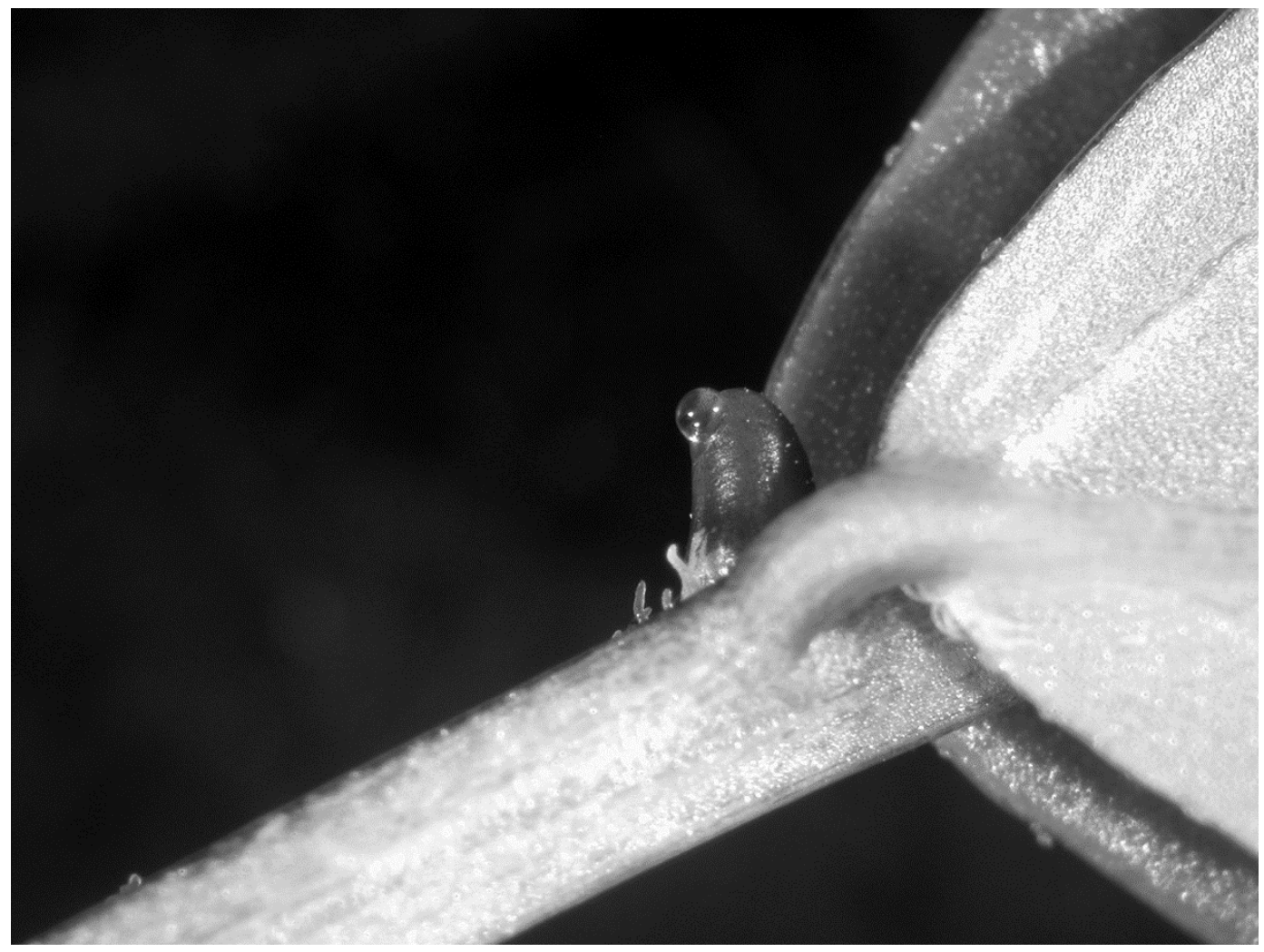


Figure 3.2: Light filter cylinder arrangement. The letter $\mathrm{D}$ indicates plants subjected to leaf damage

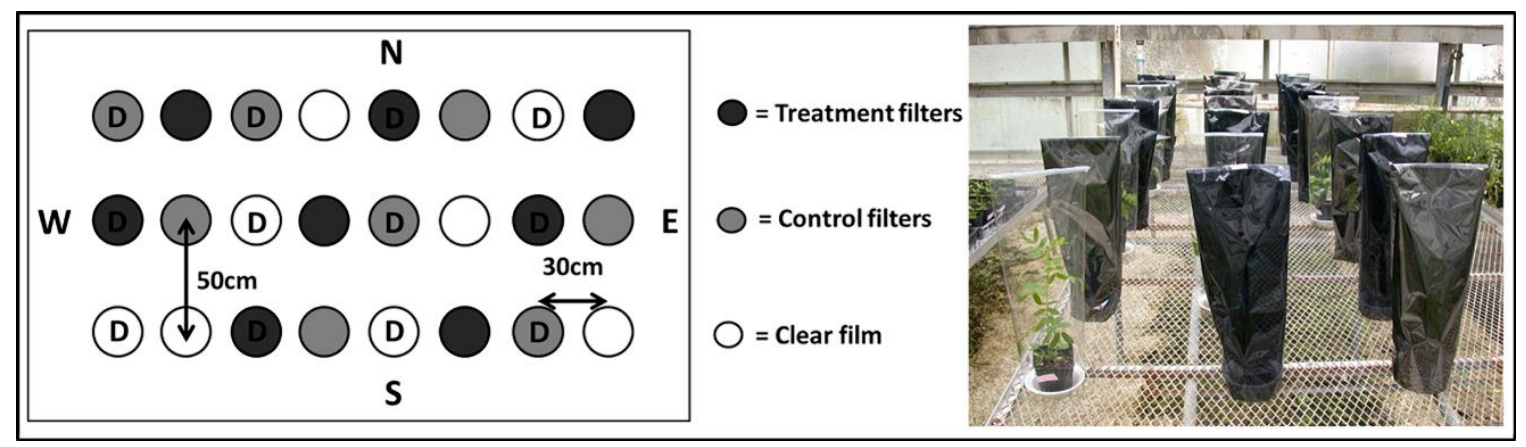


Figure 3.3: Mean percentage of light of different wavelengths (300-1000nm) transmitted through the three filter types. Light grey bands indicate red and far-red light wavelengths, while the dark grey band indicates crossover between the two. The sharp rise in percentage light transmission in film 1, starting at around 710nm, indicates the desired increase in R:FR light ratio within film 1 cylinders.

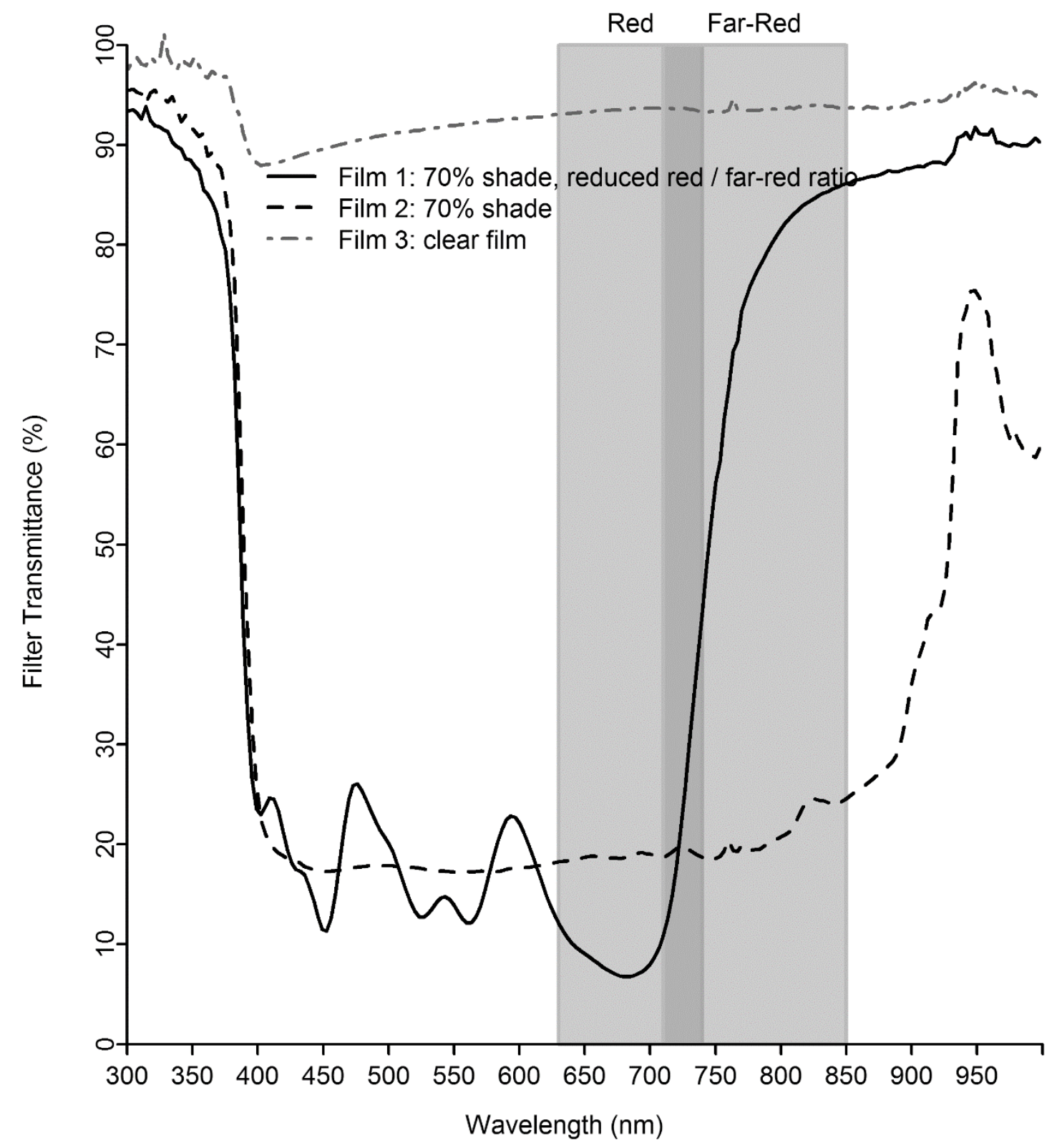


Figure 3.4: Mean sugar production (mg) by damaged and undamaged plants subjected to three light treatments. Error bars indicate standard error. Letters indicate significant differences.

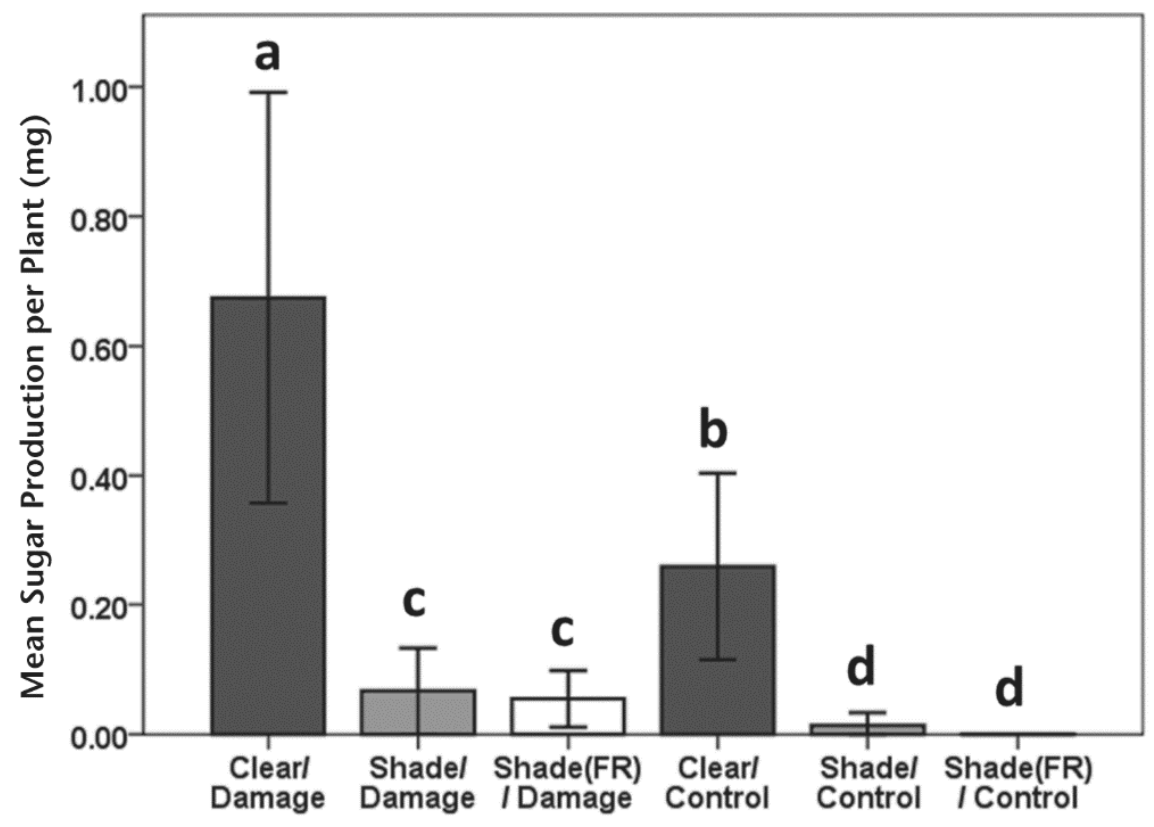




\section{CHAPTER IV}

\section{EXPLORING HOW, NOT WHETHER, ANTS AFFECT REPRODUCTIVE FITNESS}

IN SENNA MEXICANA VAR. CHAPMANII 
Jones et al. - How ants affect plant fitness in S. chapmanii

Exploring how, not whether, ants affect reproductive fitness in Senna mexicana var. chapmanii

Ian M. Jones ${ }^{1}$, Suzanne Koptur, and Jorge E. Peña

${ }^{1}$ Department of Biological Sciences, Florida International University, 11200 S.W. 8th

Street, Miami, Florida 33199, Email: ijone002@fiu.edu, Tel: 7863404673 


\section{ABSTRACT}

1. Extrafloral nectar (EFN) mediates food-for-protection mutualisms between plants and ants. Ant-plant mutualisms are keystone associations, occurring within a complex web of biotic interactions. As such, these interactions may affect plant fitness in a number of ways, both positive and negative.

2. In Senna mexicana var. chapmanii, the presence of ants has been shown to increase seed set. This increase in reproductive fitness is not the result of one interaction, however, but the balance of many. We conducted a field study to determine not whether but how ants affect reproductive fitness in S. chapmanii.

3. Thirty plants were established in a semi-natural area adjacent to native pine rockland habitat in southern Florida. Ants were excluded from half of the plants by painting a sticky resin (Tanglefoot) around the base of each stem.

4. Over the course of a single flowering season (October-May), we observed the effects of ants on the activity of herbivores, predators, pollinators, and predispersal seed predators. We also observed the overall effects of ants on plant size and reproductive output.

5. Plants with ants were quicker to establish, grew larger, and produced floral displays that attracted more pollinators than plants without ants. Contrary to our expectations, relative pollinator efficiency, and rates of pre-dispersal seed predation, were unaffected by ants.

6. In S. chapmanii, ants did not appear to affect the outcome of other plant-insect associations, rather only the scale at which they occurred. Ants affected plant 
reproductive fitness simply by facilitating growth and establishment, with coincidental effects on reproductive investment.

Key words: Ant-plant interactions; extrafloral nectar; plant defense; Senna mexicana var. chapmanii.

\section{INTRODUCTION}

Extrafloral nectaries (EFNs) are glands that secrete nectar (solutions of sugar and other compounds) located outside of flowers, and have been reported on species belonging to 93 families and 332 genera (Koptur, 1992; Marazzi et al., 2013). These nectaries may serve diverse ecological roles (Baker et al. 1978; Becerra and Venable 1989; Wagner and Kay 2002; Gonzalez-Teuber and Heil 2009; Heil 2011), however, their primary function is the attraction of predatory insects, predominantly ants, which provide plants with a form of indirect defense against herbivores (Bentley 1977; Koptur 1992; Rosumek et al. 2009).

Many studies have identified food for protection mutualisms between ants and plants (Koptur 1992; Rosumek et al. 2009). In some cases, plants provide domatia and food bodies as well as EFN, and the resulting interactions may be highly specialized. Janzen (1966) observed that Acacia cornigera plants succumbed to herbivory when resident Pseudomyrmex ferruginea ants were experimentally removed. Plants that provide only EFN are normally involved only in facultative interactions with ants (Rosumek et al. 2009). Despite the less specialized nature of these interactions, 
significant fitness benefits for plants have been reported (Koptur 1979; Koptur 1984; Oliveira 1997; Rudgers 2004; Koptur et al. 2013).

The presence of ants may benefit plants in a number of ways. Aggressive ants have been shown to reduce herbivore numbers on many plant species (Letourneau and Barbosa 1999), and numerous studies have observed reduced rates of herbivore damage in the presence of ants (Janzen 1966; Bruna et al. 2004; Del-Claro et al. 2006). Extrafloral nectar is found on the fruits of many species. Indeed, production of EFN has been shown to increase during fruit production, in line with optimal defense theory (Wackers and Bonifay 2004; Holland et al. 2009). These observations suggest a role for ants in the protection of developing fruit. In addition to the provision of defense, the proximity of ant nests may benefit plants by enhancing soil nutrient concentrations (Wagner 1997; Wagner and Nicklent 2010). Wagner (1997) found that nests of Formica perpilosa at the base of Acacia constricta shrubs enhanced nitrate, ammonium, and phosphorus availability in the surrounding soil. Plants with nests at their base produced significantly more seeds than plants without nests (Wagner 1997).

Despite these well-documented benefits, plants may also suffer a range of costs associated with their ant partners. Some less aggressive ant species consume nectar, but provide no defensive benefits for plants (Freitas et al. 2000; Ruhren 2003). Indeed, in a few cases ants have even been seen to affect plant defense negatively (Frederickson and Gordon 2007; Mooney 2007; Rosumek et al. 2009). Conversely, overly aggressive ants may deter beneficial insects such as predators (Torres-Hernandez et al. 2000; Nahas et al. 2012), parasitoids (Styrsky and Eubanks 2007; Rosumek et al. 2009), and pollinators 
(Ness 2006; Hernández-Cumplido et al. 2010; Assunção et al. 2014). Several studies have shown that pollinators recognize the dangers posed by aggressive ants (HernándezCumplido et al. 2010, Assunção et al. 2014). Assunção et al. (2014) placed plastic ants on the petals of Heteropterys pteropetala, and found that flowers with plastic ants produced significantly less fruit than control flowers.

Ant-plant associations occur not in isolation, but within a complex web of biotic interactions, and in a framework provided by the abiotic environment. In the cactus, Ferocactus wislizeni, plants defended by Solenopsis xyloni ants exhibit reduced herbivory and increased flowering. These plants, however, receive fewer and shorter visits from pollinators, which are deterred by the same ferocious ants (Ness 2006). Understanding the outcome of ant-plant interactions, therefore, requires that we focus on the broad multi-guild, multi-trophic interactions of which they are a part. While the presence of ants has been shown to boost reproductive fitness in a number of EFN producing species (Oliveira 1997; Freitas et al. 2000; Rudgers 2004; Rosumek et al. 2009; Heil et al. 2015), the specific mechanisms by which ants facilitate increased plant fitness are not fully understood for many species. In the present study, we aimed to determine not whether, but how ants increase plant reproductive fitness in the known myrmecophile, Senna mexicana (Jacq.) var. chapmanii (Isely).

Senna mexicana var. chapmanii (hereafter referred to as Senna chapmanii) is native to south Florida, and the Caribbean. The species grows in pine rockland habitat and rockland hammock edges as an upright or sprawling subshrub up to $1.2 \mathrm{~m}$ in height, spreading broader than tall. Flowers offer no nectar to floral visitors, and are visited by 
bees collecting pollen by 'buzzing' the anthers (Koptur. S personal observation).

Extrafloral nectaries occur on the pedicels of flowers in the inflorescences, as well as throughout the foliage between basal leaflets. Previous work with S. chapmanii has shown that EFN production is responsible for the recruitment of ants to plants (Jones and Koptur 2014). Ants have also been shown to remove key herbivores (Koptur et al. 2015), and plants with ants excluded suffer increased herbivore damage and reduced seed set (Jones et al. unpublished data).

We conducted an 8 month field study (October-May), encompassing one entire flowering season for $S$. chapmanii. The presence of ants on test plants was manipulated to study the process by which ants increase reproductive fitness in S. chapmanii. We observed the effects of ants on plant size and reproductive potential. We determined the effects of ants on rates of flowering, fruit set, and seed production. Finally, we observed the effects of ants on the activity and effectiveness of pollinators, and on pre-dispersal seed predators.

We predicted that the presence of ants would lead to increased plant size and increased flower production. We secondly predicted that ants would have a neutral or negative effect on pollination rates, but that those flowers that did set fruit, would be more likely to reach maturity in the presence of ants. During previous studies we have regularly seen ants patrolling developing fruit, and we hypothesized that a reduction in pre-dispersal seed predation would account for much of the difference in seed set between plants with and without ants. 


\section{MATERIALS AND METHODS}

A field study was carried out at the University of Florida's Tropical Research and Education Center (TREC) in Homestead, Florida, USA. The climate is subtropical, with average minimum and maximum temperatures of $3.2-24.8^{\circ} \mathrm{C}$ in January and $22.7-32.4^{\circ} \mathrm{C}$ in July (Koptur et al. 2015). The study site consisted of flat calcareous limestone rocklands that have been rock-ploughed for agriculture. We used a 2 acre plot, previously overgrown with exotic pest plants, which had been cleared of vegetation except for a few large native trees. Adjacent to the western edge of the plot is a fragment of pine rockland habitat, a protected natural area.

Senna chapmanii plants were grown from seeds in a greenhouse at Florida International University (FIU), Miami, FL, USA. Seeds were collected from multiple individuals in a single population on Big Pine Key, in the lower Florida Keys (under Research Permit \# FFO4RFKD-2014-0, National Wildlife Refuge System - National Key Deer Refuge). Three months after germination, thirty plants were transplanted into the experimental site. Plants were mulched with wood chips and watered for two months, beginning in August 2014, until they were established. Plants were installed in an evenly spaced array, at least $4 \mathrm{~m}$ from their nearest neighbor, and divided into two treatments: (1) ants present (control); and (2) ants excluded. Ants were excluded one month prior to the start of data collection by painting a sticky gel (Tanglefoot ${ }^{\mathrm{TM}}$ ) around the base of the stem. Treatments were assigned systematically to ensure an even distribution across the site. Data were collected over a period of 8 months, from October 2014 to May 2015. 


\section{Insect surveys}

Each week, one active inflorescence was chosen from all plants that were in flower, and used as a census locale. Each chosen branch was studied over a period of two minutes, and the numbers and species of ants, herbivores, and predators were recorded. Any new species were collected as voucher specimens and brought back to the lab at FIU for identification.

In addition to surveys of insects on the inflorescences, monthly ant surveys were conducted throughout the experiment, both to verify that ant exclusion treatments were working and to determine any temporal changes in ant activity at the study site. A single non-flowering branch was chosen from each plant, and the number and species of ants was recorded over a period of two minutes.

Pollinator observations were also conducted on a weekly basis. Plants with active inflorescences were observed for periods of 15 minutes, and the number of flower visitors was observed. Both the identity of the visitor, and the length of the visit was recorded. For each plant observed, the number of inflorescences at the time of the observation was recorded, so the effects of inflorescence number on pollinator attraction could be determined. Pollinator observations were carried out between 08:00 and 17:00hr, and over 15 hours of observation time was accumulated, equally distributed between treatment and control plants. 


\section{Plant size and reproductive fitness}

Plant size was estimated monthly throughout the study by counting the number of branches. A branch was classified as any growing stem with at least ten leaves. Senna chapmanii is a sprawling subshrub, growing broader than tall and commonly branching from near the base. As such, the number of branches is an effective proxy for plant size.

During the course of the experiment, three open flowers were collected from each study plant to determine the average number of ovules per flower. Flowers were collected from each plant on an opportunistic basis but, each week, an equal number of flowers were collected from treatment and control plants. Where possible, flowers from an individual plant were taken from different inflorescences, and spread out over time. Flowers were returned to the lab, and their ovaries were dissected under a light microscope to determine number of ovules. The mean number of ovules per flower was calculated for each plant.

Measures of gross plant reproductive output (numbers of inflorescences, flowers, mature fruit, and mature seeds) were measured on a weekly basis throughout the experiment. Each week, any new inflorescences were labelled with a numbered jewelry tag. The number of open flowers, new fruit set, and the number of mature fruit were then recorded for both new and existing inflorescences. Mature fruit were collected from each plant and returned to the lab. Fruit were dissected to determine the number of fertilized ovules, the number of intact seeds, and the number of herbivorized seeds. The number of fertilized ovules could be determined by counting the seed chambers in the mature fruit. Because Senna species are buzz-pollinated, and require an insect visitor to set seeds 
(Marazzi et al. 2015), the proportion of ovules fertilized in each plant can be used as a measure of pollinator effectiveness. Herbivorized seeds were counted as any seeds with obvious herbivore damage, along with empty seed chambers that contained seed debris. Empty seed chambers that contained no evidence of herbivore activity were assumed to be aborted seeds.

The overall rate of pre-dispersal seed predation was calculated for each plant as the number of herbivorized seeds divided by the total number of developing seeds (fertilized ovules minus aborted seeds). Effective fecundity was calculated for each plant as the number of non-predated mature seeds divided by the total number of ovules. Herbivores found within seed pods were collected and identified. Larval herbivores were reared in the lab and identified as adults. Voucher specimens were preserved and stored at FIU.

\section{Extrafloral nectar}

Extrafloral nectar (EFN) production was measured in each plant, every two months throughout the study. A single branch was selected from each plant, and any insects present were removed by hand. Nectaries were then washed by lightly spraying with water. Leaves were then dried with tissue paper, and branches were sealed within fine mesh bags to exclude insects. Bags were placed on branches at 7pm, and removed 12 hours later for nectar measurements at $7 \mathrm{am}$.

Combined nectar volume from the five most apical leaves was measured using 1 , 2 , and $10 \mu 1$ micropipettes. Nectar concentration was measured using a handheld refractometer, and total sugar production was estimated from the combination of these 
measurements (see Jones \& Koptur, 2014). In the results, EFN is expressed as total sugar production.

\section{Statistical Analysis}

Insect survey data were not normally distributed even after transformation. As such, mean insect numbers, from each guild, were compared between treatments using Mann-Whitney U tests.

The number and duration of pollinator visits were compared between treatments using Mann-Whitney U tests. The relationship between pollinator visits and number of active inflorescences was analyzed using a two-tailed Spearman correlation. The rate of pre-dispersal seed predation was also compared between treatments using a MannWhitney U test.

Mean measures of plant fitness, including plant size, and numbers of inflorescences, flowers, fruits, and seeds were compared between treatments using MannWhitney U tests.

\section{RESULTS}

Ants

During our censuses, a total of 96 ants from 9 species were observed in the inflorescences of Senna chapmanii. The majority of ant activity within the inflorescences (84\%) could be attributed to four species: Camponotus floridanus (25\%), Camponotus 
sexguttatus (23.9\%), Camponotus planatus (19.8\%), and Brachymrmex obscurior $(14.6 \%)$.

A total of 144 ants were observed on the foliage of $S$. chapmanii during monthly ant surveys. The same four species found on inflorescences accounted for the majority of ant activity on leaves, representing $15.5 \%, 9.7 \%, 9 \%$, and $45 \%$ of ant activity, respectively. Brachymrmex obscurior was the dominant species on the foliage, while Camponotus species were seen most frequently in the inflorescences.

Ant numbers were significantly higher on control plants than on Tanglefoottreated plants, both in the inflorescences $(\mathrm{N}=30, \mathrm{df}=29, \mathrm{U}=12.5, \mathrm{P}<0.001)$, and during monthly foliar ant surveys $(\mathrm{N}=30, \mathrm{df}=29, \mathrm{U}=27.5, \mathrm{P}<0.001)$.

\section{Herbivores and predators}

A total of 34 herbivores were observed in the inflorescences of S. chapmanii, of which the most abundant were pierid caterpillars belonging to three species, Abaeis nicippe (Cramer) (the sleepy orange), Phoebis philea (L.) (the orange-barred sulfur), and Phoebis sennae (L.) (the cloudless sulfur). Thirteen pierid caterpillars were recorded, accounting for $38.2 \%$ of herbivore observations. The second most abundant herbivore was the leucaena psyllid, Heteropsylla cubana. Eight groups of psyllid nymphs were observed in inflorescences, accounting for $23.5 \%$ of herbivore observations. Numbers of pierid caterpillars $(\mathrm{N}=30, \mathrm{df}=29, \mathrm{U}=97, \mathrm{P}=0.539)$ and psyllid nymphs $(\mathrm{N}=30, \mathrm{df}=29$, $\mathrm{U}=107, \mathrm{P}=0.758$ ) did not differ between treatments although, in both cases, overall numbers were higher in the absence of ants than they were in the presence of ants (Figure $1)$. 
A total of 21 predators were observed in the inflorescences of S. chapmanii. Predators included spiders (14), coccinellid beetles (4), and predatory wasps (3). The total number of predators observed did not differ significantly between treatments $(\mathrm{N}=30$, $\mathrm{df}=29, \mathrm{U}=89.5, \mathrm{P}=0.3)$.

\section{Pre-dispersal seed predators}

Although evidence of pod-boring seed predators was often observed (frass and residue from predated seeds), the herbivores themselves were only recovered on four occasions, three times from control plants, and once from plants with ants excluded. The pod borers observed belonged to two species, one coleopteran, and one lepidopteran. The rate of seed predation did not differ between treatments $(\mathrm{N}=30, \mathrm{df}=29, \mathrm{U}=112.5, \mathrm{P}=1.0)$ (figure 2A).

\section{Pollinators}

A total of 14 pollinator visits were observed during 63 observations (15 hours and 45 minutes). Ten of those visits (71\%) were by the sweat bee, Augochlora pura. The remaining visits were made by the honey bee, Apis mellifera (2), a metallic hoverfly, Ornidia obesa (1), and a skipper butterfly, Euphyes arpa (1). Augochlora pura was the only visitor that appeared to effectively collect pollen from the anthers of $S$. chapmanii, so analyses of pollinator visits took into account only this visitor.

Plants with ants present were visited by pollinators significantly more frequently than plants from which ants were excluded (Control $\mathrm{N}=33$, Tanglefoot $\mathrm{N}=30, \mathrm{df}=62$, 
$\mathrm{U}=348, \mathrm{P}=0.003)$. The mean duration of pollinator visits was also significantly longer on plants with ants present (Control $\mathrm{N}=33$, Tanglefoot $\mathrm{N}=30, \mathrm{df}=62, \mathrm{U}=346, \mathrm{P}=0.003$ ) (Figure 3). Pollination efficiency (number of fertilized ovules/total number of ovules produced), however, did not differ between plants with and without ants $(\mathrm{N}=30, \mathrm{df}=29$, $\mathrm{U}=108, \mathrm{P}=0.818$ ) (figure 2B). No positive correlation was seen between the number of active inflorescences on a given plant at the time of pollinator observations, and the number of pollinator visits $(\mathrm{N}=63, \mathrm{r}=0.253, \mathrm{P}=0.516$ ) (figure 4).

\section{Plant size and reproductive fitness}

Plant size increased over the course of the study in plants with ants, but remained relatively stable in plants without ants. Plants with ants were significantly larger than those without ants during the months of January $(\mathrm{N}=30, \mathrm{df}=29, \mathrm{U}=64.5, \mathrm{P}=0.044)$, April $(\mathrm{N}=30, \mathrm{df}=29, \mathrm{U}=60.5, \mathrm{P}=0.030)$, and May $(\mathrm{N}=30, \mathrm{df}=29, \mathrm{U}=54, \mathrm{P}=0.014)$ (figure 5).

The number of ovules counted in dissected flowers ranged from 25-39, and the mean number of ovules per flower was $30(\mathrm{SD}=2.962)$. Measures of gross reproductive fitness, such as number of inflorescences $(\mathrm{N}=30, \mathrm{df}=29, \mathrm{U}=81, \mathrm{P}=0.187)$, number of flowers $(\mathrm{N}=30, \mathrm{df}=29, \mathrm{U}=84.5, \mathrm{P}=0.244)$, mature fruit $(\mathrm{N}=30, \mathrm{df}=29, \mathrm{U}=109.5$, $\mathrm{P}=0.878)$, and mature seeds $(\mathrm{N}=30, \mathrm{df}=29, \mathrm{U}=106, \mathrm{P}=0.739)$ did not differ significantly between treatments (figure 6). Effective fecundity was not significantly different between treatment and control plants $(\mathrm{N}=30, \mathrm{df}=29, \mathrm{U}=103, \mathrm{P}=0.627)$ (figure $2 \mathrm{C})$. 


\section{Extrafloral nectar production}

Mean extrafloral nectar production was not affected by the presence or absence of ants $(\mathrm{N}=30, \mathrm{df}=29, \mathrm{U}=104.5, \mathrm{P}=0.732)$. Extrafloral nectar production, however, decreased over the course of the study, and this decline was more pronounced in the absence of ants (Figure 7).

\section{DISCUSSION}

The application of Tanglefoot ${ }^{\mathrm{TM}}$ was effective in excluding ants from treatment plants for the duration of the study, and although herbivore numbers did not differ significantly between treatments, ants have previously been observed to remove herbivores from S. chapmanii plants (Koptur et al. 2015), and to reduce overall herbivory rates (Jones et al. unpublished data). Ants have long been known to defend plants through the removal of herbivores, and this phenomenon has been seen on many plant species (e.g., Bentley 1977; Oliveira and Rico-Gray 2007; Rosumek et al. 2009; Heil 2015).

On control plants, ants were regularly seen patrolling flowers and developing fruit. Despite this, no difference was measured in the rate of seed predation between treatments. Although surprising, this result was not wholly unexpected. While several authors have observed increased EFN production on and around developing fruit, in line with optimal defense theory (Holland et al 2009; Falcao et al 2014), no study, to our knowledge, has ever found ants to reduce pre-dispersal seed predation. Lenoir and Pihlgren (2006) observed ten species of ants attracted to EFNs of the Bush vetch, Vicia 
sepium. Despite their numbers, ants had no effect on seed predation, which was predominantly by the leaf beetle, Bruchus atomarius. Ruhren (2003) also observed no effects of ants on the specialist seed predator, Sennius cruentatus, on Chamaecrista nictitans. In this case, the beetles may have evaded detection by living inside developing seed pods. Pod-boring seed predators may pose a particular problem for ant defended plants. In the common vetch, Vicia sativa, seed damage by pod-boring tortricid moths has been shown to be greater in the presence of ants than in the absence of ants (Koptur and Lawton 1988). It was suggested that ants may even facilitate pod-boring herbivores by patrolling the fruit and deterring predators and parasitoids (Koptur and Lawton 1988).

The flowers of Senna species are buzz-pollinated by pollen collecting bees (Marazzi et al. 2015). Only one insect, the sweat bee Augochlora pura, was observed to effectively remove pollen from the poricidal anthers of S. chapmanii flowers. Flower visits by this insect were significantly more frequent, and their duration significantly longer, on plants with ants present. This result was surprising, as aggressive ants have more often been seen to deter pollinators (Ness 2006; Assunção et al. 2014; Ohm and Miller 2014), and pollinators have been observed to recognize the danger posed by ants (Hernández-Cumplido et al. 2010; Assunção et al. 2014). We are not alone, however, in observing increased pollination rates in the presence of ants. Holland et al. (2011) excluded ants from senita cacti, in the Sonoran Desert, and observed a reduction in pollination rates in the absence of ants.

Although the number and duration of pollinator visits was higher in the presence of ants, pollination efficiency (defined as the proportion of ovules fertilized for each 
plant) did not differ between treatments. It is likely, therefore, that the observed increase in pollinator visits in the presence of ants simply reflected the larger size and increased floral displays of plants with ants. Oliveira (1997) observed higher pollination rates in Caryocar brasiliense in the presence of ants, and drew similar conclusions. Ants reduced herbivore damage to vegetative tissues, resulting in healthier plants that supported larger, more attractive, floral displays (Oliveira 1997).

We did not observe significant differences in measures of gross reproductive fitness (numbers of inflorescences, flowers, mature fruit, and seeds) between treatments. We have, however, previously observed increased seed production in S. chapmanii plants with ants present, compared with plants from which ants were excluded (Jones et al. unpublished data). Effective fecundity (defined as the proportion of ovules that survived to become mature seeds) also did not differ between treatments in the present study. These results, along with our insect surveys, indicate that in the case of $S$. chapmanii, ants do not benefit plant fitness by increasing the survivorship of flowers or developing fruit.

So the question remains, how do ants increase reproductive fitness in $S$. chapmanii? Throughout the course of the study, plant size increased rapidly in the presence of ants, and remained fairly constant in their absence. After four months, plants with ants had significantly more growing stems than plants with ants excluded. These results suggest that by removing herbivores (Koptur et al. 2015) and reducing rates of leaf damage (Jones et al. unpublished data), ants on S. chapmanii support plant growth and thereby increase plant reproductive potential. We have previously shown that 
increased EFN production leads to increased ant attendance on S. chapmanii (Jones and Koptur 2015). Given that only the youngest few leaves on each growing stem produce EFN (Jones and Koptur 2015), increasing the number of growing stems is likely important for $S$. chapmanii plants to attract and maintain beneficial ant partners.

Extrafloral nectar measurements revealed a sharp decline in per-leaf sugar production over the course of the study. These measurements were taken between October and May, and the same pattern was seen in a previous field season, in which measurements were taken between April and February (Jones et al. unpublished data). These results suggest that the decline in EFN production represents an ontogenetic rather than a seasonal or phenological pattern, and that EFN may be most important for plant establishment and early growth in S. chapmanii.

The presence of ants has been shown to boost reproductive fitness in a number of EFN producing species (Oliveira 1997; Freitas et al. 2000; Rudgers 2004; Rosumek et al. 2009; Heil et al. 2015). Indeed, we have previously shown that ants increase reproductive fitness in S. chapmanii (Jones et al. unpublished data). Despite these many examples, the specific mechanisms by which ants facilitate increased plant fitness have rarely been explored, and likely vary from species to species, and from habitat to habitat.

Ants may benefit plant reproductive fitness in a number of ways. For example, by reducing herbivory rates (Janzen 1966; Bruna et al. 2004; Del-Claro et al. 2006) or herbivore numbers (Letourneau and Barbosa 1999), facilitating effective pollination (Oliveira 1997; Holland et al. 2011), protecting flowers or developing fruits (Wackers and Bonifay 2004; Holland et al. 2009), or even providing nutrient subsidies by nesting 
among plant roots (Wagner 1997; Wagner and Nicklent 2010). Conversely, plants that host ants may incur certain ecological costs. Aggressive ants have been known to deter beneficial insects such a pollinators (Ness 2006; Hernández-Cumplido et al. 2010; Assunção et al. 2014), predators (Torres-Hernandez et al. 2000; Nahas et al. 2012; Koptur et al. 2015), and parasitoids (Styrsky and Eubanks 2007; Rosumek et al. 2009). Some defensive ants are also known to cheat their mutualistic partners by removing reproductive structures to promote vegetative growth (Yu and Pierce 1998). In order for plants to benefit from their interactions with ants, the combined effects of these interconnected processes must be weighed in their favor.

In the case of $S$. chapmanii, what might have been a complicated equation appears fairly simple. The presence of ants on plants, particularly during the months of establishment, appears to deter folivores and contribute to enhanced plant size. The relative effects of ants on rates of pollination, fruit development, and seed predation appear minimal. Any differences in reproductive fitness in the presence of ants, likely occur because plants are faster to establish, reach larger sizes, and can spare more resources for reproduction.

Food-for-protection mutualisms between plants and ants have often been shown to enhance plant reproductive fitness (for example Rosumek 2009). Understanding the intraguild and multitrophic interactions that underline these benefits may allow us to harness ant-plant interactions in agricultural settings where herbivore damage, and the overuse of pesticides, are worldwide concerns. 


\section{ACKNOWLEDGMENTS}

The authors thank Scott Zona for his generosity with greenhouse facilities. Help with insect specimen identification came from Mark Deyrup and Jeason Clayborn.

Constructive input on the manuscript was also provided by Jamie Theobald, and Jennifer

Richards. Financial support was provided in the form of three research grants from the

Lloyd Kelly foundation for tropical botany. Statistical consultation was provided by

Alejandra Matamala. This is contribution number ...?... to the Florida International

University Program in Tropical Biology.

\section{REFERENCES}

Assunção, M.A., Torezan-Silingardi. H.M., \& Del-Claro, K. (2014) Do ant visitors to extrafloral nectaries of plants repel pollinators and cause an indirect cost of mutualism? Flora-Morphology, Distribution, Functional Plant Ecology, 209, 244-249.

Baker, D.A., Hall, L.J., \& Thorpe, J.R. (1978) A study of the extrafloral nectaries of Ricinus communis. New Phytologist, 81, 129-137.

Becerra, J.X.I., \& Venable, D.L. (1989) Extrafloral nectaries: a defence against anthomoptera mutualisms? Oikos, 55, 276-280.

Bentley, B.L. (1977) The protective function of ants visiting the extrafloral nectaries of Bixa orellana (Bixaceae). Journal of Ecology, 65, 27-38.

Bruna, E.M., Lapola, D.M., Vasconcelos, H.L. (2004) Interspecific variation in the defensive responses of obligate plant-ants: experimental tests and consequences for herbivory. Oecologia, 138, 558-565.

Del-Claro, K., Byke, J., Yugue, G.M., \& Morato, M.G. (2006) Conservative benefits in an ant-hemipteran association in the Brazilian tropical savanna. Sociobiology, 47, 415421.

Falcão, J.C.F., Dáttilo, W., Izzo, T.J. (2014) Temporal variation in extrafloral nectar secretion in different ontogenic stages of the fruits of Alibertia verrucosa S. Moore (Rubiaceae) in a Neotropical savanna. Journal of Plant Interactions, 9, 137-142. 
Frederickson, M.E., \& Gordon, D.M. (2007). The devil to pay: a cost of mutualism with Myrmelachista schumanni ants in 'devil's gardens' is increased herbivory on Duroia hirsuta trees. Proceedings of the Royal Society of London. Series B, Biological Sciences, 274, 1117-1123

Freitas, L., Galetto, L., Bernardello, G., \& Paoli, A.A.S. (2000) Ant exclusion and reproduction of Croton sarcopetalus (Euphorbiaceae). Flora, 195, 398-402.

Gonzalez-Teuber, M., \& Heil, M. (2009) Nectar chemistry is tailored for both attraction of mutualists and protection from exploiters. Plant Signaling and Behaviour, 4, 809-813.

Heil, M. (2011) Nectar: generation, regulation and ecological functions. Trends in Plant Science, 16(4), 191-200.

Heil, M. (2015) Extrafloral nectar at the plant-insect interface: A spotlight on chemical ecology, phenotypic plasticity, and food webs. Annual Review of Entomology, 60, 213232.

Hernández-Cumplido. J., Benrey, B., \& Heil, M. (2010) Attraction of flower visitors to plants that express indirect defence can minimize ecological costs of ant-pollinator conflicts. Journal of Tropical Ecology, 26, 555-577.

Holland, J.N., Chamberiain, S.A., \& Horm, K.C. (2009). Optimal defence theory predicts investment in extrafloral nectar resources in an ant-plant mutualism. Journal of Ecology, 97(1), 89-96.

Holland, J.N., Chamberlain, S.A., \& Miller, T.E.X. (2011) Consequences of ants and extrafloral nectar for pollinating seed-consuming mutualism: ant satiation, floral distraction, or plant defense? Oikos, 120, 381-388.

Janzen, D.H. (1966) Coevolution of mutualism between ants and acacias in Central America. Evolution, 20, 249-275

Jones, I.M., \& Koptur, S. (2015) Dynamic extrafloral nectar production: The timing of leaf damage affects the defensive response in Senna mexicana var. chapmanii (Fabaceae). American Journal of Botany, 102, 58-66.

Koptur, S. (1979) Facultative mutualism between weedy vetches bearing extrafloral nectaries and weedy ants in California. American Journal of Botany, 66(9), 1016-1020.

Koptur, S. (1984) Experimental evidence for defense of Inga (Mimosoideae) saplings by ants. Ecology, 65, 1787-1793.

Koptur, S. \& Lawton, J.H. (1988) Interactions among vetches bearing extrafloral nectaries, their biotic protective agents, and herbivores. Ecology, 69, 278-283.

Koptur, S. (1992). Extrafloral nectary-mediated interactions between insects and plants. Pp 81-129 in Bernays. E. A. (ed). Insect-plant interactions. Vol IV. CRC Press. Boca Raton. 
Koptur, S., Palacios-Rios, M., Diaz-Castelazo, C., Mackay, W.P., \& Rico-Gray, V. (2013) Nectar secretion on fern fronds associated with lower levels of herbivore damage: field experiments with a widespread epiphyte of Mexican cloud forest remnants. Annals of Botany, 111, 1277-1283.

Koptur, S., Jones I.M., \& Pena J.E. (2015) The Influence of Host Plant Extrafloral Nectaries on Multitrophic Interactions: An Experimental Investigation. PLOS one, 10(9), e0138157.

Lenoir, L. \& Pihlgren, A. (2006) Effects of grazing and ant/beetle interaction on seed production in the legume Vicia sepium in a seminatural grassland. Ecological Entomology, 31, 601-607.

Letourneau, D.K., \& Barbosa, P. (1999) Ants, stem borers, and pubescence in Endospermum in Papua New Guinea. Biotropica, 31, 295-302.

Marazzi, B.J., Bronstein, L., \& Koptur, S. (2013). The diversity, ecology and evolution of extrafloral nectaries: current perspectives and future challenges. Annals of Botany, 111, 1243-1250.

Marazzi, B., Conti, E., \& Endress, P.K. (2015) Diversity in anthers and stigmas in the buzz-pollinated genus Senna (Leguminosae-Cassiinae). International Journal of Plant Sciences, 168(4), 371-391.

Mooney, K.A. (2007) Tritrophic effects of birds and ants on a canopy food web, tree growth, and phytochemistry. Ecology, 88, 2005-2014.

Nahas, L., Gonzaga, M.O., \& Del-Claro, K. (2012) Emergent impacts of ant and spider interactions: herbivory reduction in a tropical savanna tree. Biotropica, 44, 498-505.

Ness, J.H. (2006) A mutualism's indirect costs: The most aggressive plant bodyguards also deter pollinators. Oikos, 113, 506-514.

Ohm, J.R., \& Miller, T.E.X. (2014) Balancing anti-herbivore benefits and anti-pollinator costs of defensive mutualists. Ecology, 95, 2924-2935.

Oliveira, P.S. (1997) The ecological function of extrafloral nectaries: Herbivore deterrence by visiting ants and reproductive output in Caryocar brasiliense (Caryocaraceae). Functional Ecology, 11, 323-330.

Oliveira, P.S., and Rico-Gray, V. (2007) The ecology and evolution of ant-plant interactions. Thompson, J.N. (ed). The University of Chicago Press. Chicago.

Rosumek, F.B., Silveira, F.A.O., Neves, F.D.S., Barbosa, N.P.D.U., Diniz, L., Oki, Y., Pezzini, F., Fernandes, G.W., \& Cornelissen, T. (2009) Ants on plants: A meta-analysis of the role of ants as plant biotic defenses. Oecologia, 160, 537-549.

Rudgers, A. (2004) Enemies of herbivores can shape plant traits: selection in a facultative ant-plant mutualism. Ecology, 85, 192-205. 
Ruhren, S. (2003) Seed predators are undeterred by nectar-feeding ants on Chamaecrista nictitans (Caesalpineaceae). Plant Ecology, 166, 189-198.

Styrsky, J.D., \& Eubanks, M.D. (2007) Ecological consequences of interactions between ants and honeydew-producing insects. Proceedings of the Royal Society of London, Series B. Biological Sciences, 274, 151-164.

Torres-Hernandez, L., Rico-Gray, V., Castillo-Guevara, C., \& Vergara, J.A. (2000) Effect of nectar-foraging ants and wasps on the reproductive fitness of Turnera ulmifolia (Turneraceae) in a coastal sand dune in Mexico. Acta Zoologica Mexicana, 81, 13-21.

Wackers, F.L., \& Bonifay, C. (2004) How to be sweet? Extrafloral nectar allocation by Gossypium hirsutum fits optimal defense theory predictions. Ecology, 85, 1512-18.

Wagner, D. (1997) The influence of ant nests on Acacia seed production, herbivory and soil nutrients. Journal of Ecology, 85, 83-93.

Wagner, D., \& Kay, A. (2002) Do extrafloral nectaries distract ants from visiting flowers? An experimental test of an overlooked hypothesis. Evolutionary Ecology Research, 4, 293-305.

Wagner, D., \& Nicklent, E.F. (2010) Ant nest location, soil nutrients and nutrient uptake by ant-associated plants: Does extrafloral nectar attract ant nests and thereby enhance plant nutrition? Journal of Ecology, 98, 614-624.

Yu, D.W., \& Pierce, N.E. (1998) A castration parasite of an ant-plant mutualism.

Proceedings of the Royal Society of London, Series B. Biological Sciences, 265, 375-382. 


\section{FIGURES}

FIGURE 4.1: Key herbivores on S. chapmanii plants with (Control) and without (Tanglefoot) ants. Bars represent mean numbers of herbivores per observation per plant. Error bars represent standard error.
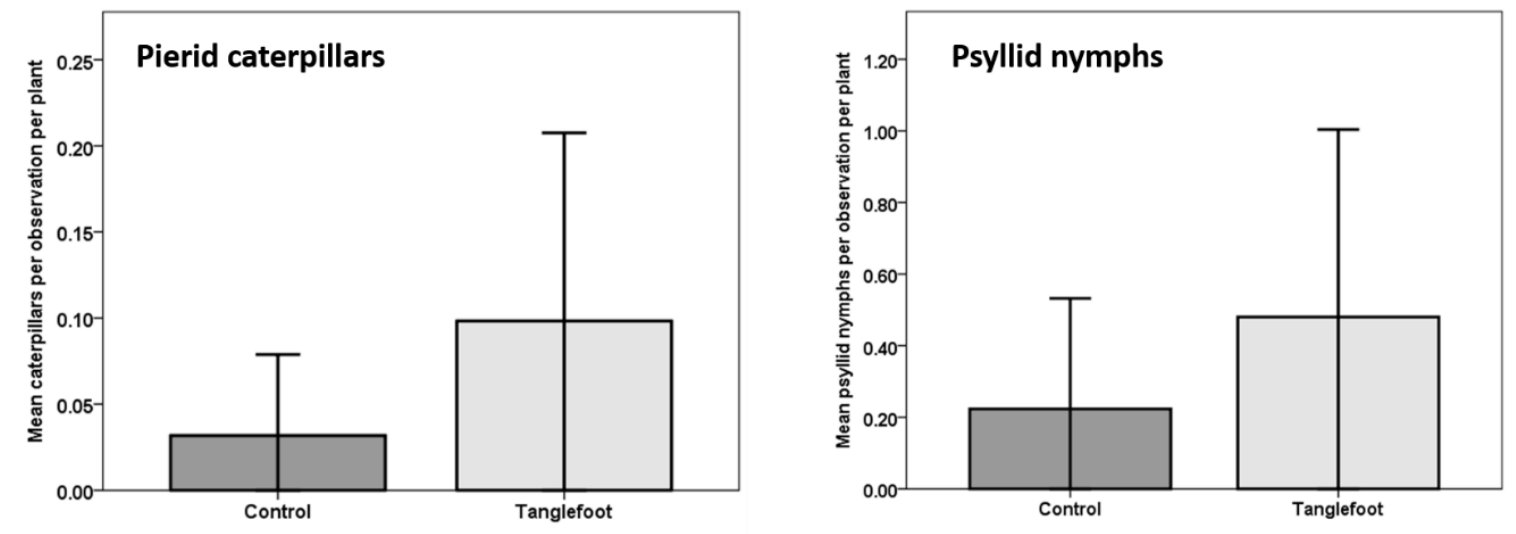
FIGURE 4.2: A. Mean rates of pre-dispersal seed predation on S. chapmanii plants with (Control) and without (Tanglefoot) ants. Seed predation was calculated for each plant as the number of herbivorized seeds divided by the total number of developing seeds (fertilized ovules minus aborted seeds); B. Mean pollinator efficiency on S. chapmanii plants with and without ants. Pollinator efficiency was measured as the proportion of ovules fertilized for each plant; C. Mean effective fecundity of S. chapmanii plants with and without ants. Effective fecundity was calculated for each plant as the number of nonpredated mature seeds divided by the total number of ovules. Error bars represent standard error in all cases.
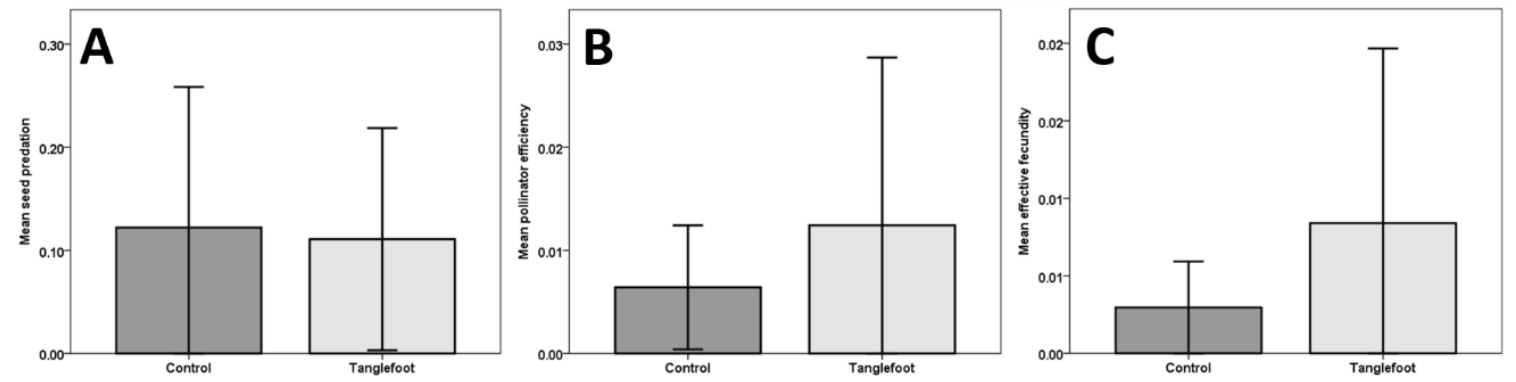
FIGURE 4.3: Mean number (A) and duration (B) of pollinator visits on S. chapmanii plants with and without ants. Error bars represent standard error. Stars indicate significant differences.
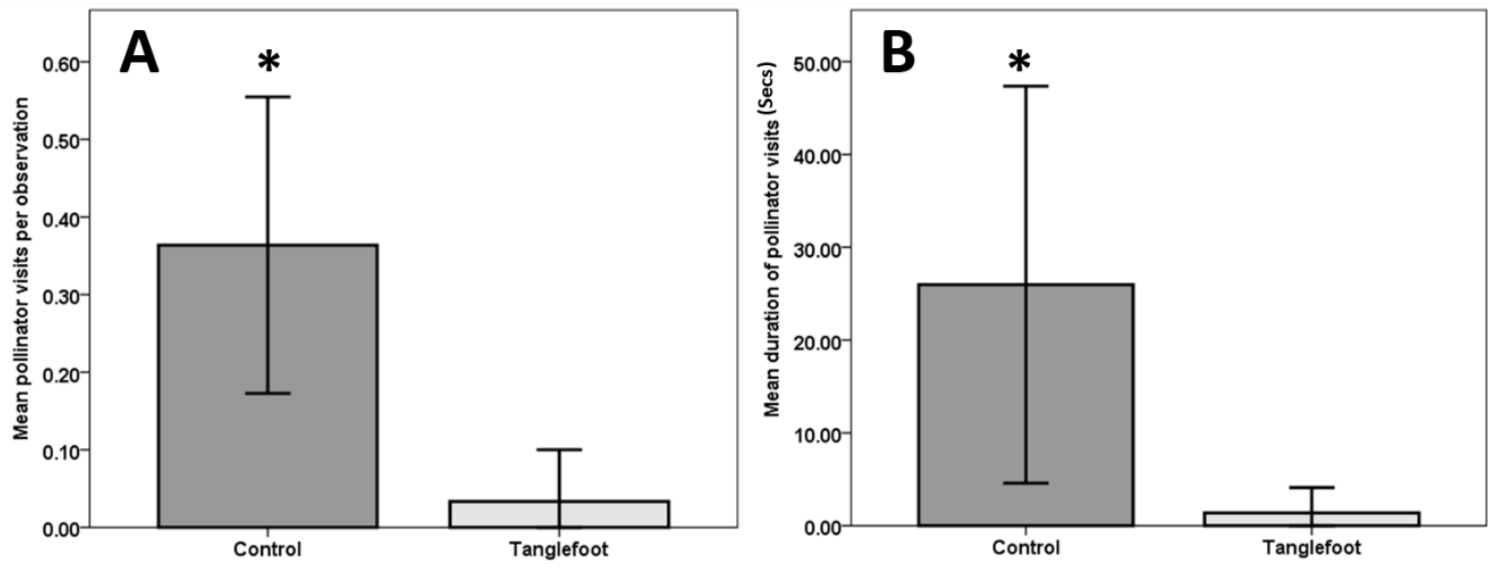
FIGURE 4.4: Correlation between the number of active inflorescences on $S$. chapmanii plants at the time of observation and the number of pollinator visits. Circles represent the mean number of pollinator visits per observation, on plants with different numbers of inflorescences.

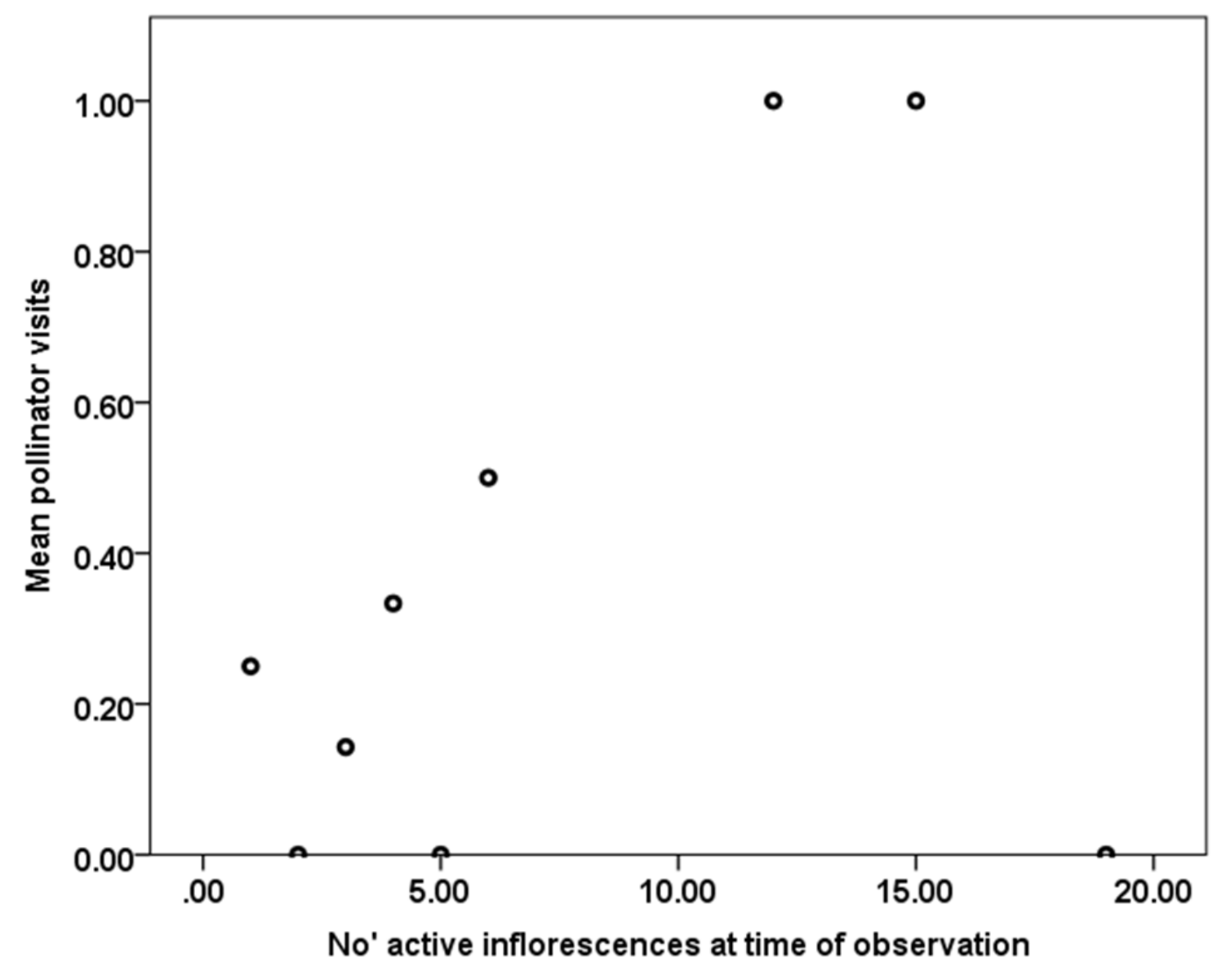


FIGURE 4.5: Mean size of $S$. chapmanii plants with (Control) and without (Tanglefoot) ants for each month of the experiment. Plant size was estimated as the number of growing stems with ten or more leaves. Error bars represent standard error. Stars indicate significant differences.

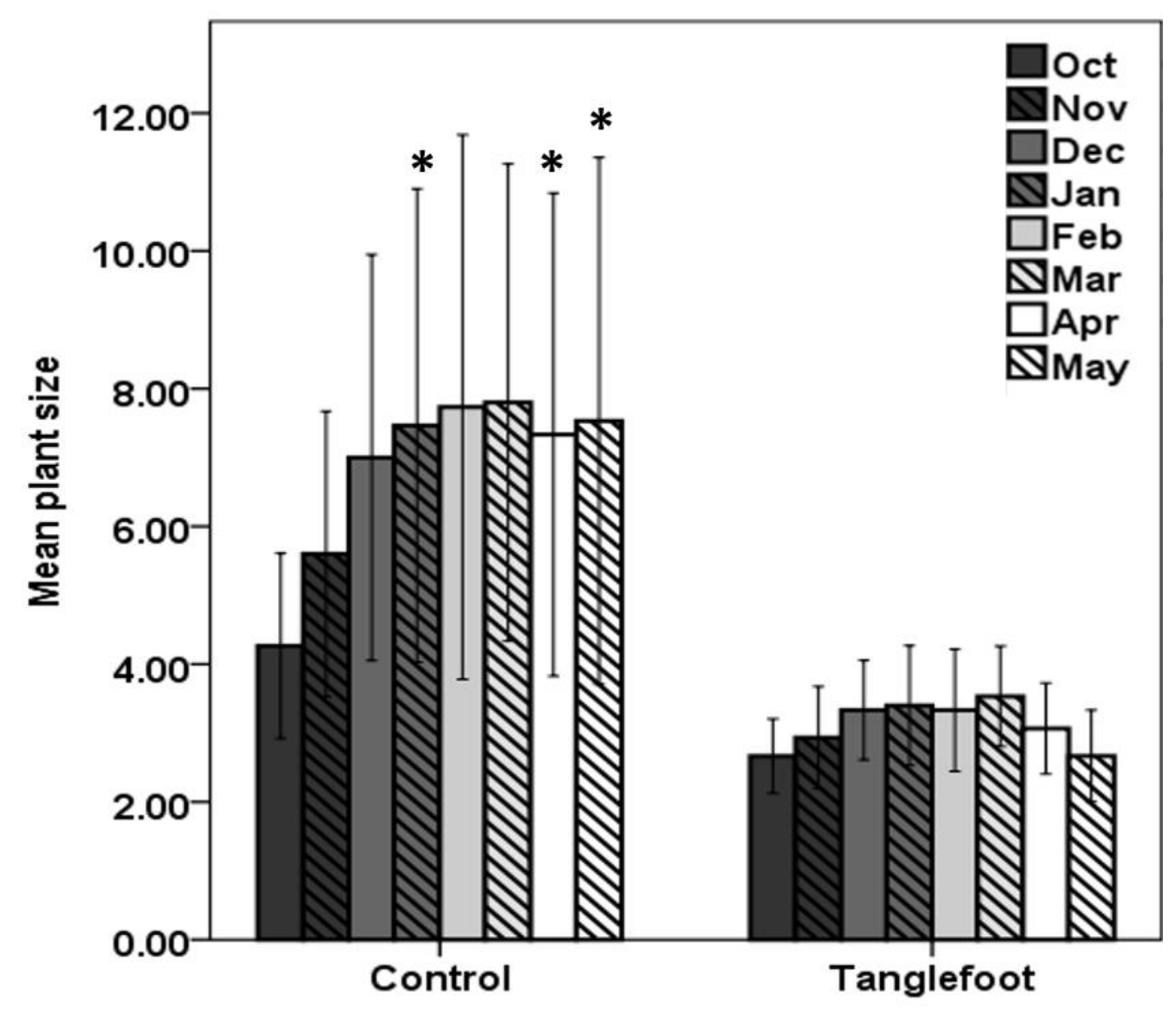


FIGURE 4.6: Reproductive fitness of S. chapmanii plants with (Control) and without (Tanglefoot) ants. Bars represent the means of weekly measurements taken over the course of the 8 month experiment. Error bars represent standard error.

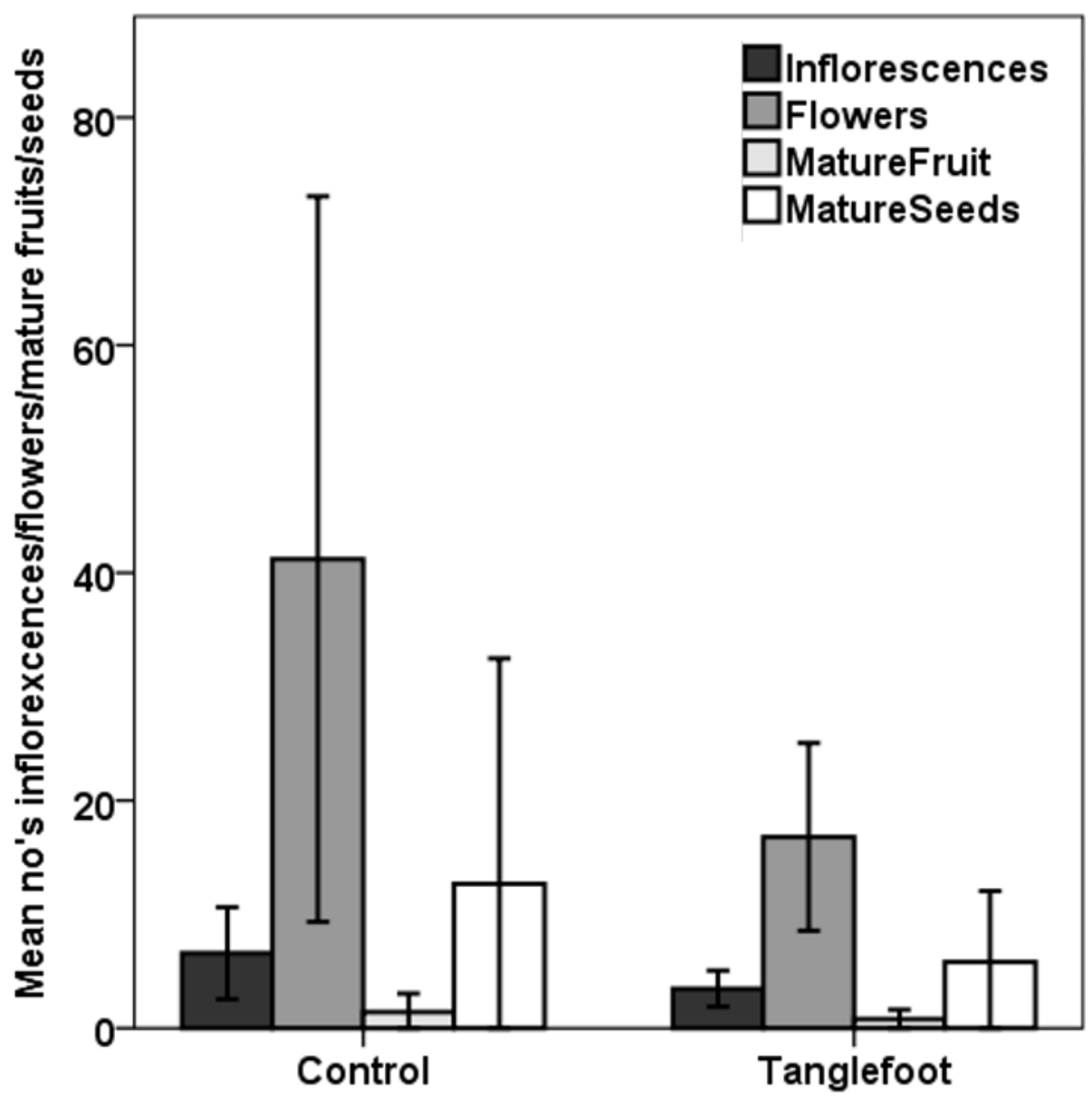


FIGURE 4.7: Extrafloral nectar production in S. chapmanii plants with (Control) and without (Tanglefoot) ants. Bars represent mean nectar production of all plants from bimonthly measurements taken throughout the 8 month experiment. Error bars represent standard error.

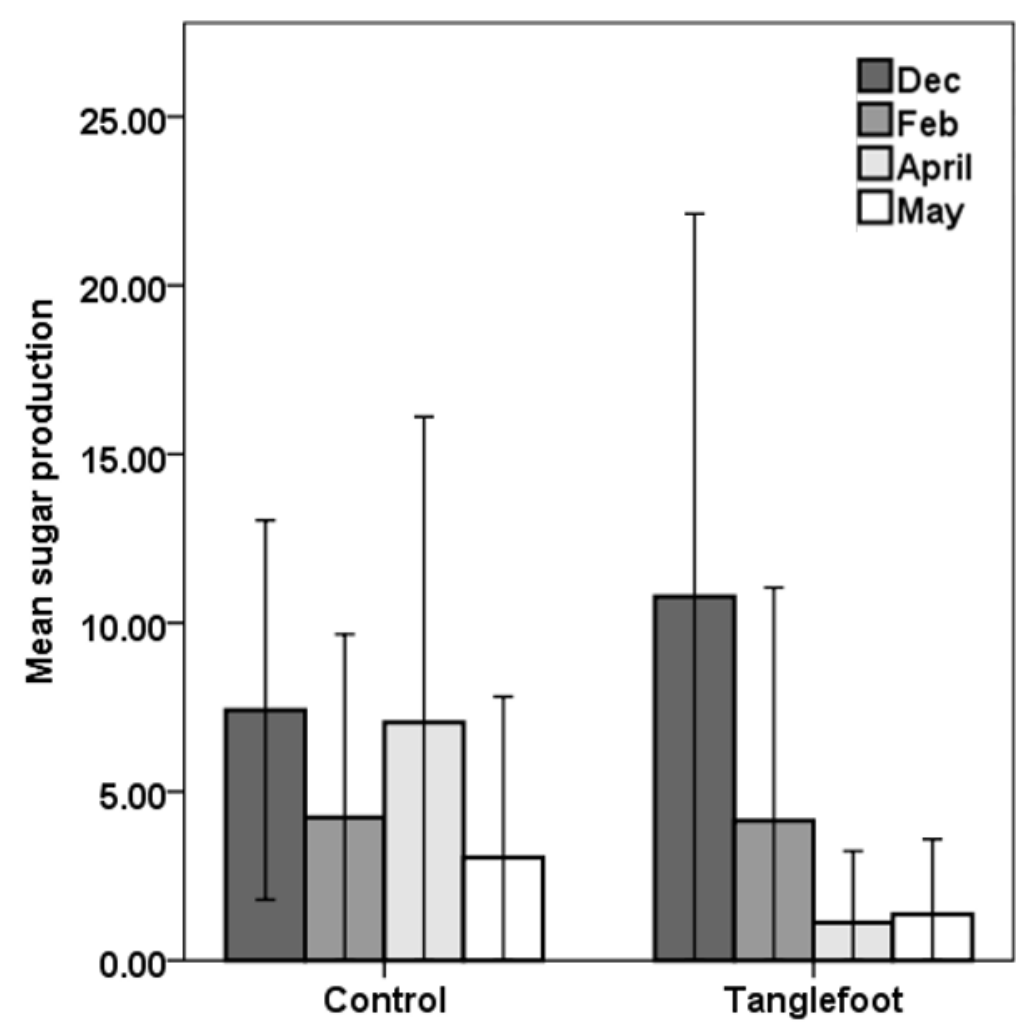




\section{CONCLUSIONS AND FUTURE DIRECTIONS}

Many plant species produce extrafloral nectar (EFN) to attract insect bodyguards, most commonly ants. In the great majority of cases, plants benefit from the presence of ants (Chamberlain and Holland 2009; Rosumek et al. 2009), however, the outcome of ant-plant interactions are dependent on a host of biotic and abiotic factors. The broad theme of my dissertation was to understand the ecology of EFN mediated ant-plant interactions in Senna mexicana var. chapmanii, a perennial legume native to the pine rockland habitats of south Florida. Pine rockland habitats contain a high proportion of EFN-bearing plants (27\%) (Koptur 1992a), but the dynamics of EFN production in these species have rarely been studied (but see Rutter \& Rausher 2004; Jones \& Koptur 2015). Pine rockland habitats are characterized by an open canopy, with high levels of light reaching the species-rich herb layer. Over the last century, however, much of the pine rocklands have been destroyed, and remaining fragments are frequently mismanaged (Barrios et al. 2011). In particular, the fires that maintain the open canopy structure are often suppressed (Possley et al. 2008). I sought to answer the question: How might changes in conditions within the pine rocklands affect the maintenance and outcome of ant-plant interactions?

In chapter I, I showed that $S$. chapmanii produced more EFN at night, than during the day. Extrafloral nectar production was also increased in response to leaf damage and, most interestingly, the timing of leaf damage affected the magnitude of the plants response. Plants damaged in the morning produced more EFN in response to leaf damage than those damaged at night. To our knowledge this is an entirely novel finding, and 
future studies should seek to further explore the effects of damage timing on plant behavioral responses.

In chapter I, I also showed that damage to young leaves of $S$. chapmanii elicited a stronger defensive response than damage to older leaves. These results are in line with optimal defense theory, and support the findings of several other studies on EFN producing species (Heil et al. 2004; Radhika et al. 2008; Kwok and Laird 2012). The results of these greenhouse experiments provide convincing evidence that $\mathrm{EFN}$ acts as an inducible indirect defense trait in S. chapmanii. In order to further elucidate the ecological role of EFN in S. chapmanii, I conducted a novel field experiment which showed that damage to the leaves of $S$. chapmanii resulted in significantly higher ant visitation and recruitment behavior.

In chapter II, I explored the effects of light conditions on the outcome of ant-plant interactions in S. chapmanii. In sunny habitats, plants with ants suffered less herbivore damage, produced more seeds, and grew larger than plants from which ants had been excluded. In shaded habitats, however, the presence of ants had no effect on herbivory rates, seed set, or plant size. I concluded that ants represent an important biotic defense against herbivores in $S$. chapmanii, but their effects on plant fitness are dependent on light conditions. My results suggest that even minor changes in habitat structure within the pine rocklands could have devastating effects on the fitness of low lying herbaceous species, particularly those that rely on mutualistic ants for defense. Future work should compare the effects of habitat degradation in the pine rocklands on plants with and 
without EFNs. Determining how disruption of fire regimes has affected ant assemblages in the pine rocklands would also be an informative and timely avenue for future research.

As pine rockland habitats become overgrown, plants in the low lying herb layer will not only experience lower overall light intensities, but also qualitative changes in light stimuli. Far-red light, for example, is a component of the solar spectrum (710$850 \mathrm{~nm}$ ) that is heavily reflected by plant tissues (Izaguirre et al. 2006). Increases in farred radiation, relative to the red portion of sunlight $(620-750 \mathrm{~nm})$, can be used by many plants as an indicator of competition or impending shade (Ballaré 1999, 2014). Exposure to such light ratios has been shown to promote competitive behaviors in some species, which coincide with reduced resource allocation to defensive traits (Moreno et al. 2009; Rasmann et al. 2009; Agrawal et al. 2012).

In chapter III, I conducted a controlled greenhouse study to examine the specific effects of light quantity and quality (increased far-red/red light ratios) on EFN production in S. chapmanii, both in damaged and undamaged plants. Plants in light-limited conditions produced significantly less EFN than those in high light conditions, and leaf damage elicited increased EFN production regardless of light conditions. Ratios of farred/red light, however, did not appear to affect EFN production in either damaged or undamaged plants. These results were surprising as light spectral quality has been observed to affect EFN production significantly in both lima beans (Radhika et al. 2010) and passion fruit (Izaguirre et al. 2013). We speculate that evolving in the pine rocklands, where plants receive a high degree of direct sunlight, has left $S$. chapmanii unable to respond physiologically to these qualitative light stimuli. One thing that is clear from our 
results, however, is that $S$. chapmanii down-regulates EFN production in response to shade. This down-regulation likely contributes to the reduction in ant-defense received by plants in shady habitats.

The presence of ants leads to increased seed set in $S$. chapmanii. This increase in reproductive fitness, however, is not the result of one interaction but the balance of many. In chapter IV we conducted an eight month field study to examine the mechanism by which ants affect reproductive fitness in S. chapmanii. Over the course of a single flowering season (October-May), we observed the effects of ants on the activity of herbivores, predators, pollinators, and pre-dispersal seed predators. We also observed the overall effects of ants on plant size and reproductive output. Plants with ants were quicker to establish, grew larger, and produced floral displays that attracted more pollinators. Contrary to our expectations, relative pollinator efficiency, and rates of predispersal seed predation, were unaffected by ants. Ants did not affect the outcome of the plants interactions with pollinators or pre-dispersal seed predators, rather only the scale at which they occurred. Ants appeared to affect plant reproductive fitness simply by facilitating growth and establishment, with coincidental effects on reproductive investment.

Through a series of greenhouse and semi-field experiments, I have contributed to an improved understanding of plant resource allocation, and the dynamics of widespread defensive trait. The mutualism between plants and defensive ants was first described by Thomas Belt in 1874 (Belt 1874) and, since that time, many studies have identified EFN mediated mutualisms between ants and plants (for example: Koptur, 1992b; Rosumek et 
al., 2009). Despite this extensive literature, relatively little attention has been paid to the role of EFN in crop plants, and strikingly few studies have taken place in agricultural settings. One obstacle that has hindered the transition of EFN research from ecological theory to applied pest management is the influence of ecological context on the outcome of EFN mediated interactions. Future research should continue to address this obstacle, and explore opportunities to utilize EFN in agricultural ecosystems. In a world of fading resources it is time to work with nature, and shift our focus from simply understanding ant-plant symbioses to harnessing their potential to provide effective and low cost options for pest control.

\section{LITERATURE CITED}

Ballare, C.L. 1999. Keeping up with the neighbours: phytochrome sensing and other signalling mechanisms. Trends in Plant Science 4: 97-102.

Ballare, C.L. 2014. Light regulation of plant defense. Annual Review of Plant Biology 65: 335-363.

Barrios, B., Arellano, G. and Koptur, S. 2011. The effects of fire and fragmentation on occurrence and flowering of a rare perennial plant. Plant Ecology 212: 1057-1067.

Belt, T. 1874. The Naturalist in Nicaragua, London, J. Murray.

Chamberlain, S.A., and Holland, J.N. 2009. Quantitative synthesis of context dependency in ant-plant protection mutualisms. Ecology 90: 2384-2392.

Heil, M., Feil, D., Hilpert, A., and Linsenmair, K.E. 2004. Spaciotemporal patterns in indirect defense of a South-East Asian and-plant support the optimal defense hypothesis. Journal of Tropical Ecology 20: 573-580.

Izaguirre, M.M., Mazza, C.A., Astigueta, M.S., Ciarla, A.M., and Ballare, C.L. 2013. No time for candy: passion fruit (Passiflora edulis) plants down-regulate damage-induced extra floral nectar production in response to light signals of competition. Oecologia 173: 213-221. 
Jones, I.M., and Koptur, S. 2015. Dynamic extrafloral nectar production: The timing of leaf damage affects the defensive response in Senna mexicana var. chapmanii (Fabaceae). American Journal of Botany 102: 58-66.

Koptur, S. 1992a. Plants with Extrafloral Nectaries and Ants in Everglades Habitats. The Florida Entomologist 75 (1): 38-50.

Koptur, S. 1992b. Extrafloral nectary-mediated interactions between insects and plants. Pp 81-129 in Bernays. E. A. (ed). Insect-plant interactions. Vol IV. CRC Press. Boca Raton.

Kwok, K.E., and Laird, R.A. 2012. Plant age and the inducibility of extrafloral nectaries in Vicia faba. Plant Ecology 213(11): 1823-1832.

Possley, J., Woodmansee, S.W. and Maschinski, J. 2008. Patterns of plant composition in fragments of globally imperiled pine rockland forest: effects of soil type, recent fire frequency, and fragment size. Natural Areas Journal 28 (4): 379-394.

Radhika, V., Kost, C., Bartram, S., Heil, M., and Boland, W. 2008. Testing the optimal defence hypothesis for two indirect defences: extrafloral nectar and volatile organic compounds. Planta 228: 449-457.

Radhika, V., Kost, C., Mithofer, A., and Boland, W. 2010. Regulation of extrafloral nectar secretion by jasmonates in lima bean is light dependent. Proceedings of the National Academy of Sciences, USA 107: 17228-17233.

Rosumek, F.B., Silveira, F.A.O., Neves, F.D., Barbosa, N.P.D., Diniz, L., Oki, Y., Pezzini, F., Fernandes, G.W., and Cornelissen, T. 2009. Ants on plants: a meta-analysis of the role of ants as plant biotic defenses. Oecologia 160: 537-549.

Rutter, M.T., and Rausher, M.D. 2004. Natural selection on extrafloral nectar production in Chamaecrista fasciculata: the costs and benefits of a mutualism trait. Evolution 58: 2657-2668. 
VITA

\section{IAN MATTHEW JONES}

Born, Kingston upon Thames, UK

2001-2004

B.S., Biology

University of Birmingham

Birmingham, UK

2005-2006

M.S., Applied Entomology

Imperial College London

London, UK

2012-2013

Best student paper in ecology award

Botanical Society of America Conference

New Orleans, Louisiana

2011-2016

Doctoral candidate

Florida International University

Miami, Florida

Best student paper in ecology Award

Botanical Society of America conference

New Orleans, Louisiana

Dissertation Year Fellowship

Florida International University

Miami, Florida

\section{PUBLICATIONS AND PRESENTATIONS}

Koptur, S., Jones I. M., Pena J. E. 2015 The Influence of Host Plant Extrafloral Nectaries on Multitrophic Interactions: An Experimental Investigation. PLOSone. 10. 9. e0138157.

Jones, I. M., Koptur, S. 2015. Quantity Over Quality: Light Intensity, but not Red/FarRed Ratio, Affects Extrafloral Nectar Production in Senna mexicana var. chapmanii. Functional Ecology. 5. 18. 4108-4114.

Jones, I. M., Koptur, S. 2015. Dynamic extrafloral nectar production: The timing of leaf damage affects the defensive response in Senna mexicana var. chapmanii. American Journal of Botany. 102. 1. 58-66.

Jones, I. M. Ant-plant interactions in the pine rocklands: a study of Senna chapmanii. Pine Rockland Conference. Homestead, FL., 08/2014. 
Jones, I. M., Brunton, E. R., Burgess, I. F. 2013. 0.4\% dimeticone spray, a novel physically acting household treatment for control of cat fleas. Veterinary Parasitology. 199. 1. 99-106.

Jones, I. M. Understanding extrafloral nectar mediated arthropod interactions and their associated costs in Senna mexicana var. chapmannii. Florida Native Plant Society, Invited speaker, Miami, FL., 03/2013.

Jones, I. M. The plants of Kilimanjaro. FIU Plant Talk, Invited speaker, FIU, Miami, FL., 06/2013.

Jones, I. M. Temporal and developmental changes in extrafloral nectar production in Senna mexicana var. chapmanii: is extrafloral nectar an inducible defense? BSA Conference, New Orleans, LA., 08/2013. $1^{\text {st }}$ place, Best Student Contributed Paper, Ecological Section.

Jones, I. M. Understanding the costs of induced plant defenses. Pine Rockland Conference. Homestead, FL., 08/2012.

Jones, I. M. Lethal Attraction: Using pheromones to bring house dust mites into contact with pesticides. FIU Biology Symposium, Miami, FL., 01/2011.

Oliver, T. H., Jones, I. M., Cook, J.M., Leather, S.R. 2008. Avoidance responses of an aphidophagous ladybird, Adalia bipunctata, to aphid- tending ants. Ecological Entomology. 33. 4. 523-528. 